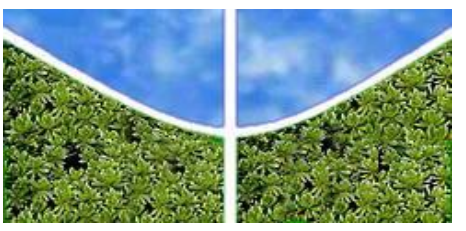

UNIVERSIDADE DE BRASÍLIA

INSTITUTO DE BIOLOGIA

DEPARTAMENTO DE BOTÂNICA

\title{
COLONIZAÇÃO DE TREMBLEYA PARVIFLORA EM ÁREAS ÚMIDAS NO DISTRITO FEDERAL, BRASIL
}

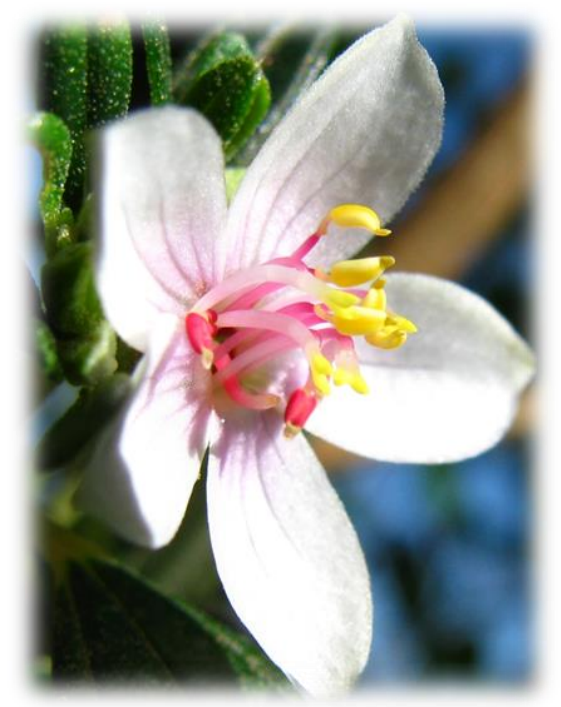

ANI CÁTIA GIOTTO

Brasília, março de 2015 
UNIVERSIDADE DE BRASÍLIA

INSTITUTO DE BIOLOGIA

DEPARTAMENTO DE BOTÂNICA

PROGRAMA DE PÓS-GRADUAÇÃO EM BOTÂNICA

\section{COLONIZAÇÃO DE TREMBLEYA PARVIFLORA EM ÁREAS ÚMIDAS NO DISTRITO FEDERAL, BRASIL}

\section{ANI CÁTIA GIOTTO}

ORIENTADOR DR. JOSÉ FELIPE RIBEIRO

Tese apresentada ao Departamento de PósGraduação em Botânica do Instituto de Biologia da Universidade de Brasília como parte dos requisitos necessários para obtenção do título de Doutora em Botânica.

Brasília, março de 2015 


\section{Colonização de Trembleya parviflora em áreas úmidas no Distrito Federal, Brasil}

\section{Ani Cátia Giotto}

Esta Tese foi julgada adequada para obtenção do Título de Doutor e aprovada em sua forma final pelo Programa de Pós-Graduação em Botânica do Instituto de Ciências Biológicas da Universidade de Brasília.

Banca Examinadora:

Prof $^{\circ}$ Dr $^{\circ}$ José Felipe Ribeiro

Presidente

Dr ${ }^{\circ}$ Fernando Souza Rocha

Membro Externo da Banca Examinadora

$\operatorname{Prof}^{\mathrm{a}} \mathrm{Dr}^{\mathrm{a}}$ Heloisa Sinatora Miranda

Membro Externo da Banca Examinadora

Prof $^{a}$ Dr $^{\mathrm{a}}$ Sarah Cristina Caldas Oliveira

Membro da Banca Examinadora

Prof $^{\circ}$ Dr $^{\circ}$ Fabian Borghetti

Membro da Banca Examinadora

Prof $^{\mathrm{a}}$ Dr $^{\mathrm{a}}$ Cássia Beatriz Rodrigues Munhoz

Membro Suplente da Banca Examinadora 
Ao meu filho. 


\section{AGRADECIMENTOS}

Deus, obrigada por tudo.

Agradeço aos meus pais, Dirce e Elio, e à minha irmã, Ana Kelly. Amo vocês. Mãe, muito obrigada por toda a ajuda e todo o seu esforço. Nada seria possível sem você e sem o seu exemplo de vida.

Ao Chesterton, pelo "Ton" de cores e sons que a vida tem com você, por nosso filho, pela confiança, pelo amor, por sua ajuda e, principalmente, por todos os detalhes. Essa tese é tão sua quanto minha.

À Cássia, por ser uma amiga, uma mãe e um exemplo de profissional.

Ao Felipe, pela orientação e, sobretudo, pelo carinho e atenção em todos os momentos.

Aos que muito ajudaram no laboratório, na casa de vegetação e que aproveitaram o campo no sol, na chuva, atolando nas Veredas, e sempre rindo muito -, especialmente, Chesterton U. O. Eugênio, Reynaldo M. Melo, Meghan F. Guerra (até em chuva de granizo), Camila S. Silva, Isadora N. S. R. Nascimento, Alexandre E. Viana, Menic S. P. Silva, Aldení Lima, Malu Dutra, Amanda M. Costa, Thiago Mello, Tassiana R. R. Santos, Priscila Reis e Paula Emert. Bom trabalho, boas fotos, bons vídeos, bons momentos! Ao Thiago Mello, pela amizade, por sua ajuda e pelas conversas. Ao Reynaldo, pelo cuidado e pela responsabilidade com os experimentos enquanto eu estive nos Estados Unidos. Ao Chesterton U. O. Eugênio, Reynaldo Melo, Thiago Mello, Priscila Reis, Jair E. Q. F. Júnior, Alexandre E. Viana, André R. O. Ribeiro, Dr. Cássia e Dr. Regina na ajuda com a identificação das espécies e pelo carinho. À Josemília Miranda e à Marina Melo pela ajuda no Herbário.

Às amigas Maura Rejane (pela figura das áreas de estudo) e Anne Priscila, pela amizade que continua mesmo com a distância. Aos amigos circenses, por cada momento de alegria e de superação que passamos juntos - a companhia de vocês foi mais que especial. Pati, obrigada! 
Aos professores e funcionários do Instituto de Biologia - especialmente Dra. Lúcia Helena S. Silva, Dra. Regina Oliveira, Dr. Paulo Câmara, Dr. José Carlos, Dr. Rosane Colevatti, Dr. Fabian Borghetti, Dra. Sarah Oliveira, Dra. Cristiane Ferreira, Dr. Augusto Franco, Dr. Manuel Cláudio, Dr. Lúcio Flávio e Dra. Mercedes Bustamante -, pelos ensinamentos e pelo auxílio. Aos membros das bancas, pelas contribuições na realização deste trabalho.

Aos colegas de pesquisa do Cerrado, Chesterton U. O. Eugênio, Aldení Lima, Malu Dutra, Leandro Ruas, Marcelo Kuhlmann, Anabele Gomes, Desirée (muito obrigada pelas sementes de Erianthus sp.), Aryanne Amaral, Thiago Mello, Priscila Reis, André Rodolfo, Ana Gabriela, Juliana Silvestre, Isa Melo e Maria Rosa Zanatta, pelo convívio e pela troca de conhecimentos. À saudosa Michelle Bordini (in memoriam), pelas horas de conversa.

Aos funcionários da Estação Experimental de Biologia, seu Fábio, Dona Olinda, Evandro e Aldo, e à Dra. Rita de Cássia. Aos funcionários da Termobiologia Dona Odete, Seu Manoel, seu Francisco e Seu Antônio, pelo carinho e atenção de sempre. À Dra. Andréa Peñaloza, pelo auxílio com o aprendizado em citogenética.

À Beth Middleton e à Evelyn Anemaet, que me acolheram carinhosamente e me ensinaram muito durante o doutorado sanduíche nos Estados Unidos. Ao Darren, pelas conversas e aulas de estatística. Thank you.

Agradeço ao Instituto Chico Mendes de Conservação da Biodiversidade, pela autorização para a realização do trabalho no Parque Nacional de Brasília (n. 32012-5) e na Estação Ecológica de Águas Emendadas (n. 32948-2). Ao Instituto Brasileiro do Meio Ambiente e dos Recursos Naturais Renováveis (IBAMA), pela autorização de exportação de sementes.

Este estudo teve apoio da CAPES (bolsa de doutorado e bolsa sanduíche - 10031/13-8), CNPq (563134/2010-0) e Projeto Biomas (Confederação Nacional da Agricultura e Pecuária). Este estudo também recebeu suporte técnico do Núcleo Regional do DF da RedeComCerrado/MCT. 
...e contempla descuidoso o firmamento azul, as nuvens que se espacejam nos ares, a folhagem lustrosa e os troncos brancos das pindaíbas a copa dos ipês e as palmas dos buritis a ciciar a modo de harpas eólias, músicas sem conta com o perpassar da brisa.

Como são belas aquelas palmeiras! ...

Correm as horas vem o sol descambando; refresca a brisa, e sopra rijo o vento. Não ciciam mais os buritis; gemem, e convulsamente agitam as flabeladas palmas.

É a tarde que chega.

(Alfredo d'Escragnole Taunay; Inocência) 


\section{RESUMO}

Nas Veredas ocorre atualmente aumento populacional do estrato arbustivo, causando redução na diversidade vegetal da comunidade. $\mathrm{O}$ objetivo geral deste estudo foi investigar a estrutura populacional da espécie arbustiva Trembleya parviflora (D. Don) Cogn. (Melastomataceae) e seu efeito na germinação e no banco de sementes em Veredas com alta e baixa colonização dessa espécie, respectivamente na Estação Ecológica de Águas Emendadas (ESECAE) e no Parque Nacional de Brasília (PNB). Na estrutura populacional, foram amostrados indivíduos nos estratos inferior, médio e superior. A maior germinabilidade foi encontrada para sementes armazenadas após um mês (47\%), em temperatura alternada (46\%) e coletadas no PNB (48\%). No banco de sementes emergiram 22.325 plântulas (78\% T. parviflora). A abundância e a riqueza de plântulas foram semelhantes entre o período chuvoso e o seco, mas a ESECAE apresentou menor riqueza e diversidade. Além disso, o acúmulo de serapilheira reduziu a abundância de plântulas. A redução na umidade aumentou a dominância de T. parviflora, sugerindo que o rebaixamento do lençol freático favorece a sua expansão em Veredas. A área avaliada na ESECAE (14.295 ind.ha ${ }^{-1}$ ) apresentou densidade significativamente maior (19x) que a área do PNB (725 ind.ha ${ }^{-1}$ ) em todos os estratos e nos inventários inicial e final. Esses resultados contribuem com conhecimentos de base a respeito do ciclo de vida e impactos da espécie T. parviflora sobre comunidades nativas das Veredas, ambiente crucial para a manutenção de nascentes e bacias hidrográficas no Cerrado. Estes dados serão muito úteis na conservação e manejo deste tipo de Área de Proteção Permanente.

Palavras-chave: aumento de arbustos, bioma Cerrado, germinação, população, banco de sementes, Veredas. 


\begin{abstract}
In the last decades, in the Brazilian Palm Swamps (locally known as Veredas), it is occurring the expansion of the vegetation's shrubby layer at the expense of its plant biodiversity in general. The objective of this work was to evaluate the structure of Trembleya parviflora's (Melastomataceae) population structure and its effects in the seedbanks, as well as the germination rate of the seeds present in it, in two Veredas with different levels of dominance by this shrub: One with a small population of $T$. parviflora (Brasilia National Park-BNP) and the other showing a bigger one (Águas Emendadas Ecological Station-AEES). We counted the number of individuals in order to access T. parviflora's population structure. Germinability was higher for seeds collected in PNB (48\%), stored during one month (47\%), and kept in alternating temperatures during the germination period (46\%). In the seed bank, 22.325 seeds sprouted (T. parviflora comprising $78 \%$ of them). Seedlings abundance and richness were similar in both, dry and rainy seasons, but AEES showed less richness and diversity. Also, seedling abundance was affected by the litter layer's thickness. Moisture reduction increased T. parviflora's dominance, suggesting that a subsiding in the water table level favours its expansion in Veredas. The density of bushes in the AEES preserve was 19 times higher (14.295 in.ha $\left.{ }^{-1}\right)$ than in PNB (725 in.ha $\left.{ }^{-1}\right)$. The results about $T$. parviflora's life cycle and impacts on native communities of plants are essential for the knowledge of Veredas, crucial vegetation for maintaining Cerrado's rivers sources as well as watershed. These data will be very useful for the conservation and management of these Permanent Protected Areas.
\end{abstract}

Keywords: Cerrado, germination, population, shrub increase, seed bank, swampy grasslands (Vereda). 


\section{SUMÁRIO}

Lista de tabelas .................................................................................................................................... xi

Lista de figuras ................................................................................................................. xii

Lista de apêndice ........................................................................................................................ xiv

Introdução Geral ....................................................................................................................... 15

Objetivo Geral e Específicos ................................................................................................... 18

Referências Bibliográficas .......................................................................................................... 20

Capítulo 1 - Mudanças ambientais locais influenciam a capacidade de germinação de

Trembleya parviflora (Melastomataceae) em Veredas?...................................................... 23

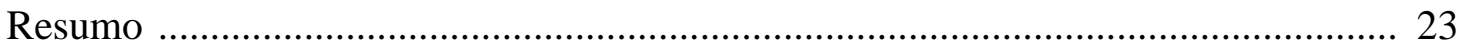

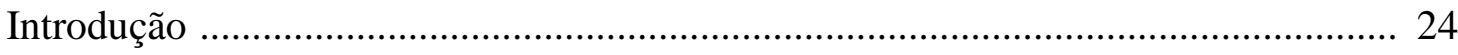

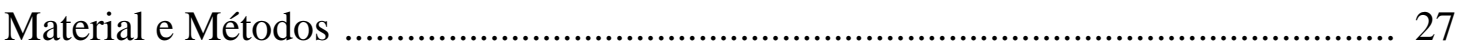

Coleta e tratamento do material .................................................................... 27

Experimentos de germinação ........................................................................... 28

Influência de dióxido de carbono na germinação de Trembleya parviflora ........ 29

Delineamento experimental e análise de dados .................................................... 29

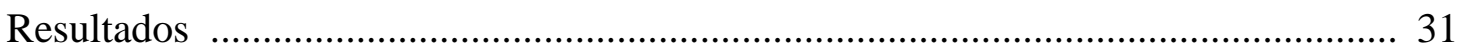

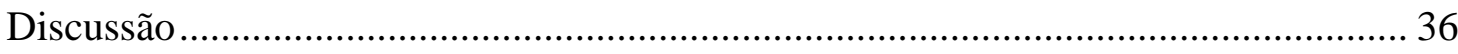

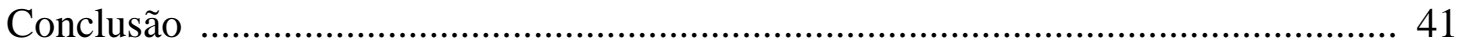

Referências Bibliográficas ................................................................................ 42

Capítulo 2 - Adensamento de Trembleya parviflora (D. Don) Cogn. (Melastomataceae) reduz a diversidade florística do banco de sementes em Veredas no Brasil Central? 46

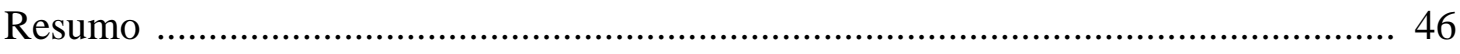

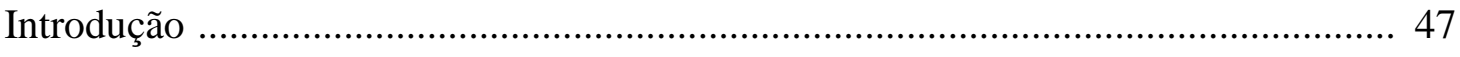




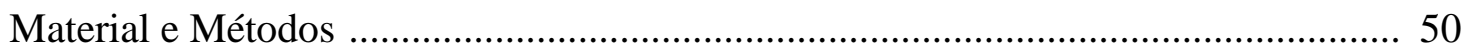

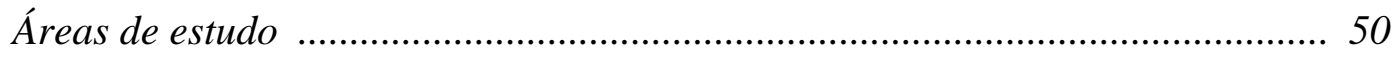

Coleta do banco de sementes ........................................................................ 50

Análise de dados ...................................................................................... 54

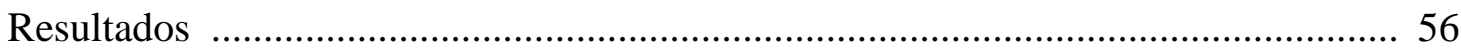

Composição de espécie no banco de sementes no solo ....................................... 56

Influência da flutuação hídrica no substrato do banco de sementes .................. 59

Influência da flutuação hídrica no hábito .......................................................... 62

Influência da adição de serapilheira ................................................................. 63

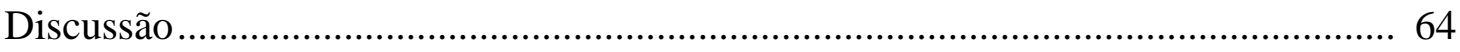

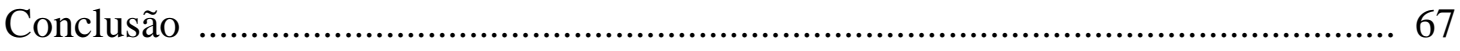

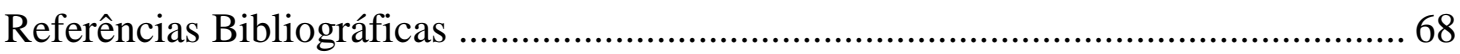

Capítulo 3 - Estrutura populacional de Trembleya parviflora (Melastomataceae), um arbusto que está dominanto as Veredas no Brasil Central ............................................. . 73

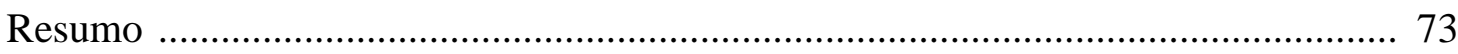

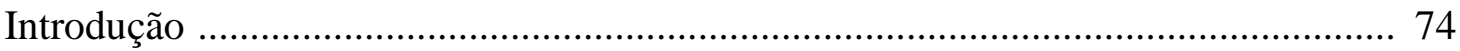

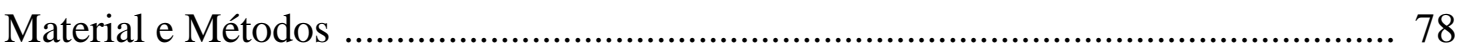

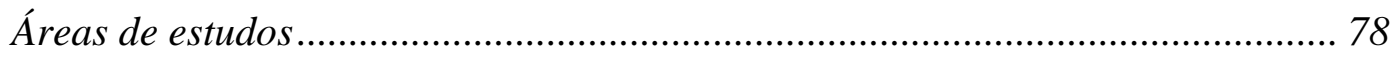

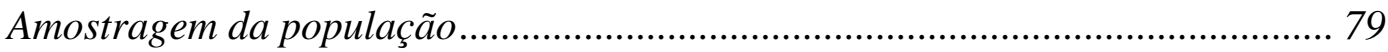

Medição do lençol freático ............................................................................... 81

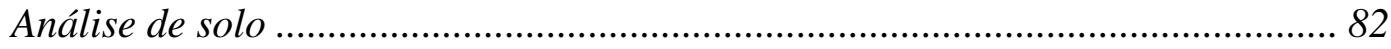

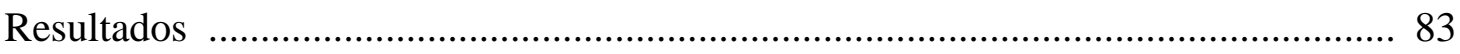

Estrutura e dinâmica da população... .............................................................. 83

Flutuação da profundidade do lençol freático.................................................... 88 


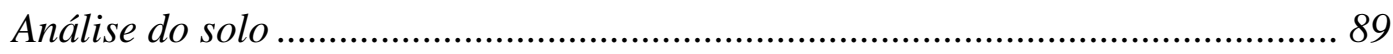

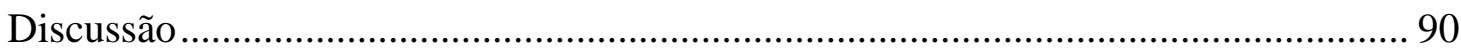

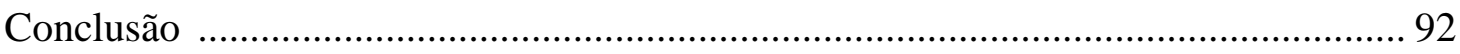

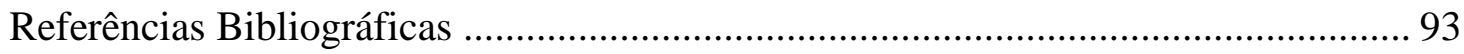

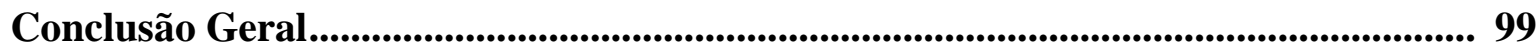

Apêndice 


\section{LISTA DE TABELAS}

\section{Capítulo 1}

Tabela 1. Resultados de ANOVA fatorial sobre os efeitos de área de coleta (PNB e ESECAE), tempo de armazenamento (1, 3, 9, e 15 meses após a coleta), temperatura da câmara de germinação $\left(25^{\circ} \mathrm{C}\right.$ ou entre 20 a $\left.30^{\circ} \mathrm{C}\right)$ e condição de disponibilidade hídrica (submersão ou substrato úmido) para germinabilidade (\%), tempo médio (dias) e coeficiente de velocidade de germinação (\%) (CVG) de Trembleya parviflora. .34

Tabela 2. Tempo médio de germinação e coeficiente de velocidade de germinação de sementes de Trembleya parviflora coletadas na Estação Ecológica de Águas Emendadas (ESECAE) e no Parque Nacional de Brasília (PNB), colocadas para germinar após 1, 3, 9 e 15 meses da coleta em câmara com temperatura constante $\left(25^{\circ} \mathrm{C}\right)$ ou alternada $\left(20\right.$ e $30^{\circ} \mathrm{C}$, período escuro e luminoso, respectivamente) submetidas à submersão em água ou sobre substrato umedecido (controle) .35

\section{Capítulo 2}

Tabela 1. Número de espécies, famílias e indivíduos ocorrentes no banco de sementes germináveis no solo, submetido a três condições de umidade do substrato (alagado, intermediário e umedecido) com ou sem adição de serapilheira de Veredas do Parque Nacional de Brasília (PNB) e na Estação Ecológica de Águas Emendadas (ESECAE) no Distrito Federal, Brasil.... .57

\section{Capítulo 3}

Tabela 1. Densidade inicial e final, recrutamento e mortalidade de indivíduos de Trembleya parviflora amostrados nos estratos de inferior, médio e superior em 2012 e 2013 no Parque Nacional de Brasília e na Estação Ecológica de Águas Emendadas, Distrito Federal, Brasil. .83

Tabela 2. Variáveis químicas e físicas de amostras do solo coletadas em quatro pontos de amostragem, nas Veredas do Parque Nacional de Brasília (PNB) e na Estação Ecológica de Águas Emendadas (ESECAE), Brasília .89 


\section{LISTA DE FIGURAS}

\section{Capítulo 1}

Figura 1. Áreas de estudo ( $\square$ ) em destaque no Parque Nacional de Brasília (PNB) e na Estação Ecológica de Águas Emendadas (ESECAE), Distrito Federal, Brasil

Figura 2. Germinação cumulativa $(\%)$ de sementes de Trembleya parviflora coletadas no Parque Nacional de Brasília ( $\square$ ) e na Estação Ecológica de Águas Emendadas (०), colocadas para germinar após $1,3,9$ e 15 meses da coleta em câmara com temperatura constante $\left(25^{\circ} \mathrm{C}\right.$, linha contínua) ou alternada $\left(20\right.$ e $30^{\circ} \mathrm{C}$, período escuro e luminoso, respectivamente - linha pontilhada) submetidas à submersão (símbolos fechados) ou sobre substrato umedecido (símbolos abertos)

\section{Capítulo 2}

Figura 1. Pontos de coleta em Veredas no Parque Nacional de Brasília (PNB) e na Estação Ecológica de Águas Emendadas (ESECAE), Distrito Federal, Brasil

Figura 2. Abundância das espécies ocorrentes no banco de sementes germináveis no solo em Veredas do Parque Nacional de Brasília (PNB) e na Estação Ecológica de Águas Emendadas (ESECAE), Distrito Federal, Brasil. Trembleya parviflora está representada pelo eixo à esquerda, em preto, e as demais à direita, em cinza .58

Figura 3. Diagrama de Venn demonstrando o número de espécies exclusivas e em comum do banco de sementes coletado após o período chuvoso e seco e o Índice de similaridade de Chao-Sørensen \pm intervalo de confiança, entre duas Veredas do Parque Nacional de Brasília (PNB) e na Estação Ecológica de Águas Emendadas (ESECAE), Distrito Federal, Brasil .... .59

Figura 4. Ordenação NMDS para composição de espécies do banco de sementes germináveis de quatro pontos de coleta em Veredas do Parque Nacional de Brasília ( $\square$ e a) e da Estação Ecológica de Águas Emendadas ( o e •) coletado após o período chuvoso (símbolo fechado) e seco (símbolo aberto) e submetido a três condições de umidade do substrato (alagado, intermediário e umedecido) no Distrito Federal, Brasil 
Figura 5. Perfis de Diversidade de espécies do banco de sementes germináveis no solo em Veredas do Parque Nacional de Brasília (PNB) e da Estação Ecológica de Águas Emendadas (ESECAE), coletado após o período chuvoso (linhas preta) e seco (linhas cinza) submetido a três condições de umidade do substrato (alagado, intermediário e umedecido) no Distrito Federal, Brasil. .61

Figura 6. Curva de acumulação de espécies utilizando o método de rarefação para indivíduos do banco de sementes germináveis de Veredas do Parque Nacional de Brasília (PNB) e da Estação Ecológica de Águas Emendadas (ESECAE) coletado após o período chuvoso e seco submetido a três condições de umidade do substrato (alagado, intermediário e umedecido) no Distrito Federal, Brasil .63

\section{Capítulo 3}

Figura 1. Transectos de amostragem de indivíduos de Trembleya parviflora no Parque Nacional de Brasília e na Estação Experimental de Águas Emendadas, Distrito Federal. ○ Pontos de coleta de solo para análises físico-químicas. .80

Figura 2. Altura média $(\mathrm{cm})$ de indivíduos de Trembleya parviflora amostrados nos estratos inferior, médio e superior em 2012 e 2013 em Veredas na Estação Ecológica de Águas Emendadas e no Parque Nacional de Brasília, Distrito Federal, Brasil. (Média \pm desvio padrão). .85

Figura 3. Diâmetro médio $(\mathrm{cm})$ de indivíduos de Trembleya parviflora amostrados nos estratos médio e superior em 2012 e 2013 em Veredas na Estação Ecológica de Águas Emendadas e no Parque Nacional de Brasília, Distrito Federal, Brasil. (Média \pm desvio padrão). .85

Figura 4. Frequência de classes de altura de indivíduos de Trembleya parviflora amostrados nos estratos inferior, médio e superior em 2012 e 2013 em Veredas na Estação Ecológica de Águas Emendadas e no Parque Nacional de Brasília, Distrito Federal, Brasil. .86

Figura 5. Frequência de classes de diâmetro de indivíduos de Trembleya parviflora amostrados nos estratos médio e superior em 2012 e 2013 em Veredas na Estação Ecológica de Águas Emendadas e no Parque Nacional de Brasília, Distrito Federal, Brasil.

Figura 6. Distância entre a lâmina de água do lençol freático e a superfície do solo em poços instalados em cada um dos quatro pontos de amostragem no Parque Nacional de Brasília (PNB, em cinza) e na Estação Ecológica de Águas Emendadas (ESECAE, em preto), Distrito Federal, Brasil. Valores negativos representam lençol freático abaixo da superfície do solo .88

Figura 7. Combinação do primeiro e do segundo componente principal da análise de PCA ilustrando a influência das variáveis edáficas na densidade de Trembleya parviflora do Parque Nacional de Brasília (PNB, em cinza) e da Estação Ecológica de Águas Emendadas (ESECAE, em preto), Distrito Federal, Brasil. .90 


\section{LISTA DE APÊNDICE}

\section{Capítulo 3}

Apêndice 1. Composição florística e abundância de espécies no banco de sementes coletado após o período chuvoso e seco, sob os tratamentos de umidade de substrato (alagado-SA, intermediário-SI e umedecido-SU) e influência de serapilheira de Veredas do Parque Nacional de Brasília (PNB) e da Estação Ecológica de Águas Emendadas (ESECAE), Distrito Federal,

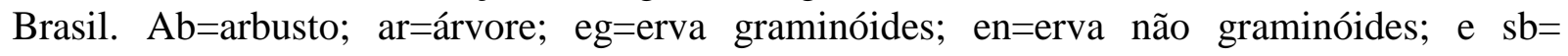
subarbusto. Dados entre parênteses referem-se às plântulas oriundas do tratamento com deposição de serapilheira. 


\section{Introdução Geral}

Veredas se expressam como complexos vegetacionais do bioma Cerrado que ocorrem em ambientes úmidos, caracterizadas pela palmeira Mauritia flexuosa L.f. (buriti; Arecaceae) assim como espécies arbustivas-arbóreas e estrato herbáceo-graminoso, que ocupa a maior parte da área (Eiten 2001; Araújo et al. 2002). Essa fitofisionomia ocorre próxima às nascentes e em solos hidromórficos mal drenados ou muito mal drenados (Eiten 2001) e pode ser dividida em zonas de fundo, meio e borda, delimitadas de acordo com a altura do lençol freático e estrato vegetativo (Meirelles et al. 2004). A área de borda da Vereda apresenta solo com melhor drenagem e pode conter arvoretas e arbustos mais adensados. A parte do meio possui solo saturado com água em grande parte do ano e vegetação tipicamente campestre. No fundo, o solo permanentemente saturado com água e essencialmente orgânico, possui cobertura brejosa onde ocorrem os buritis e ilhas de vegetação mais densa com pequenos arbustos e arvoretas (Almeida et al. 1983; Araújo et al. 2002; Guimarães et al. 2002).

A presença de Vereda promove equilíbrio geoecológico e hidrológico do Cerrado, pois esse ambiente constitui-se de bacias coletoras de água protegendo nascentes e fornecendo água para cursos d'água (Meirelles et al. 2002). A Vereda ainda exerce forte influência na manutenção da fauna, pois torna-se local para pouso da avifauna e atua como refúgio, abrigo, fonte de alimento e área para a reprodução da fauna silvestre (Castro 1980; Brandão et al. 1994; Carvalho 1991). Áreas úmidas auxiliam na manutenção de alta diversidade e produtividade de ecossistemas (Hickman 1990), além de contribuir significativamente com os processos globais de transferência de gases do efeito estufa (Ewel 1991). 
A atividade agropecuária, o avanço da urbanização, a construção de estradas e de canais de drenagem e a exploração comercial de argila e turfa geram a degradação desse habitat (Carvalho 1991). Esses processos causam graves consequências como assoreamento, ressecamento do solo, redução do volume hídrico, erosão, perda da beleza e biodiversidade, sendo maximizados pela sensibilidade a alterações (Boaventura 1988) e pela pequena capacidade de recuperação desse ecossistema (Guimarães et al. 2002).

A fitofisionomia Vereda é protegida por lei por ser Área de Preservação Permanente (Brasil 1992). No entanto, o novo Código Florestal não abrange a complexidade da área natural das zonas da Vereda e pode reduzir o tamanho da área conservada, considerando-se que as áreas de transição entre os solos lateríticos e os solos hidromórficos possam ser excluídos do conceito desse ambiente (Rosolen et al. 2014). De acordo com Munhoz \& Ribeiro (2008), apesar da importância das Veredas em relação aos diversos aspectos ambientais, poucos estudos estão estruturados em relação à dinâmica da distribuição das espécies, assim como as inter-relações com outras fisionomias adjacentes, estratégias ecológicas da vegetação, aspectos da germinação de sementes - enfim, trabalhos que representem a compreensão desses e outros fatores no processo de sucessão.

Atualmente, intervenções antrópicas podem acelerar os processos de rebaixamento do lençol freático ameaçando a dinâmica natural dos ambientes de áreas úmidas. Essa alteração determina a redução das espécies herbáceas habituadas a maior grau de encharcamento, as quais, com o tempo, passam a ser sombreadas e substituídas pelo estrato arbustivo-arbóreo que se instala nas áreas com menor umidade no solo (Eiten 2001; Meirelles et al 2004). No Distrito Federal, rápidas transformações na paisagem estão sendo geradas pela densa colonização de espécies lenhosas nativas de Veredas como Trembleya parviflora (D. Don) Cogn. (Silva-Júnior e Felfili 1996; Meirelles et al. 2004), Macairea 
radula (Bonpl.) DC. e Lavoisiera bergii Cogn. da família Melastomataceae (Munhoz e Ribeiro 2008).

Trembleya parviflora, endêmica do Brasil, ocorre na Mata Atlântica e no Cerrado, e, neste último, nas fitofisionomias: Campos Sujo, Limpo, Rupestre e de Altitude; Vereda, Floresta Montana e bordas de Mata Ciliares e de Galeria (Martins e Bernardo 2010; Munhoz et al. 2011). A espécie apresenta-se como arbustos e subarbustos eretos (Martins 1991). A floração e a frutificação ocorrem entre os meses de fevereiro e outubro (Munhoz et al. 2011). Os frutos, cápsulas, apresentam grande quantidade de minúsculas sementes, as quais são dispersas pelo vento entre agosto e setembro (Rocha et al. 2008; Munhoz et al. 2011).

Especificamente em relação aos meios de regeneração de populações vegetais tropicais, verifica-se que essa regeneração ocorre por meio da chuva de sementes, do banco de sementes do solo, do banco de plântulas e pela formação de bosque com emissão rápida de brotos e/ou raízes oriundas de indivíduos danificados (Garwood 1989). A estrutura de populações de plantas reflete da ação de variáveis abióticas e bióticas atuando sobre indivíduos atuais e antigos, os quais influenciam o arranjo espacial e também as estruturas etária e genética de seus membros (Hutchings 1997). Estas variáveis promovem mudanças temporais e espaciais na abundância de indivíduos nas populações. A mensuração de natalidade e mortalidade possibilita responder questões relacionadas com a coexistência de espécies raras e comuns, assim como sobre os processos responsáveis pela flutuação dessas taxas na comunidade (Watkinson 1997).

As alterações nas estruturas de uma população ao longo do tempo fornecem embasamento para estudos de dinâmica populacional. Esses estudos analisam recrutamento, mortalidade, crescimento e estratégia de vida de determinada espécie (Schiavini et al. 2001). O recrutamento e a mortalidade permitem identificar em 
determinado local a capacidade de regeneração, além da ocorrência de perturbações (Harper 1977), colonização de determinado ambiente e os processos responsáveis pela flutuação destas taxas populacionais (Watkinson 1997).

A germinação das sementes, por sua vez, constitui o primeiro passo para a exploração de novos habitats, este processo pode influenciar, quantitativamente, as populações das espécies nas áreas de ocorrência (Ramírez-Padilla e Valverde 2005). As alterações de estabelecimento nos habitats refletem na composição do banco de sementes, que é formado por todas as sementes viáveis no solo de uma área, acima deste ou enterradas (Simpson et al. 1989; Almeida-Cortez 2004), como um sistema dinâmico de entrada e saída de diásporos (Fenner 1985; Garwood 1989). O banco de sementes do solo representa importante repositório para a manutenção da riqueza de espécies vegetais de um habitat (Berge e Hestmark 1997).

\section{Objetivo Geral e Específicos}

Investigar a estrutura populacional de Trembleya parviflora e o efeito dessa população na germinação e em bancos de sementes em áreas de Veredas.

Para tanto, a tese foi dividida em três capítulos com os seguintes títulos e objetivos específicos: 
Capítulo 1 - Mudanças ambientais locais influenciam a capacidade de germinação de Trembleya parviflora (Melastomataceae) em Veredas?

Determinar o efeito da alternância de temperatura, períodos de armazenamento e as condições de submersão, déficit hídrico e concentração de $\mathrm{CO}_{2}$ sobre a germinação de sementes de T. parviflora, coletadas em duas áreas Veredas com diferenças no tamanho populacional da espécie.

Capítulo 2 - Adensamento de Trembleya parviflora (D. Don) Cogn. (Melastomataceae) reduz a diversidade florística do banco de sementes em Veredas no Brasil Central?

Analisar a abundância e a riqueza na composição florística do banco de sementes em áreas de Vereda em diferentes épocas do ano, em diferentes condições de adensamento de indivíduos de T. parviflora, de umidade no substrato e de presença de serapilheira.

Capítulo 3 - Estrutura populacional de Trembleya parviflora (Melastomataceae), um arbusto que está dominando as Veredas no Brasil Central

O objetivo deste estudo foi avaliar a estrutura de duas populações de Trembleya parviflora no Distrito Federal em diferentes Veredas, procurando relacionar as características de crescimento de plantas, mortalidade, recrutamento, incremento à densidade da população na área no intervalo de um ano e meio. 


\section{Referências bibliográficas}

Almeida-Cortez, J.S. 2004. Dispersão e Banco de Sementes. Pp. 225-235. In: A.G. Ferreira \& F. Borghetti (Eds.). Germinação: do básico ao aplicados. Artmed, Porto Alegre. Almeida, J.R.; Baruqui, F.M.; Baruqui, A.M. \& Motta, P.E.F. 1983. Principais solos de várzeas do Estado de Minas Gerais e suas potencialidades agrícolas. Informe Agropecuário 9: 70-78.

Araújo, G.M.; Barbosa, A.A.A.; Arantes, A.A. \& Amaral, A.F. 2002. Composição florística de Veredas no município de Uberlândia, MG. Revista Brasileira de Botânica 25: 475-493.

Berge, G. \& Hestmark, G. 1997. Composition of seed banks of roadsides, stream verges and agricultural fields in southern Norway. Pp. 77-90. In: Annales Botanici Fennici Finnish Zoological and Botanical Publishing Board.

Boaventura, R.S. 1988. Preservação das Veredas; síntese. Pp. 109-119. In: Encontro Latino Americano: Relação Ser Humano / Ambiente. Anais.

Brandão, M.; Carvalho, P.G.S. \& Baruqui, E.M. 1994. Veredas: uma abordagem integrada. Daphne 4(2): 29-57.

Brasil. 1992. Resoluções Conama 1984/1991. Semam/Ibama. Brasília, DF. 245 p.

Carvalho, P.G.S. 1991. As Veredas e sua importância no Domínio dos Cerrados. Informe Agropecuário 168: 47-54.

Castro, J.P.C. 1980. As Veredas e a sua proteção jurídica. Análise e Conjuntura 10: 321331.

Eiten, G. 2001. Vegetação natural do Distrito Federal. Brasília: Sebrae.

Ewel, K.C. 1991. Ecoystem experiments in wetlands. Pp. 181-191.In: Money H.A. (Ed.). Ecosystem experiments. Chichester: John Wiley \& Sons.

Fenner, M. 1985. Seed Ecology. Chapman and Hall, London.

Garwood, N.C. 1989. Tropical soil seed banks: a review. Pp. 149-209. In: M.A. Leck, V.T. Parker and R.L. Simpson (Eds.). Ecology of soil seed banks. Academic Press, San Diego.

Guimarães, A.J.M.; Araújo, G.M. \& Corrêa, G.F. 2002. Estrutura fitossociológica em área natural e antropizada de uma Vereda em Uberlândia, MG. Acta Botanica Brasilica 16(3): 317-329.

Harper, J.L. 1977. Population biology of plants. Londres: Academic Press. 
Hickman, C.A. 1990. Forest-wetland trends in the United-States: an economic perspective. Forest Ecology and Management 33-34: 227-238.

Hutchings, M.J. 1997. The structure of plant populations. Pp.325-358. In: Plant ecology. M.J. Crawley (Ed.). Blackwell Science, Oxford.

Martins, E. 1991. A tribo microlicieae (Melastomataceae) no Estado de São Paulo. Dissertação de Mestrado. Universidade Estadual de Campinas, São Paulo.

Martins, A.B. \& Bernardo, K.F.R. 2010. Trembleya in Lista de Espécies da Flora do Brasil. Jardim Botânico do Rio de Janeiro. (http://floradobrasil.jbrj.gov.br /2010/FB009983).

Meirelles, M.L.; Guimarães, A.J.M.; de Oliveira, R.C.; Araújo, G.M. \& Ribeiro, J.F. 2004. Impactos sobre o estrato herbáceo de Áreas Úmidas do Cerrado. Pp. 41-68. In: Aguiar, L.M.S.; Camargo, A.J.A. (Ed.). Cerrado: ecologia e caracterização. Planaltina, DF: Embrapa Cerrados.

Meirelles, M.L.; Oliveira, R.C.; Vivaldi, L.J.; Santos, A.D. \& Correia, J.R. 2002. Espécies de estrato herbáceo e profundidade do lençol freático em áreas úmidas do cerrado. Planaltina, Embrapa Cerrados.

Munhoz, C.B.R.; Eugênio, C.U.O. \& Oliveira, R.C. 2011. Vereda: guia de campo. Brasília: Rede de Sementes do Cerrado.

Munhoz, C.B.R. \& Ribeiro, J.F. 2008. Veredas. Pp. 156-162. In: F.O. Fonseca (Org). Água emendadas/Distrito Federal. Secretaria de Desenvolvimento Urbano e Meio Ambiente. Brasília.

Ramírez-Padilla, C.A. \& Valverde, L. 2005. Germination responses of three cogeneric cacus species (Neobuxbaumia) with differents degrees of rarity. Journal of Aris Environments 61: 333-343.

Rocha, D.M.S.; Barbosa-Silva, D. \& Bucci, F.F.B. 2008. Espécies introduzidas e exóticas. Pp. 190- 198. In: F.O. Fonseca (Org). Água emendadas/Distrito Federal. Secretaria de Desenvolvimento Urbano e Meio Ambiente. Brasília: Seduma.

Rosolen, V.; de Oliveira, D.A. \& Bueno, G.T. 2014. Pp. 1-8.Vereda and Murundu wetlands and changes in Brazilian environmental laws: challenges to conservation. Wetlands Ecology and Management.

Silva-Júnior, M.C. \& Felfili, J.M. 1996. A vegetação da Estação Ecológica de Águas Emendadas. Brasília: Instituto de Ecologia e Meio Ambiente do Distrito Federal. 
Simpson, R.L.; Allessio Leck, M. \& Parker, V.T. 1989. Seed banks: general concepts and methodological issues. Pp. 3-8. In: Ecology of Soil Seed Banks. M.A. Leck, V.T. Parker \& R.L. Simpson (Eds). Academic Press, San Diego, California.

Schiavini, I.; Resende, J.C.F. \& Aquino, F.G. 2001. Dinâmica de populações de espécies arbóreas em Mata de Galeria e Mata Mesófila na margem do Ribeirão Panga, MG. Pp. 267-296. In: Ribeiro, J.F.; Fonseca, C.E.L.; Souza-Silva, J.C. (Ed.). Cerrado: caracterização e recuperação de Matas de Galeria. Planaltina: Embrapa.

Watkinson, A.R. 1997. Plant population dynamics. Pp. 359-400. In: Crawley, M.J. (Ed.). Plant ecology. Londres: Blackwell Scientific Publications. 


\section{Capítulo 1 - Mudanças ambientais locais influenciam a capacidade de germinação de}

Trembleya parviflora (Melastomataceae) em Veredas?

\section{Resumo}

Nas Veredas, Áreas Úmidas do bioma Cerrado, ocorre atualmente o aumento populacional de algumas espécies do estrato arbustivo causando redução na diversidade vegetal da comunidade. Esse aumento pode ser explicado pela eficiência na germinação sob as diferentes condições ambientais as quais as plantas e as sementes estão submetidas. Este estudo avaliou efeitos de temperatura, condição de submersão, déficit hídrico do substrato, armazenamento e concentração de $\mathrm{CO}_{2}$ na germinação de sementes de Trembleya parviflora. A germinação se iniciou entre o $4^{\circ}$ e o $15^{\circ}$ dia. A maior germinabilidade foi encontrada para sementes armazenadas após um mês (47\%), em temperatura alternada (46\%), coletadas em área úmida com baixa densidade da espécie (48\%) e disponibilidade hídrica e concentração de $\mathrm{CO}_{2}$ não afetaram significativamente a germinação. Sementes armazenadas por maior período apresentaram maior germinabilidade na condição de baixa umidade no substrato. O tempo médio de germinação variou entre cinco e 14 dias e o coeficiente de velocidade de germinação entre sete e 19\%. A alternância de temperatura reduziu o tempo médio, aumentou a velocidade e a germinabilidade de $T$. parviflora. A presença maciça de indivíduos da espécie pode estar relacionada com a capacidade das sementes germinarem em temperaturas alternantes tanto na condição de submersão quanto em redução hídrica logo após a dispersão e por um período superior a um ano.

Palavras-chave: áreas úmidas campestres, armazenamento de sementes, Cerrado, germinabilidade, viabilidade. 


\section{Introdução}

Estudos sobre a influência de água, luz e temperatura são essenciais para entender os aspectos ecológicos, fisiológicos e bioquímicos envolvidos nos processos de germinação de sementes (Labouriau 1983; Vázquez-Yanes e Orozco-Segovia 1993). As sementes de espécies presentes em ambientes extremos possuem diferentes estratégias para lidar com condições adversas. Em áreas úmidas, por exemplo, existem sementes insensíveis ao alagamento (Guo et al. 1998) ou mesmo capazes de permanecer debaixo de água durante longos períodos de tempo sem perda significativa da viabilidade (Marques \& Joly 2000; Parolin et al. 2003) - mecanismos de escape ou tolerância à inundação para evitar a deterioração produzida pela submersão (Parolin et al. 2003; Ferreira et al. 2010).

As condições hidrológicas, especialmente regimes de flutuação, são conhecidas por influenciarem a composição florística e processos de dinâmica em comunidades de áreas úmidas (Keddy 2000; Munhoz et al. 2008; Eugênio et al. 2011). A sazonalidade de condições de inundação e seca pode influenciar na estrutura das comunidades vegetais, de acordo com a tolerância das diferentes espécies presentes a esses regimes (Nicol et al. 2003; Cherry e Gough 2006; Munhoz et al. 2008). A disponibilidade de água no solo influencia na dispersão de sementes e os períodos de secas e inundações podem estimular ou inibir a germinação de sementes presentes no solo e ainda afetar o estabelecimento das plantas (Cherry e Gough 2006). Além disso, de modo mais extremo, o rebaixamento no nível do lençol freático cria oportunidade para o estabelecimento de espécies adaptadas a águas mais rasas em áreas consideradas úmidas (Nicol et al. 2003).

No Brasil Central, no Cerrado, a Vereda é uma fitofisionomia que ocorre em ambientes úmidos, os quais geralmente ocorrem próximos às nascentes e em solos hidromórficos mal drenados ou muito mal drenados (Eiten 2001). As Veredas apresentam dois estratos, um 
herbáceo-graminoso, que ocupa a maior parte da área, e outro arbustivo-arbóreo, onde predomina a espécie Mauritia flexuosa L. f. (Arecaceae), que caracteriza esta fitofisionomia (Eiten 2001). Em ambientes campestres de áreas úmidas, as alterações nos regimes hidrológicos de longo prazo podem facilitar a entrada de espécies lenhosas com redução de riqueza e abundância de espécies do estrato herbáceo (Eiten 2001; Meirelles et al. 2002; Santos e Munhoz 2012). Nesses ambientes vem ocorrendo o aumento significativo das populações de espécies arbustivas nativas, principalmente indivíduos da família Melastomataceae, em provável consequência do rebaixamento do lençol freático causado por intervenções antrópicas adjacentes (Meirelles et al. 2002).

As espécies arbustivas de Melastomataceae no bioma Cerrado ocorrem desde locais com solos bem drenados aos locais com encharcamento periódico ou permanente e apresentam germinabilidade mais elevada em temperaturas entre $20^{\circ} \mathrm{C}$ e $30^{\circ} \mathrm{C}$ (Carreira e Zaidan 2007; Rodrigues e Silveira 2012). Sabe-se, para esta família, que valores inferiores ou superiores de temperatura $\left(15^{\circ} \mathrm{C}\right.$ ou $\left.35^{\circ} \mathrm{C}\right)$ impedem ou reduzem a germinação podendo induzir a dormência das sementes que ficariam disponíveis no solo (Pereira-Diniz e Ranal 2006; Rodrigues e Silveira 2012).

Sementes de Melastomataceae apresentam longevidade e viabilidade entre 12 (Zaia e Takaki 1998) e 42 meses de armazenamento (Rodrigues e Silveira 2012). Essa característica permite a sobrevivência em ambientes sazonais e a germinação em momentos adequados para o desenvolvimento da plântula (Rodrigues e Silveira 2012). A resposta à sazonalidade ambiental aliada às possíveis variações genéticas ainda influenciam em diferenças nos parâmetros germinativos, como tempo e germinabilidade, entre populações da mesma espécie (Fenner 1991; Baskin e Baskin 1998). Existem poucos estudos sobre a biologia da germinação de espécies dessa família relacionados com 
variação interpopulacional no Cerrado (Sales et al. 2013) e também em relação a concentrações de $\mathrm{CO}_{2}$.

A variação na germinação sob o efeito direto do aumento da concentração de $\mathrm{CO}_{2}$ nas sementes ou sobre as gerações de plantas matrizes varia de forma acentuada entre espécies (Marty e BassiriRad 2014). Esses autores observaram que com o agrupamento das espécies em formas de vida, o sucesso da germinação de sementes expostas diretamente à concentração elevada de $\mathrm{CO}_{2}$ pouco mudou para gramíneas, aumentou $16 \%$ para arbustos e reduziu 26\% para arbóreas. Marty e BassiriRad (2014) ressaltam ainda que as respostas na germinação de sementes às mudanças ambientais locais e globais podem auxiliar no desenvolvimento de modelos ecológicos mais robustos à tais alterações.

Trembleya parviflora (D. Don) Cogn., espécie com características de pioneira da família Melastomataceae, apresenta grandes populações em áreas úmidas (Eiten 2001; Meirelles et al. 2002). Essa espécie apresenta grande produção de sementes e possui alta plasticidade e limite de tolerância às condições ambientais (Albuquerque et al. 2013). Em uma Vereda no Brasil Central a redução na diversidade de espécies na comunidade foi associada com o aumento das populações de T. parviflora (Santos e Munhoz 2012).

Neste estudo foi considerado que o conhecimento da germinação de T. parviflora torna-se essencial para entender processos tais como estabelecimento de plantas, sucessão e regeneração natural, sendo uma das ferramentas básicas para a gestão populacional da espécie em Unidades de Conservação (Vázquez-Yanes e Orozco-Segovia 1993). Partiu-se da hipótese de que o aumento das populações dessa espécie em áreas úmidas pode ocorrer em parte devido ao maior sucesso germinativo proporcionado pela redução da disponibilidade hídrica no solo por causa da redução do lençol freático.

O objetivo foi determinar o efeito da alternância de temperatura, períodos de armazenamento, condições de submersão e concentração de $\mathrm{CO}_{2}$ sobre a germinação de 
sementes de T. parviflora, coletadas em duas áreas Veredas com diferenças no tamanho populacional da espécie. Este estudo parte da premissa de que T. parviflora tem elevado sucesso por apresentar alta germinabilidade e pelo fato de as sementes manterem a viabilidade por longos períodos, permitindo que essas permaneçam dormentes no solo até que condições favoráveis surjam. Relacionada a esse fato, uma segunda premissa é que variações ambientais em Veredas afetam positiva ou negativamente a germinação dessa espécie; uma vez que a população da espécie apresenta aumento quando o lençol freático das Veredas é rebaixado, espera-se que a espécie apresente menor germinabilidade em condição de submersão.

\section{Material e Métodos}

\section{Coleta e tratamento do material}

Frutos de Trembleya parviflora foram coletados em Veredas em duas Unidades de Conservação no Distrito Federal: Em área do Parque Nacional de Brasília (PNB 1546'38,98"S e 4758'34,70"W) onde acontece o início da colonização de Trembleya parviflora e em área na Estação Ecológica de Águas Emendadas (ESECAE $15^{\circ} 33^{\prime} 31,18^{\prime \prime} \mathrm{S}$ e $\left.47^{\circ} 35^{\prime} 45,36^{\prime \prime W}\right)$ onde há grande densidade da espécie. A coleta foi realizada em setembro de 2012, final do período de frutificação e da estação seca na região.

O clima da região é Aw, de acordo com a classificação de Köppen, sendo caracterizado por uma estação chuvosa entre outubro a abril e uma estação seca de maio a setembro. As temperaturas variam entre 12 e $28,5^{\circ} \mathrm{C}$ e a precipitação média anual é de aproximadamente 1500mm (IBGE 2004). 


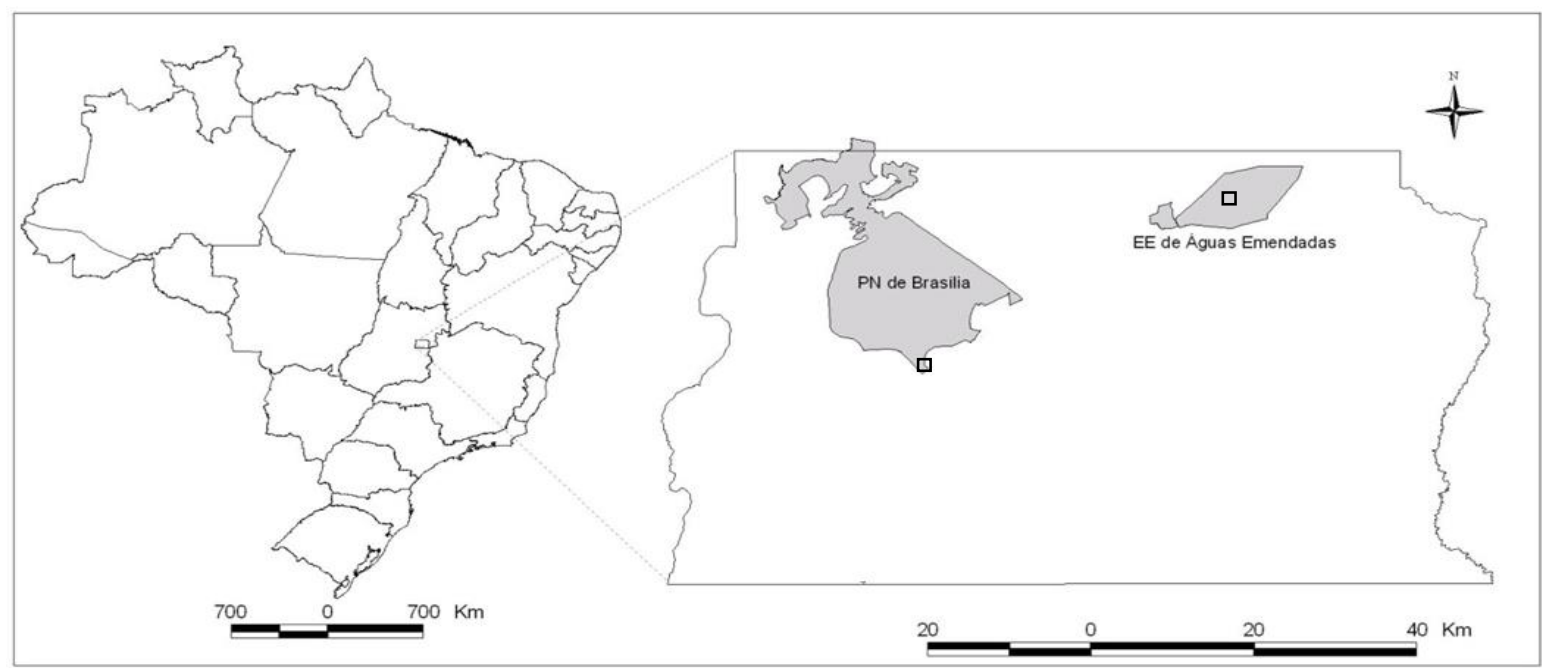

Figura 1. Áreas de estudo ( $\square$ ) em destaque no Parque Nacional de Brasília (PNB) e na Estação Ecológica de Águas Emendadas (ESECAE), Distrito Federal, Brasil.

Os frutos de T. parviflora coletados de ambos os locais foram secos à sombra em temperatura ambiente no Laboratório Experimental de Biologia da Universidade de Brasília. As sementes foram retiradas, triadas e separadas de materiais inertes e homogeneizadas manualmente. As sementes foram acondicionadas em envelopes de papel permeável, identificadas e armazenadas em temperatura ambiente de laboratório durante os 15 meses de experimentos. As sementes foram desinfetadas com hipoclorito de sódio a $2 \%$, por cinco minutos, e posteriormente lavadas em água destilada para retirar o excesso do produto para a realização dos experimentos de germinação.

\section{Experimentos de germinação}

A condição de submersão em água encontrada de forma natural em ambientes de áreas úmidas, especialmente nas Veredas, foi simulada em laboratório por meio da manutenção das sementes imersas em água destilada (160ml aproximadamente; oxigênio entre 6,0 e $7,7 \mathrm{mgO}_{2} \cdot 1^{-1}$ ), sobre duas folhas papel filtro e sob gaze, para evitar que as sementes boiassem, em caixas gerbox $(11 \times 11 \times 3,5 \mathrm{~cm})$. Esse tratamento foi comparado ao controle, no qual as sementes foram colocadas sobre o mesmo substrato úmido em placas 
de Petri $(9 \mathrm{x} 1,5 \mathrm{~cm})$ com 5 a 10ml de água, simulando as áreas de menor disponibilidade de água.

Os testes de germinação foram realizados em câmaras de germinação do tipo B.O.D. (Tecnal, Te-4013) com temperatura alternante entre $20^{\circ} \mathrm{C}$ e $30^{\circ} \mathrm{C}\left( \pm 2^{\circ} \mathrm{C}\right)$ (período escuro e luminoso, respectivamente) e constante de $25^{\circ} \mathrm{C}$, ambas com fotoperíodo de 12 horas, proporcionada pela presença de luz fluorescente branca. Avaliamos em ensaios prévios que as sementes não germinam no escuro nas temperaturas alternadas e constante testadas neste estudo. Os tratamentos de submersão, controle, temperatura constante e alternada foram realizados para sementes coletadas no PNB e na ESECAE após 1, 3, 9 e 15 meses de armazenamento em temperatura ambiente de laboratório nos envelopes de papel.

\section{Influência de dióxido de carbono na germinação de Trembleya parviflora}

No National Wetlands Research Center (NWRC), nos Estados Unidos, foi realizado experimento de germinação para verificar se a concentração dióxido de carbono $\left(\mathrm{CO}_{2}\right)$ do ambiente antiga e atual (260 e 380ppm, respectivamente) influenciariam na germinação de $T$. parviflora. Para tanto, foram utilizadas câmaras de germinação com temperatura constante de $25^{\circ} \mathrm{C}$, umidade de $70 \%$, fotoperíodo de 12 horas e concentração pré-industrial e atual de $\mathrm{CO}_{2}$.

\section{Delineamento experimental e análise de dados}

Para determinar o efeito da alternância de temperatura, períodos de armazenamento e a condição de submersão e controle sobre a germinação de $T$. parviflora foi utilizado delineamento para análise fatorial com quatro fatores (com quatro níveis para tempo de armazenamento, dois níveis de área de coleta, dois níveis de temperatura da câmara e dois níveis para umidade de substrato). Foram utilizadas 25 sementes por placa de Petri ou 
caixa gerbox de polietileno transparente vedadas com filme plástico (cinco repetições, totalizando 1000 sementes em cada tempo de armazenamento).

Para verificar o efeito da concentração de $\mathrm{CO}_{2}$ foi utilizado delineamento inteiramente casualizado com 8 repetições por tratamento. Foram montadas 16 placas de Petri com 25 sementes cada, sendo metade colocada em atmosfera com baixa concentração de $\mathrm{CO}_{2}(260 \mathrm{ppm})$ e metade submetida à atmosfera com concentração atual de $\mathrm{CO}_{2}$ (380ppm).

A germinabilidade foi considerada como a porcentagem de sementes germinadas em relação ao número de sementes dispostas a germinar (Labouriau 1983). Para o cálculo do tempo médio de germinação utilizamos a equação: $\bar{t}=\frac{\sum_{i=n}^{k} n_{i} t_{i}}{\sum_{i=n}^{k} n_{i}}$, onde, $t_{i}$ foi o tempo entre o início do experimento e a $i$-ésima observação (dias); $n_{i}$, o número de sementes que germinam no tempo $t_{i}$ (número referido para a $i$-ésima observação); e $k$ o último tempo de germinação de sementes (Labouriau 1983). O coeficiente de velocidade de germinação (CVG) foi medido pela equação: $C V G=\left(\sum_{i=l}^{k} f_{i} / \sum_{i=l}^{k} f_{i} x_{i}\right) 100$, onde, $f_{i}$ foi o número de sementes recém germinadas no dia $i ; \mathrm{x}_{\mathrm{i}}$, o número de dias da semeadura, e $k$, o último dia de germinação (Nichols e Heydecker 1968).

A distribuição normal dos dados de germinabilidade, tempo médio e coeficiente de velocidade de germinação foi avaliada pelo teste Kolmogorov-Smirnov e quando essa premissa de normalidade da distribuição não foi atendida os dados foram transformados por raiz quadrada. Sendo alcançada a normalidade dos dados, os testes posteriores foram realizados (Zar 1999; Santana e Ranal 2004). Os dados foram submetidos à ANOVA fatorial, seguida do teste Tukey (para o experimento do efeito da alternância de temperatura, períodos de armazenamento e as condições de umidade do substrato) ou teste T para amostras independentes (para experimento do efeito da concentração de $\mathrm{CO}_{2}$ ) sendo cada placa de Petri ou caixa gerbox uma unidade amostral. Para todas as análises 
estatísticas utilizamos alfa de 5\%. As análises foram realizadas em ambiente $\mathrm{R}$ 3.0.2 (Package stats) (R Core Team 2013).

\section{Resultados}

A germinação de T. parviflora variou de 14 a $70 \%$ entre os tratamentos e o início da germinação ocorreu do $4^{\circ}$ ao $10^{\circ}$ dia (Figura 2). A germinação das sementes tende a estabilizar aproximadamente até o $15^{\circ}$ dia. A maior germinabilidade média foi encontrada para sementes após um mês de coleta (47\%; média) diferindo apenas de 15 meses de armazenamento $(40 \%)$. As sementes coletadas no Parque Nacional de Brasília apresentaram em média maior germinabilidade (48\%) se comparadas às de Águas Emendadas (39\%) (Figura 2 e Tabelas 1 e 2). Não se observou diferença na germinabilidade sob a condição de redução de disponibilidade hídrica (43\%) em comparação com a condição de submersão (42\%). Sementes colocadas para germinar em temperatura alternada mostraram maior germinabilidade (46\%) se comparadas àquelas em temperatura constante (40\%) (Figura 2 e Tabela 1).

A interação de cada um dos tempos de armazenamento e a condição de umidade do substrato evidenciou a redução da germinabilidade de sementes armazenadas por 15 meses quando colocadas na condição de submersão se comparadas com as de menor disponibilidade hídrica (Tabela 1). As demais interações significativas reforçam o resultado de menor germinabilidade observada em sementes armazenadas por 15 meses, em submersão, sob temperatura constante e coletadas na ESECAE. Esse padrão não foi observado para sementes coletadas na mesma área e no mesmo período quando submetidas à temperatura constante e/ou alternada em substrato úmido. 
O tempo médio de germinação (TM) variou entre 5 e 14 dias e o coeficiente de velocidade de germinação (CVG) entre 7 e 19\% (Tabela 1). Após 1 e 15 meses de armazenamento as sementes apresentaram os maiores valores de TM e menores que CVG se comparados com 3 e 9 meses. Sementes coletadas no PNB apresentaram menor TM e maior CVG.

A condição de disponibilidade hídrica não determinou diferença em relação ao TM, entretanto, sementes submersas apresentaram maior CVG em relação às sementes colocadas sob reduzida disponibilidade hídrica. A temperatura alternada entre 20 a $30^{\circ} \mathrm{C}$ influenciou na redução do TM e no aumento do CVG se comparada com a temperatura constante de $25^{\circ} \mathrm{C}$.

As interações significativas encontradas intensificaram as diferenças existentes entre os períodos de armazenamento (Tabela 2). A interação da condição de umidade de substrato com armazenamento mostrou que a condição de submersão tende a elevar os valores de TM quando as sementes foram armazenadas por 15 meses comparadas com os demais períodos de armazenamento em substrato umedecido. Essa tendência se repetiu para a condição de temperatura da câmara, sendo que as sementes armazenadas por 15 meses tiveram maior tempo médio em relação aos outros períodos de armazenamento. $\mathrm{O}$ coeficiente de velocidade de germinação foi influenciado pelas interações pareadas da condição tempo de armazenamento com local, tempo de armazenamento com condições de umidade de substrato e tempo de armazenamento com temperatura da câmara, sendo os menores coeficientes $(\mathrm{CVG})$ encontrados para sementes armazenadas por 15 meses.

As concentrações pré-industrial e atual de $\mathrm{CO}_{2}, 260$ e 380ppm não influenciaram na germinação (14 e $15 \%$, respectivamente; $\left.t_{13 ; 0,05}=0,01 ; \mathrm{p}=0,80\right)$, no tempo médio ( 7 dias e 8 dias, respectivamente; $\left.t_{13 ; 0,05}=-0,44 ; p=0,46\right)$ e coeficiente de velocidade de germinação $\left(10\right.$ e $11 \%$, respectivamente; $\left.t_{13 ; 0,05}=-1,31 ; \mathrm{p}=0,21\right)$. 

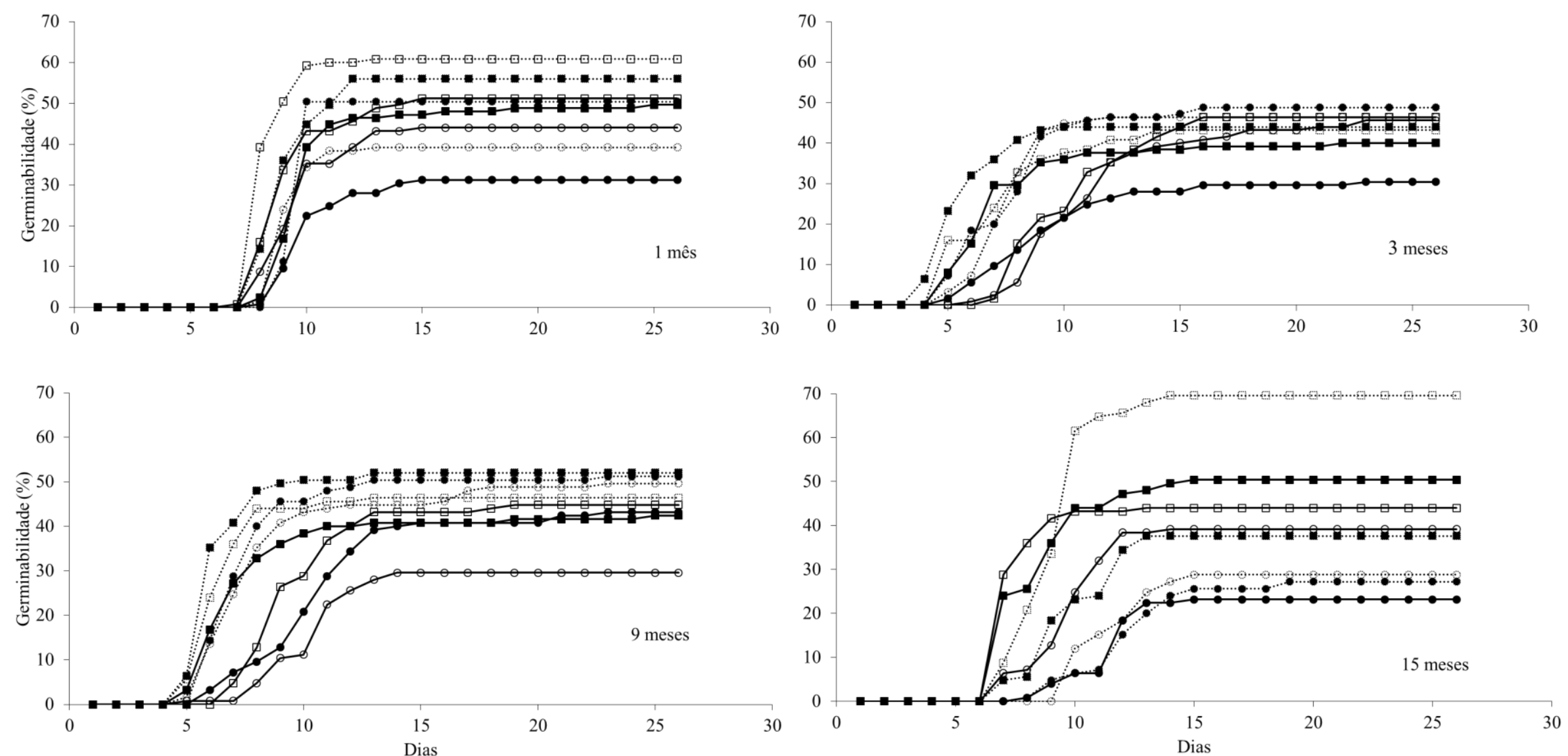

Figura 2. Germinação cumulativa (\%) de sementes de Trembleya parviflora coletadas no Parque Nacional de Brasília (口) e na Estação Ecológica de Águas Emendadas ( $)$, colocadas para germinar após $1,3,9$ e 15 meses da coleta em câmara com temperatura constante $\left(25^{\circ} \mathrm{C}\right.$, linha contínua) ou alternada $\left(20\right.$ e $30^{\circ} \mathrm{C}$, período escuro e luminoso, respectivamente - linha pontilhada) submetidas à submersão (símbolos fechados) ou sobre substrato umedecido (símbolos abertos). 
Tabela 1. Resultados de ANOVA fatorial sobre os efeitos de área de coleta (PNB e ESECAE), tempo de armazenamento (1, 3, 9, e 15 meses após a coleta), temperatura da câmara de germinação $\left(25^{\circ} \mathrm{C}\right.$ ou entre 20 a $\left.30^{\circ} \mathrm{C}\right)$ e condição de disponibilidade hídrica (submersão ou substrato úmido) para germinabilidade (\%), tempo médio (dias) e coeficiente de velocidade de germinação (\%) (CVG) de Trembleya parviflora.

\begin{tabular}{lrrrrrrr}
\hline & \multicolumn{3}{c}{ Germinabilidade } & \multicolumn{2}{c}{ Tempo médio } & \multicolumn{2}{c}{ CVG } \\
\hline Fatores & Gl & F & P-values & F & P-values & F & \multicolumn{1}{c}{ P- } \\
& & & & & & & \multicolumn{1}{c}{ values } \\
\hline Tempo (T) & 3 & 3,9 & $\mathbf{0 , 0 1 1}$ & 27,0 & $<\mathbf{0 , 0 0 1}$ & 27,8 & $<\mathbf{0 , 0 0 1}$ \\
Área (A) & 1 & 31,9 & $<\mathbf{0 , 0 0 1}$ & 96,6 & $<\mathbf{0 , 0 0 1}$ & 87,1 & $<\mathbf{0 , 0 0 1}$ \\
Temperatura da Câmara (TC) & 1 & 13,2 & $<\mathbf{0 , 0 0 1}$ & 45, & $<\mathbf{0 , 0 0 1}$ & 45,5 & $<\mathbf{0 , 0 0 1}$ \\
Disponibilidade Hídrica (DH) & 1 & 3,7 & 0,058 & 2,9 & 0,088 & 4,0 & $\mathbf{0 , 0 4 7}$ \\
T x A & 3 & 8,0 & $<\mathbf{0 , 0 0 1}$ & 5,3 & $\mathbf{0 , 0 0 2}$ & 6,3 & $\mathbf{0 , 0 0 1}$ \\
T x TC & 3 & 1,1 & 0,341 & 38,3 & $<\mathbf{0 , 0 0 1}$ & 37,9 & $<\mathbf{0 , 0 0 1}$ \\
A x TC & 1 & 0,3 & 0,581 & 0,2 & 0,660 & 0,04 & 0,841 \\
T x DH & 3 & 3,7 & $\mathbf{0 , 0 1 4}$ & 14,1 & $<\mathbf{0 , 0 0 1}$ & 12,9 & $<\mathbf{0 , 0 0 1}$ \\
A x DH & 1 & 0,4 & 0,502 & 4,6 & $\mathbf{0 , 0 3 4}$ & 3,0 & 0,087 \\
TC x DH & 1 & 0,4 & 0,502 & 3,1 & 0,080 & 3,2 & 0,078 \\
T x A x TC & 3 & 1,8 & 0,152 & 0,03 & 0,991 & 0,4 & 0,771 \\
T x A x DH & 3 & 0,4 & 0,771 & 1,2 & 0,308 & 2,3 & 0,081 \\
T x TC x DH & 3 & 3,0 & $\mathbf{0 , 0 3 4}$ & 2,6 & 0,053 & 2,3 & 0,078 \\
A x TC x DH & 1 & 7,1 & $\mathbf{0 , 0 0 9}$ & 1,6 & 0,204 & 0,7 & 0,393 \\
T x A x TC x DH & 3 & 5,3 & $\mathbf{0 , 0 0 2}$ & 1,0 & 0,396 & 1,0 & 0,393 \\
\hline Resíduos & $\mathbf{1 2 8}$ & \multicolumn{7}{c}{} & & & & & \\
\hline
\end{tabular}




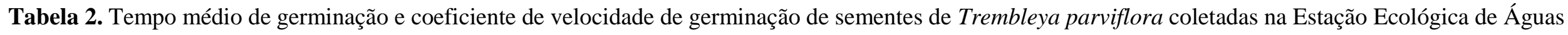

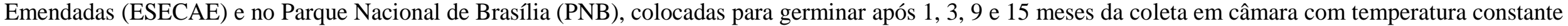
$\left(25^{\circ} \mathrm{C}\right)$ ou alternada $\left(20\right.$ e $30^{\circ} \mathrm{C}$, período escuro e luminoso, respectivamente) submetidas à submersão em água ou sobre substrato umedecido (controle).

\begin{tabular}{|c|c|c|c|c|c|c|c|c|}
\hline \multirow{3}{*}{$\begin{array}{l}\text { Local } \\
\text { Temperatura } \\
\text { Disponibilidade Hídrica }\end{array}$} & \multicolumn{4}{|c|}{ ESECAE } & \multicolumn{4}{|c|}{ PNB } \\
\hline & \multicolumn{2}{|c|}{ Constante } & \multicolumn{2}{|c|}{ Alternada } & \multicolumn{2}{|c|}{ Constante } & \multicolumn{2}{|l|}{ Alternada } \\
\hline & Submersa & Controle & Submersa & Controle & Submersa & Controle & Submersa & Controle \\
\hline Meses de armazenamento & \multicolumn{8}{|c|}{ Tempo Médio de Germinação (dias) } \\
\hline 1 & $10,3 \pm 0,68$ & $9,95 \pm 0,27$ & $9,78 \pm 0,07$ & $9,47 \pm 0,35$ & $8,03 \pm 1,36$ & $9,55 \pm 0,68$ & $9,43 \pm 0,38$ & $8,59 \pm 0,21$ \\
\hline 3 & $9,49 \pm 0,97$ & $11,64 \pm 1,78$ & $7,89 \pm 0,91$ & $7,79 \pm 0,42$ & $9,43 \pm 0,38$ & $10,58 \pm 1,01$ & $5,93 \pm 0,4$ & $7,42 \pm 2,24$ \\
\hline 9 & $10,81 \pm 1,76$ & $10,6 \pm 1,13$ & $7,94 \pm 1,18$ & $8,42 \pm 1,13$ & $7,5 \pm 1,23$ & $9,97 \pm 1,31$ & $6,63 \pm 0,34$ & $6,94 \pm 1,06$ \\
\hline \multirow[t]{2}{*}{15} & $11,44 \pm 0,99$ & $9,85 \pm 0,5$ & $12,43 \pm 1,03$ & $11,64 \pm 0,34$ & $8,64 \pm 0,64$ & $7,67 \pm 0,38$ & $9,97 \pm 0,73$ & $9,35 \pm 0,23$ \\
\hline & \multicolumn{8}{|c|}{ Coeficiente de Velocidade de Germinação (\%) } \\
\hline 1 & $10,51 \pm 0,73$ & $10,06 \pm 0,29$ & $10,23 \pm 0,08$ & $10,57 \pm 0,39$ & $12,74 \pm 2,1$ & $10,51 \pm 0,73$ & $10,62 \pm 0,43$ & $11,65 \pm 0,28$ \\
\hline 3 & $10,64 \pm 1,21$ & $8,74 \pm 1,27$ & $12,81 \pm 1,59$ & $12,87 \pm 0,68$ & $10,31 \pm 0,8$ & $9,52 \pm 0,86$ & $16,91 \pm 1,13$ & $14,33 \pm 3,68$ \\
\hline 9 & $9,45 \pm 1,47$ & $9,52 \pm 1,05$ & $12,84 \pm 2,02$ & $12,06 \pm 1,71$ & $13,63 \pm 2,31$ & $10,18 \pm 1,45$ & $15,11 \pm 0,79$ & $14,67 \pm 2,05$ \\
\hline 15 & $8,8 \pm 0,78$ & $10,17 \pm 0,5$ & $8,09 \pm 0,66$ & $8,6 \pm 0,24$ & $11,62 \pm 0,84$ & $13,06 \pm 0,63$ & $10,07 \pm 0,73$ & $10,7 \pm 0,26$ \\
\hline
\end{tabular}




\section{Discussão}

A maior germinabilidade de $T$. parviflora foi encontrada para sementes com menor tempo de armazenamento, período que coincide com o início da estação chuvosa e quando ocorre a dispersão de sementes da espécie (Albuquerque et al. 2013). Consequentemente, logo após a dispersão de sementes de T. parviflora existirá disponibilidade hídrica no solo, e no experimento essa condição de elevada umidade não restringiu e, ainda, possibilitou maior velocidade de germinação. A sincronização de frutificação e dispersão durante período chuvoso (Kubitzki e Ziburski 1994) e a capacidade de sementes submersas germinarem foi observado para espécies de áreas úmidas como para Inga sessilis (Vell.) Mart. (Lieberg e Joly 1993; Okamoto e Joly 2000) e Himatanthus sucuuba (Spruce ex Müll. Arg.) Woodson (Ferreira et al. 2007). Essa estratégia fenológica e a presença de mecanismos nas sementes e nas plântulas que permitam a sobrevivência em solo encharcado auxiliam no estabelecimento de certas espécies de áreas úmidas (Marques e Joly 2000) que podem auxiliar na ampla distribuição e na atual expansão de T. parviflora em áreas de vereda.

O Cerrado tem como característica uma estação seca bem definida e rigorosa, de quase seis meses, com mínima ou nenhuma pluviosidade, entretanto, pelas condições topográficas e de solo, as Veredas apresentam zonas úmidas ou alagadas o ano todo (Eiten 2001). Isso pode ser determinante para o sucesso na emergência de $T$. parviflora tanto no período chuvoso quanto no seco, nessas zonas, em virtude da plasticidade da espécie em germinar em condição de submersão e em menor umidade no substrato. Como pressuposto, se a dispersão ocorrer em porções das áreas úmidas onde há redução da lâmina d'água do lençol freático, mas com umidade suficiente para a germinação e emergência de plântulas a espécie seria favorecida. 
Além das variações hídricas, outras características de áreas úmidas são as alternâncias de luminosidade e/ou temperaturas diurnas e noturnas. Esses fatores podem ser ressaltados com a abertura de clareiras as quais permitem entrada de luz e promove variações de temperaturas na superfície do solo que, por consequência, afeta a germinação (Válio e Scarpa 2001). Essas características são distintas quando há dossel impedindo a entrada de luz e causando menor flutuação na temperatura do solo em ambientes florestais (Baider et al. 1999) e campestres (Insausti e Soriano 1995). Em ambientes campestres de áreas úmidas, a maior disponibilidade de luz no solo ocorre com o ressecamento ou ocasional morte de indivíduos graminóides principalmente após o período seco do ano (Insausti e Soriano 1995; Munhoz et al. 2008). Esses eventos coincidem com o período de dispersão de T. parviflora, determinando condições ótimas de luz, umidade e temperatura para germinação e estabelecimento no início do período chuvoso.

A alternância de temperatura possibilitou aumento da germinação de T. parviflora e da velocidade em menor tempo. Sementes em habitat natural são normalmente expostas a variações de temperatura o que pode vir a afetar positivamente o processo de germinação (Baskin e Baskin 1998). A temperatura predominante do solo influencia na velocidade em que as sementes germinarão de acordo com a amplitude térmica ótima para cada espécie (Heydecker 1977). Valores mais elevados de germinação para espécies pertencentes à família Melastomataceae são observados em amplitudes térmicas entre $20^{\circ} \mathrm{C}$ e $30^{\circ} \mathrm{C}$ e temperaturas extremas a 15 e $35^{\circ} \mathrm{C}$ reduzem a germinabilidade (Carreira e Zaidan 2007; Rodrigues e Silveira 2012). Por conseguinte, a flutuação térmica resultante das clareiras e também da diferença de temperatura diurna e noturna observadas no período de dispersão de T. parviflora favorecem a germinação. 
A germinação reduziu após 15 meses de armazenamento. Entretanto, esses valores ainda assim podem ser considerados elevados para os padrões de sementes dessa família (Carreira e Zaidan 2007), a qual possui alta percentagem de sementes vazias (Zaia e Takaki 1998, Rodrigues e Silveira 2012). A ausência das condições necessárias de temperatura, luminosidade e disponibilidade hídrica para $T$. parviflora podem levar à dormência das sementes as quais permanecem viáveis por 15 meses de armazenamento. Sementes dormentes constituem banco no solo quando algum dos fatores requeridos para a germinação não está disponível (Baider et al. 1999). A permanência de viabilidade de sementes após armazenamento também foi observada em outra espécie do mesmo gênero, T. laniflora (D. Don) Cogn., a qual foi estocada por 42 meses em temperatura de $4^{\circ} \mathrm{C}$ (Rodrigues e Silveira 2012). Outras espécies da mesma família, Tibouchina pulchra (Cham.) Cogn. e Tibouchina granulosa (Desr.) Cogn., germinaram depois de armazenadas por um ano em frascos âmbar fechados e armazenados em refrigerador com temperatura aproximada de $10^{\circ} \mathrm{C}$ (Zaia e Takaki 1998).

As sementes que formam banco de sementes transiente permanecem viáveis no período de no máximo um ano após a dispersão e no banco persistente a viabilidade se mantém após este período (Thompson e Grime 1979). Entende-se, de acordo com os dados de armazenamento, que as sementes de $T$. parviflora podem formar banco de sementes persistente. Corroborando essa afirmação, banco de sementes persistente apresenta predomínio de sementes pequenas, dormentes, leves, sem mecanismos de dispersão específicos ou defesas químicas (Thompson e Grime 1979) como a da espécie estudada (Albuquerque et al. 2013), com tamanho menor que um milímetro.

Conforme ressaltado anteriormente, o período de seca no Cerrado gera estresse hídrico de modo que a dormência seria uma estratégia eficiente caso a dispersão ocorra em zonas da 
Vereda sem água prontamente disponível. Adicionalmente, essa estratégia pode explicar o aumento da abundância de plantas de T. parviflora em Vereda depois de anos de perturbação, devido a efeitos antrópicos que levaram à redução do lençol freático (Meirelles et al. 2002). As sementes que compõem uma proporção muito elevada do banco persistente promovem o aumento de indivíduos de determinadas espécies após perturbações da vegetação e do solo (Thompson e Grime 1979). A redução do lençol nas áreas com crescente população de $T$. parviflora substituiu zonas permanentemente alagadas por sazonais, favorecendo a germinação da espécie e zonas sazonais, por sua vez, tornaram-se secas e isto promove o aumento no banco de sementes persistente com a germinação ocorrendo em momento com disponibilidade hídrica no solo.

Condições intrínsecas do ambiente influenciam a germinação das sementes (Jain 1982), e podem explicar as diferenças de germinação entre sementes de T. parviflora coletadas nas duas áreas úmidas estudadas. No Parque Nacional de Brasília (PNB), houve maior germinação apesar das sementes coletadas em ambas as Unidades de Conservação ser em média acima de 39\%. No PNB a disponibilidade hídrica gerada pelo lençol freático ocorre durante maior parte do ano (ver Capítulo 3), e dessa forma as plantas presentes estão sujeitas a menores graus de estresse hídrico por falta de umidade, diferentemente da Estação Ecológica de Águas Emendadas. Além disso, no PNB há poucos indivíduos de T. parviflora por hectare e, portanto, menor competição por recursos entre as plantas da espécie. Deste modo, estes fatores podem ter contribuído para a diferença encontrada na germinação entre as áreas. A espécie Miconia albicans (Sw.) Steud., também da família Melastomataceae, por exemplo, apresentou diferenças nas respostas de germinação quando se avaliou sementes oriundas de plantas de microhabitats distintos e extremos em gradiente de Cerrado (Sales et al. 2013). Ademais, a plasticidade específica pode estar relacionada com as variações interpopulacionais 
resultantes da variabilidade genética e/ou da plasticidade fenotípica intraespecífica que influenciam nos padrões de germinação das sementes (Fenner 1991; Baskin e Baskin 1998).

A ausência de respostas à diferente concentração de $\mathrm{CO}_{2}$ pré-industrial e atual na germinação de $T$. parviflora demonstra que a alteração do volume de $\mathrm{CO}_{2}$ pode não estar correlacionada com o aumento populacional da espécie e, mais especificamente, não influenciar na germinação. Entretanto, estudos com respostas da germinação de sementes oriundas de gerações de plantas matrizes expostas à concentração elevada de $\mathrm{CO}_{2}$ precisam ser desenvolvidos para confirmação do resultado encontrado. A concentração elevada de $\mathrm{CO}_{2}$ durante a maturação das plantas-mães reduz a proporção de sementes germinadas, entretanto, não tem efeito durante a exposição direta durante a germinação de Arabidopsis thaliana (Andalo et al. 1996). Respostas distintas entre germinação, desenvolvimento de plântulas e concentrações de $\mathrm{CO}_{2}$ podem estar relacionadas às características específicas de espécies ou de determinados genótipos (Andalo et al. 1996; Steinger et al. 2000; Edwards et al. 2001, Marty e BassiriRad 2014). Com a previsão de aumento da concentração de $\mathrm{CO}_{2}$ para os próximos anos (IPCC 2007), mais estudos - incluindo também o desenvolvimento de plântulas - podem auxiliar na explicação desses fatores.

A viabilidade de sementes de Trembleya parviflora se mantém após a dispersão, por mais de um ano. A germinação ocorreu principalmente nas simulações de condições de temperatura alternada semelhantes com as encontrada na região, com noturna mais baixa e diurna mais alta. Os resultados também evidenciaram que a germinação da espécie pode ocorrer de modo diferenciado espacialmente, pois foi observado resultado distinto dependendo da população analisada (local). Além disso, quando as sementes foram armazenadas por maior período de tempo a alta disponibilidade de água no substrato reduziu a germinação. 
Percebe-se em campo que a dispersão de sementes de $T$. parviflora tem ocorrido anualmente, e de forma intensa, a cada novo ciclo reprodutivo. Desta forma, acontece a inclusão de inúmeros novos diásporos no banco de semente persistente no solo e o incremento de novas plântulas na população. Adicionalmente, os modelos de mudança climática preveem para os trópicos a diminuição da precipitação anual, aumento no comprimento da estação seca e maior variabilidade interanual da precipitação (IPCC 2007). Nesta previsão pode ocorrer o favorecimento de espécies com as características de T. parviflora, pois este aumento esperado da frequência e da gravidade da seca (Capítulo 2, diferença na flutuação do lençol freático nas duas áreas) favoreceria a monodominância em detrimento da diversidade da comunidade presente nas Veredas (Capítulo 2, redução da riqueza e diversidade na presença de serapilheira de T. parviflora). Este cenário se agravaria com a consequente redução do lençol freático devido às atividades antrópicas ocorrentes nas áreas adjacentes às áreas úmidas, principalmente com a disponibilização de menores Áreas de Preservação Permanentes previstas no novo Código Florestal Brasileiro.

\section{Conclusão}

Trembleya parviflora apresenta capacidade de germinação mínima de 14\% logo após a dispersão ou em período superior a um ano. Deste modo, os resultados mostraram que o início da germinação ocorre relativamente rápido, principalmente sob temperaturas alternadas e não há restrições germinativas quando há excesso hídrico no período da dispersão das sementes na estação chuvosa, com diferenças entre o local de coleta e sem influência das concentrações diretas de $\mathrm{CO}_{2}$ (260 e 380ppm). A presença dessas características fisiológicas das sementes de 
T. parviflora pode auxiliar na explicação do sucesso de estabelecimento da espécie com a formação de grandes populações em comunidades de áreas úmidas no Cerrado.

\section{Referências bibliográficas}

Albuquerque, L.B.; Aquino, F.G.; Costa, L.C.; Miranda, Z.J., \& Sousa, S.R. 2013. Espécies de Melastomataceae Juss. com potencial para restauração ecológica de Mata Ripária no Cerrado. Polibotánica 35: 1-19.

Andalo, C.; Godelle, B.; Lefranc, M.; Mousseau, M. \& Till-Bottraud, I. 1996. Elevated $\mathrm{CO}_{2}$ decreases seed germination in Arabidopsis thaliana. Global Change Biology 2(2): 129135.

Baider, C.; Tabarelli, M.E. \& Mantovani, W. 1999. O banco de sementes de um trecho de Floresta Atlântica Montana (São Paulo, Brasil). Revista Brasileira Biologia 59: 319-328.

Baskin, C.C. \& Baskin, J.M. 1998. Seeds: Ecology, Biogeography, and Evolution of Dormancy and Germination. San Diego, Academic Press.

Carreira, R.C. \& Zaidan, L.B.P. 2007. Germinação de sementes de espécies de Melastomataceae de Cerrado sob condições controladas de luz e temperatura. Hoehnea 34, 261-269.

Cherry, J.A. \& Gough, L. 2006. Temporary floating island formation maintains wetland plant species richness: The role of the seed bank. Aquatic Botany 85: 29-36.

Edwards, G.R.; Newton, P.C.D.; Tilbrook, J.C. \& Clark, H. 2001. Seedling performance of pasture species under elevated $\mathrm{CO}_{2}$. New Phytologist 150(2): 359-369.

Eiten, G. 2001. Vegetação natural do Distrito Federal. Brasília, Sebrae.

Eugênio, C.U.O.; Munhoz, C.B.R. \& Felfili, J.M. 2011. Dinâmica temporal do estrato herbáceo-arbustivo de uma área de campo limpo úmido em Alto Paraíso de Goiás, Brasil. Acta Botanica Brasilica 25: 497-507.

Ferreira, C.S.; Piedade, M.T.F.; Junk, W.J. \& Parolin, P. 2007. Floodplain and upland populations of Amazonian Himatanthus sucuuba: effects of flooding on germination, seedling growth and mortality. Environmental and Experimental Botany 60: 477-483. 
Ferreira, C.S.; Piedade, M.T.F; Wittmann, A.O. \& Franco, A.C. 2010. Plant reproduction in the Central Amazonian floodplains: challenges and adaptations. AoB Plants: plq009.

Fenner, M. 1991. The effects of the parent environment on seed germinability. Seed Science Research 1: 75-84.

Guo, Y.; Shelton, M.G. \& Lockhart, B.R. 1998. Effects of flood duration and season on germination of black, cherrybark, northern red, and water oak acorns. New Forests 15: 6976.

Heydecker, W. 1977. Stress and seed germination: as agronomic view. Pp.237-282. In: Khan, A. (Eds.). The physiology and biochemistry of seed dormancy and germination. Amsterdam: Elsevier.

IBGE. 2004. Reserva Ecológica do IBGE: ambiente e plantas vasculares. Rio de Janeiro: IBGE-Divisão de Geociências. Estudos e Pesquisas. Informação Geográfica n. 3.

Insausti, P.; Soriano, A. \& Sanchez, R.A. 1995. Effects of flood-influenced factors on seed germination of Ambrosia tenuifolia. Oecologia 103: 127-132.

IPCC. 2007. Intergovernmental panel on climate change. AR4 Synthesis report. http:

//www.ipcc.ch/.

Jain, S.K. 1982. Variation and adaptative role of seed dormancy in some annual grassland species. Botanical Gazette 143: 101-106.

Keddy, P.A. 2000. Wetland ecology: principles and conservation. Cambridge: Cambridge University Press, 614 p.

Kubitzki, K. \& Ziburski, A. 1994 Seed dispersal in flood plain forests of Amazonia. Biotropica 26: $30-43$.

Labouriau, L.G. A germinação das sementes. 1983. Organização dos Estados Americanos. Programa Regional de Desenvolvimento Científico e Tecnológico. Série de Biologia. Monografia 24: 174.

Lieberg, S.A. \& Joly, C.A. 1993. Inga affinis DC (Mimosaceae): germinação e tolerância de plântulas submersão. Revista brasileira de Botânica 16: 175-179.

Marques, M.C.M. \& C.A. Joly. 2000. Estrutura e dinâmica de uma população de Calophyllum brasiliense Camb. em floresta higrófila do sudeste do Brasil. Revista Brasileira de Botânica 23: 107-112. 
Marty, C. \& BassiriRad, H. 2014. Seed germination and rising atmospheric CO2 concentration: a meta-analysis of parental and direct effects. New Phytologist, 202(2): 401-414.

Meirelles, M.L.; Oliveira, R.C.; Vivaldi, L.J.; Santos, A.D. \& Correia, J.R. 2002. Espécies de estrato herbáceo e profundidade do lençol freático em áreas úmidas do cerrado. Planaltina, Embrapa Cerrados.

Munhoz, C.B.R.; Felfili, J.M. \& Rodrigues, C. 2008. Species-environment relationship in the herb-subshrub layer of a moist Savanna site, Federal District, Brazil. Brazilian Journal of Biology 68: 25-35.

Nichols, M.A. \& Heydecker, W. 1968. Two approaches to the study of germination data. Proceedings of the International Seed Testing Association 33: 531-540.

Nicol, J.M.; Ganf, G.G. \& Pelton, G.A. 2003. Seed banks of a southern Australian wetland: the influence of water regime on the final floristic composition. Plant Ecology 168: 191205.

Okamoto, J.M. \& Joly, C.A. 2000. Ecophysiology and respiratory metabolism during the germination of Inga sessilis (Vell.) Mart. (Mimosaceae) seeds subjected to hypoxia and anoxia. Brazilian Journal of Botany 23: 51-57.

Parolin, P.; Ferreira, L.V. \& Junk, W.J. 2003. Germination characteristics and establishment of trees from central Amazonian flood plains. Tropical Ecology 44: 157-169.

Pereira-Diniz, S.G. \& Ranal, M.A. 2006. Germinable soil seed bank of a gallery forest in Brazilian Cerrado. Plant Ecology 183: 337-348.

R Core Team. 2013. R: A language and environment for statistical computing. R Foundation for Statistical Computing, Vienna, Austria.

Rodrigues, E.R.S. \& Silveira, F.A.O. 2012. Seed germination requirements of Trembleya laniflora (Melastomataceae), an endemic species from neotropical montane rocky savannas. Plant Species Biology: 37.

Sales, N.M.; Pérez-García, F. \& Silveira, F.A.O. 2013. Consistent variation in seed germination across an environmental gradient in a Neotropical savanna. South African Journal of Botany 87: 129-133.

Santana, D.G. \& Ranal, M.A. 2004. Análise estatística. Pp. 197-208. In: Ferreira, A.G. \& Borghetti, F. (Eds) Germinação: do básico ao aplicado. Porto Alegre, Artmed. 
Santos, F.F.M. \& Munhoz, C.B.R. 2012. Diversidade de espécies herbáceo-arbustivas e zonação florística em uma Vereda no Distrito Federal. Heringeriana 6: 21-27.

Steinger, T., Gall, R., \& Schmid, B. 2000. Maternal and direct effects of elevated $\mathrm{CO}_{2}$ on seed provisioning, germination and seedling growth in Bromus erectus. Oecologia 123(4): 475480.

Thompson, K. \& Grime, J.P. 1979. Seasonal variation in the seed banks of herbaceous species in ten contrasting habitats. Journal of Ecology 67: 893-921.

Válio, I.F.M. \& Scarpa, F.M. 2001. Germination of seeds of tropical pioneer species under controlled and natural conditions. Revista Brasileira de Botânica 24: 79-84.

Vázquez-Yanes, C. \& Orozco-Segovia, A. 1993. Patterns of seed longevity and germination in tropical rain forest. Annual Review of Ecology and Systematics 24: 69-87.

Zaia, J.E. \& Takaki, M. 1998. Estudo da germinação de sementes de espécies arbóreas pioneiras: Tibouchina pulchra Cogn. e Tibouchina granulosa Cogn. (Melastomataceae). Acta Botanica Brasilica 12: 221-229.

Zar, H.J. 2010. Biostatistical Analysis. New Jersey, Pearson Education India. 
Capítulo 2 - Adensamento de Trembleya parviflora (D. Don) Cogn. (Melastomataceae) reduz a diversidade florística do banco de sementes em Veredas no Brasil Central?

\section{Resumo}

O aumento populacional da espécie nativa Trembleya parviflora vem sendo observado como possível resposta à redução do lençol freático por efeitos antrópicos em Veredas no Cerrado. Como composição e abundância de espécies e as variações na saturação de água influenciam o banco de sementes nesses ambientes, o objetivo deste estudo foi analisar a diversidade florística do banco de sementes no solo em Veredas sob diferentes condições de umidade e serapilheira. O solo coletado no período seco e chuvoso, em Veredas sob alta e baixa colonização de T. parviflora, e a emergência de plântulas foi avaliada em substrato alagado, intermediário e umedecido com presença e ausência de serapilheira. Emergiram 22.325 plântulas pertencentes a 114 espécies no banco de sementes germináveis, sendo que $T$. parviflora acumulou $78 \%$ do total. A abundância de plântulas e a riqueza foi semelhante entre os períodos de coleta. A área com maior adensamento de $T$. parviflora apresentou menor riqueza e diversidade. A serapilheira de T. parviflora reduz a abundância de plântulas, entretanto, não afeta a composição de espécies. Valores extremos de umidade do substrato determinaram diminuição na emergência de plântulas, mas a redução na umidade aumentou a dominância de plântulas de T. parviflora, sugerindo que o rebaixamento do lençol freático em Veredas favorece a expansão e colonização dessa espécie nas Veredas estudadas.

Palavras-chave: alagamento, áreas úmidas, bioma Cerrado, invasibilidade de arbustos, rebaixamento do lençol freático, serapilheira. 


\section{Introdução}

As áreas úmidas possuem espécies vegetais com diferentes níveis de tolerância à sazonalidade de inundações e secas (van der Valk 1981; Capon 2003; Cherry e Gough 2006). Muitas dessas espécies germinam e são exclusivas da comunidade nas fases aquáticas, outras nas fases terrestres, e outras ainda em ambas as fases (van der Valk 1981; van der Valk e Pederson 1989; Rebellato e Nunes da Cunha 2005). Nessas áreas, a variabilidade espacial e temporal do alagamento geralmente influencia as espécies na vegetação em parâmetros como abundância, composição e formas de vida (Prado et al. 1994; Rebellato e Nunes da Cunha 2005; Munhoz e Felfili 2008ab). A disponibilidade de água no solo ainda auxilia a dispersão de sementes e afeta o estabelecimento das plantas, já que os períodos de secas e inundações podem estimular ou inibir a germinação no banco de sementes (Casanova e Brock 2000; Cherry e Gough 2006).

O banco de sementes representa reserva de sementes viáveis no solo (Simpson et al. 1989), sendo este um sistema dinâmico de entrada e saída de diásporos (Garwood 1989), garantindo a manutenção da diversidade de espécies vegetais do habitat (Cherry e Gough 2006). A composição do banco está relacionada ao tempo de permanência das sementes de cada espécie no solo sob as condições locais (van der Valk e Pederson 1989). A longevidade dos diásporos influencia, por sua vez, o banco em relação à formação de depósito de sementes transitório no solo, os quais são formados por sementes com viabilidade de um ano, e persistente, composto por sementes de longevidade maior que um ano sob condições naturais (Graham e Hutchings 1988).

A biodiversidade local pode ser afetada pela disponibilidade de sementes viáveis no solo, já que contribuem de forma rápida para o estabelecimento de plantas após rebaixamento 
no nível de água (Cherry e Gough 2006). A inundação sazonal promove flutuações nas comunidades vegetais devido às mudanças das condições ambientais que influenciam indivíduos e populações, criando direta ou indiretamente oportunidades para o estabelecimento de novos indivíduos (Sousa 1984).

Além do alagamento, outros fatores podem influenciar o tamanho e a composição do banco de sementes de áreas úmidas como características germinativas e fisiológicas (van der Valk e Pederson 1989; Leck e Simpson 1995), chuva de sementes, predação e dispersão, idade e isolamento (Parker e Leck 1985; Leck e Simpson 1995), estação do ano (Garwood 1989), posição topográfica, acúmulo e padrões de decomposição de serapilheira e propriedades químicas e físicas do solo (Prado et al. 1994; Vivian-Smith 1997). Além dos impactos antrópicos que influenciam as espécies encontradas no banco de sementes e a mudança de espécies dominantes (Orson et al. 1992).

No Brasil Central no domínio do Cerrado (Savana Brasileira) as Veredas são áreas úmidas que geralmente ocorrem próximas às nascentes e em solos hidromórficos mal drenados, caracterizadas por um estrato herbáceo-graminoso e outro arbustivo-arbóreo, onde predomina a palmeira Mauritia flexuosa L. f. (Eiten 2001). A Vereda apresenta zonas de umidade no solo, sendo a porção mais externa mais bem drenada, vizinha a áreas de Cerrado Sentido Restrito; a zona de meio é saturada com água grande parte do ano e a zona de fundo, onde ocorre uma faixa de indivíduos de M. flexuosa, apresenta solo permanentemente saturado e essencialmente orgânico (Almeida et al. 1983; Araújo et al. 2002; Guimarães et al. 2002). Essa diversificação de hábitats proporciona elevada diversidade de espécies (Araújo et al. 2002; Munhoz e Ribeiro 2008).

O adensamento da espécie nativa Trembleya parviflora em Veredas no Brasil Central tem sido destacado como possível resposta à redução do lençol freático por efeitos indiretos de 
atividades antrópicas em áreas agrícolas vizinhas (Silva-Júnior e Felfili 1996; Meirelles et al. 2004; Munhoz e Ribeiro 2008), alterando o estabelecimento de espécies herbáceas na comunidade (Meirelles et al. 2002). A dinâmica do acúmulo de serapilheira oriunda da vegetação introduz heterogeneidade temporal e espacial no ambiente, podendo afetar a estrutura e a dinâmica da comunidade de plantas (Grime 1979; Facelli e Pickett 1991; Xiong e Nilsson 1997). A formação de densa camada de biomassa reduz acentuadamente a luminosidade na superfície do solo (Facelli e Pickett 1991), podendo impedir os processos de germinação de sementes fotoblásticas positivas (Grime 1979) e o recrutamento de espécies presentes no banco de sementes, bem como a regeneração natural de habitats (Hughes e Vitousek 1993).

Partindo do pressuposto de que o banco de semente é influenciado pela composição/abundância das espécies da comunidade estabelecida, pelas variações na saturação de água no solo e pela presença de serapilheira, o objetivo deste estudo foi analisar a abundância e a riqueza na composição florística do banco de sementes em áreas de Vereda em diferentes épocas do ano sob diferentes condições de adensamento de T. parviflora, umidade no solo e serapilheira. Parte-se da hipótese de que o estresse hídrico e a deposição de serapilheira de $T$. parviflora reduzem a riqueza de espécies e que o alagamento reduz a emergência de plântulas dessa espécie. As seguintes questões foram abordadas neste estudo: a) Existem variações na composição, diversidade florística e formas de vida do banco de sementes de Veredas com diferenças no tamanho populacional de $T$. parviflora?; b) A sazonalidade climática da região e diferentes condições de umidade do substrato determinam variação na diversidade florística e nas formas de vida do banco de sementes de Vereda?; e c) O aumento de serapilheira composta por folhas de $T$. parviflora interfere na emergência de plântulas em locais onde há o adensamento da espécie? 


\section{Material e Métodos}

Áreas de estudo

O estudo foi conduzido em uma das Veredas do Parque Nacional de Brasília (PNB -

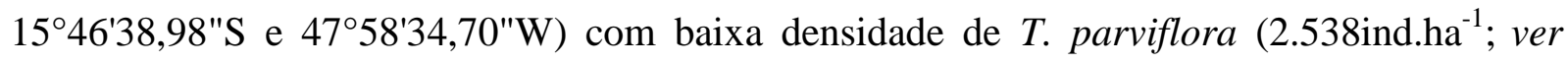

Capítulo 3) e em outra na Estação Ecológica de Águas Emendadas (ESECAE - 15³3'31,18"S e 47³5'45,36"W) com alta densidade de T. parviflora (11.590ind.ha-1 ${ }^{\circ}$, ver Capítulo 3).

Os solos nas Veredas são hidromórficos gley húmicos. O clima da região é do tipo Aw, segundo a classificação de Köppen, caracterizado pela marcante sazonalidade, onde cerca de 90\% das precipitações ocorrem de outubro a abril, com média anual de 1453mm (IBGE 2004).

\section{Coleta do banco de sementes}

As amostras do banco de sementes nas Veredas foram coletadas em abril (estação chuvosa) e agosto (estação seca). Em cada Vereda foram selecionados quatro pontos de coleta distantes 200 a 300m entre si para abranger a heterogeneidade espacial (Figura 1). Em cada ponto foi instalada uma parcela de $40 \times 25 \mathrm{~m}\left(1000 \mathrm{~m}^{2}\right)$ e nela foram coletadas 51 amostras (distantes $5 \mathrm{~m}$ entre si) para a análise do banco de sementes no solo com o auxílio de cilíndrico de PVC (policloreto de polivinila) de $15 \mathrm{~cm}$ de diâmetro por $5 \mathrm{~cm}$ de profundidade $\left(0,00088 \mathrm{~m}^{3}\right.$ de solo) totalizando $0,045 \mathrm{~m}^{3}$ por ponto de coleta, $0,18 \mathrm{~m}^{3}$ por Vereda e $0,72 \mathrm{~m}^{3}$ no experimento. Essas amostras de solo foram coletadas incluindo a serapilheira, sendo que em uma das parcelas úmidas na ESECAE, onde a camada de serapilheira era muita espessa, foi utilizado gabarito cilíndrico de PVC de $15 \times 10 \mathrm{~cm}$ para alcançar o solo, e atingir o volume de solo suficiente para a realização do experimento. 
Em viveiro, na Estação Experimental de Biologia na Universidade de Brasília, as amostras foram postas para secar à sombra em temperatura ambiente. Quando secas as amostras foram peneiradas, em peneira com malha metálica de 2 e $4 \mathrm{~mm}$, para retirada de detritos como rochas, raízes, tubérculos e bulbos, originando uma amostra mais homogênea possível (Maccherini e Dominicis 2003). Após essa homogeneização, uma sub amostra de solo (cerca de $400 \mathrm{~cm}^{3}$ ) foi selecionada e colocada para germinar em bandejas plásticas de $21 \times 15 \times 5 \mathrm{~cm}\left(1570 \mathrm{~cm}^{3}\right)$, sobre uma base esterilizada de latossolo vermelho, substrato comercial e areia (na proporção 3:2:1). Para cada ponto de coleta por Vereda foram montadas 60 bandejas, submetidas a três condições de umidade do substrato, renovadas três vezes a cada semana: 1 - substrato umedecido - adição de $80 \mathrm{ml}$ de água na bandeja com cinco perfurações para drenagem do substrato, simulando condição de baixa umidade; 2 - substrato intermediário - adição de $200 \mathrm{ml}$ de água na bandeja com cinco perfurações, simulando umidade intermediária no substrato; e 3 - substrato alagado - adição de água até formação de lâmina d'água superficial de aproximadamente $1 \mathrm{~cm}$ acima do substrato e com utilização de duas bandejas uma dentro da outra, a superior com três perfurações e a inferior sem furos, deixando substrato saturado, simulando alagamento.

Metade dessas bandejas foi mantida sem adição de serapilheira, enquanto na outra metade acrescentou-se $50 \mathrm{~g}$ de folhas secas de $T$. parviflora, para simular acúmulo de serapilheira da espécie de aproximadamente $2 \mathrm{~cm}$, como verificado em campo. Estas folhas sadias foram coletadas de indivíduos adultos e postas para secar à sombra. Doze bandejas adicionais, preenchidas somente com substrato esterilizado, foram distribuídas, por sorteio, entre as bandejas com os tratamentos, para monitoramento da contaminação, sendo que em metade delas foram adicionadas as folhas secas de $T$. parviflora, para avaliar possíveis propágulos aderidos a essas. 
O experimento totalizou 1440 bandejas (unidades experimentais) para análise com 30 bandejas (repetições) para cada condição de umidade do substrato (alagado, intermediário e umedecido) $(30 \times 3=90)$, sendo metade com adição de serapilheira e metade sem, 90 para cada um dos quatro pontos de coleta da Vereda $(90 \times 4=360)$, duas Veredas $(360 \times 2=720)$ e dois períodos de coleta $(720 \times 2=1440$ bandejas). Foram desconsideradas todas as plântulas oriundas de contaminação do viveiro.

A análise do banco de sementes no solo foi realizada pela contagem semanal de plântulas emergidas conforme descrito em Roberts (1981) por 22 semanas (intervalo entre a primeira e a segunda coleta de solo). Posteriormente, cada espécie foi classificada de acordo com tipos funcionais árvore, arbusto, subarbusto, erva graminóides e erva não graminóides (adaptado de Mendonça et al. 2008; Raunkiaer 1934):

1) Árvores - plântulas de espécie de indivíduos fanerófitos com gemas vegetativas situadas acima de 0,5m de altura, em sistemas aéreos bem expostos à atmosfera;

2) Arbustos - plântulas de espécie de indivíduos fanerófitos, com altura inferior a 5m, resistente e lenhosa inferiormente, tenra e suculenta superiormente, sem tronco predominante, porque ramifica a partir da base;

3) Subarbustos - plântulas de espécie de indivíduos caméfitos, subarbustivos inferiores a $1 \mathrm{~m}$ de altura com crescimento secundário na parte basal e herbáceo nas extremidades; 

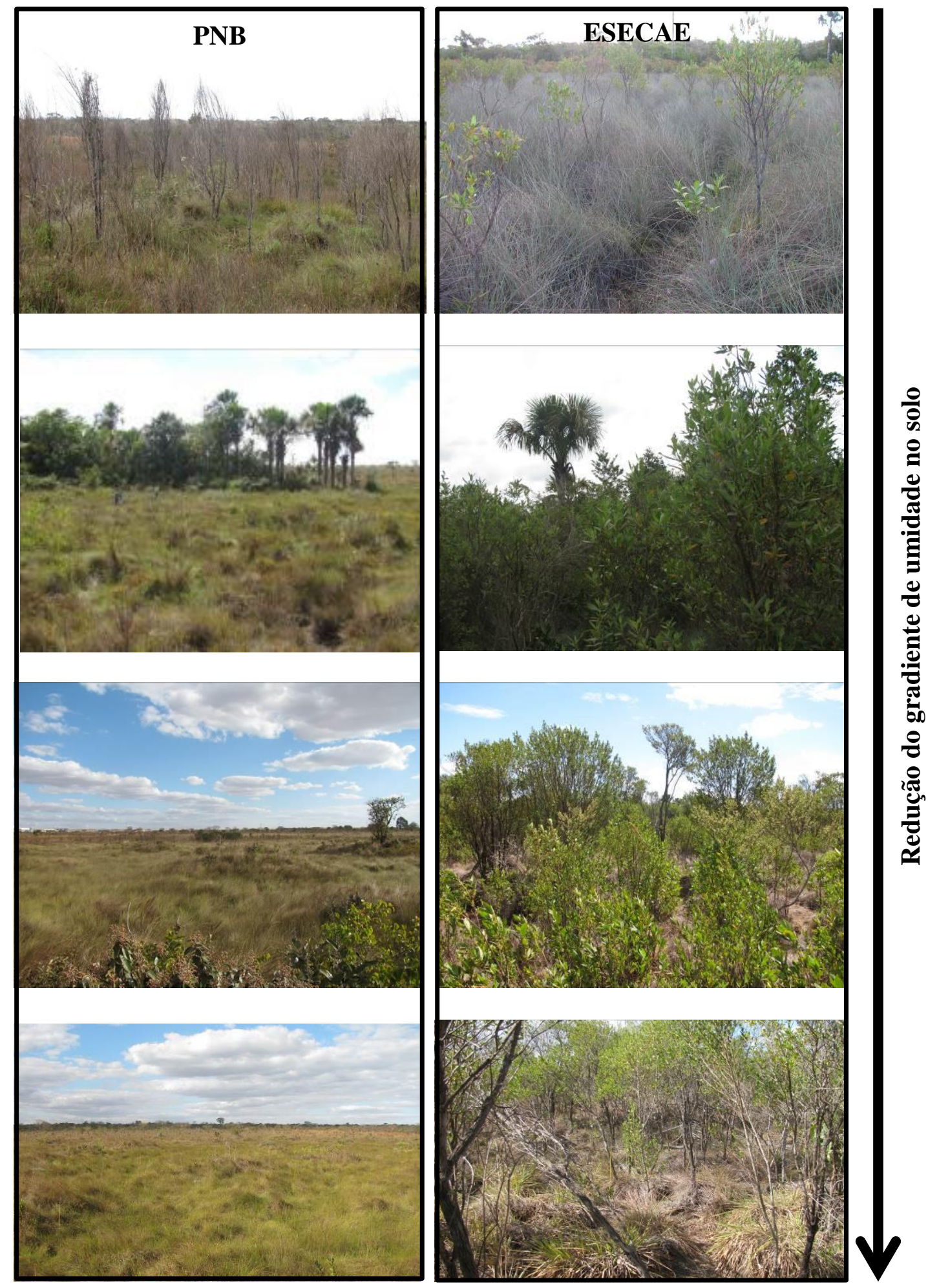

Figura 1. Pontos de coleta em Veredas no Parque Nacional de Brasília (PNB) e na Estação Ecológica de Águas Emendadas (ESECAE), Distrito Federal, Brasil. 
4) Ervas não graminóides - para plântulas de espécie de indivíduos geófitos, ervas com sistema subterrâneo de armazenamento e brotamento, que perdem a parte aérea sazonalmente; lianas, para plântulas de espécie com crescimento volúvel; indivíduos terófitos, para plantas anuais; indivíduos hemicriptófitos não monocotiledôneas delgadas para as ervas não graminóides delgadas; e indivíduos hemicriptófitos monocotiledôneas delgadas para ervas graminóides delgadas.

5) Ervas graminóides - para plântulas de espécie de indivíduos hemicriptófitos monocotiledôneas cespitosas para ervas graminóides cespitosas, entouceiradas ou robustas, ou seja, indivíduo graminóide.

Na maioria dos casos, as plântulas foram transferidas para embalagens plásticas de polietileno preenchidas com substrato base, até que atingissem estágio mais avançado de desenvolvimento para identificação final. As plântulas do banco de sementes que desenvolveram até o estágio reprodutivo foram depositadas no Herbário da Universidade de Brasília (UnB). As identificações foram feitas com base na literatura especializada, consultas a especialistas e comparações em herbário. As espécies foram classificadas em famílias de acordo com o Angiosperm Phylogeny Group III (APG III 2009) e as sinonímias e grafias dos nomes científicos foram consultadas na Lista de Espécies da Flora do Brasil (2014).

\section{Análise de dados}

A similaridade florística entre as áreas e os períodos sazonais foi avaliada pelos índices de similaridade de Chao-Sørensen (Chao et al. 2005; 2006). Utilizou-se uma matriz com as espécies e a abundância de indivíduos para cada espécie para cada área e período de coleta do banco de sementes, visando corrigir desvios de estimativa que podem ser produzidos em análises de similaridade que utilizam somente presença ou ausência de espécies (Chao et al. 
2005; 2006). O índice Chao-Sørensen e o desvio padrão foram obtidos pelo programa EstimateS 9.0 (Colwell 2013). O intervalo de confiança do índice foi obtido pela multiplicação do desvio padrão para distribuição t de Student (Manly 1997).

A relação da composição florística (riqueza) e da estrutura entre as áreas e o período de coleta foi analisada pelo método de ordenação Escalonamento Multidimensional Não-Métrico (Non-metric Multidimensional Scaling - NMDS). Utilizou-se uma matriz com a lista de espécies e número de plântulas observado. $\mathrm{O}$ espaço multidimensional foi gerado por meio de 999 permutações com a distância de Bray-Curtis para cada tratamento de umidade do substrato considerando apenas as bandejas sem serapilheira. Foi considerado que as interações se estabilizaram quando ocorreu a redução do stress (Mccune e Grace 2002). A associação das distâncias florísticas das ordenações pelas distâncias florísticas originais foi mensurada pelo coeficiente de determinação $\left(\mathrm{R}^{2}\right)$. Os padrões observados por essa ordenação foram confirmados por uma Permutational Multivariate Analysis of Variance (PerMANOVA) (Anderson 2001). Para tanto, foi utilizado o programa PC-ORD 6.0 (Mccune e Mefford 2011).

Perfis de Diversidade (Tóthmérész 1995) foram utilizados com a série exponencial de Rényi no Programa Past 3.01 (Hammer et al. 2001) para comparar a diversidade encontrada nas condições de umidade do substrato (alagado, intermediário e umedecido) nos dois períodos de amostragem (seca e chuva) de cada área. Utilizou-se matriz com os dados de abundância de plântulas por espécie considerando 120 bandejas para cada condição de umidade do substrato no período de coleta, ou seja, apenas bandejas sem adição de serapilheira.

Curvas de rarefação, com 999 interações, foram utilizadas para verificar a suficiência florística de cada Vereda e o efeito das três condições de umidade do substrato sobre os dois períodos de amostragem, a partir do programa Past 3.0 (Hammer et al. 2001) - usamos apenas 
bandejas sem adição de serapilheira. O esforço amostral foi considerado satisfatório, dado pela assíntota e estabilidade nos intervalos de confiança (95\%) das curvas de rarefação calculadas para a riqueza de espécies, e a não sobreposição dos intervalos de confiança foi considerada como diferença significativa (Cianciaruso e Batalha 2009).

Para comparar os hábitos (Godron et al. 1969), considerando o número de espécies por hábito entre as áreas e a umidade do substrato, foi aplicado o teste de qui-quadrado a partir do programa Past 3.0 (Hammer et al. 2001). Para verificar a ação da serapilheira, foi realizada a média de plântulas por $\mathrm{m}^{2}$; considerando 15 bandejas com e 15 sem adição de serapilheira em cada área, foi realizado teste $t$ de Student para amostras independentes com homodasticidade. Homogeneidade e distribuição normal dos dados foram verificadas pelo teste $\mathrm{F}$ (Fisher) e teste Shapiro-Wilk, respectivamente, no Programa Past 3.01 (Hammer et al. 2001).

\section{Resultados}

Composição de espécie no banco de sementes no solo

A abundância de plântulas encontrada no período chuvoso representou 50,27\% do total observado. As espécies Trembleya parviflora (17431), Bulbostylis junciformis (Kunth) C.B. Clarke (560), Desmoscelis villosa (Aubl.) Naudin (390) e Spermacoce latifolia Aubl. (290) apresentaram maior emergência (Apêndice 1). Duas espécies invasoras no Cerrado, Melinis minutiflora $\mathrm{P}$. Beauv e $M$. repens (Willd.) Zizka, também emergiram nos bancos estudados.

$\mathrm{Na}$ amostragem do banco de sementes da Vereda da ESECAE, foram observadas 760sementes. $\mathrm{m}^{-2}$ de 83 espécies com 11 exclusivas e no PNB 224sementes.m ${ }^{-2}$ de 103 espécies e 31 exclusivas, totalizando 22.325 plântulas pertencentes a 114 espécies em 26 famílias no banco de sementes germináveis (Tabela 1 e Figura 2). Considerando as plântulas 
que emergiram nos dois períodos de amostragem no banco de sementes germináveis, 34\% do total no PNB e $89 \%$ na ESECAE eram Trembleya parviflora (Figura 2). Essa espécie acumulou $78 \%$ do total de indivíduos germinados em todo o experimento, elevando a proporção dos arbustos em relação ao estrato graminóide principalmente na Vereda da ESECAE.

Tabela 1. Número de espécies, famílias e indivíduos ocorrentes no banco de sementes germináveis no solo, submetido a três condições de umidade do substrato (alagado, intermediário e umedecido) com ou sem adição de serapilheira de Veredas do Parque Nacional de Brasília (PNB) e na Estação Ecológica de Águas Emendadas (ESECAE) no Distrito Federal, Brasil.

\begin{tabular}{|c|c|c|c|c|c|c|c|}
\hline \multirow{2}{*}{ Área } & \multirow{2}{*}{$\begin{array}{c}\text { Tratamentos } \\
\text { Substrato/Serapilheira }\end{array}$} & \multicolumn{2}{|c|}{$\begin{array}{l}\text { Número de } \\
\text { espécies }\end{array}$} & \multicolumn{2}{|c|}{$\begin{array}{l}\text { Número de } \\
\text { famílias }\end{array}$} & \multicolumn{2}{|c|}{$\begin{array}{l}\text { Número de } \\
\text { indivíduos }\end{array}$} \\
\hline & & Sem & Com & Sem & Com & Sem & Com \\
\hline \multirow{3}{*}{ ESECAE } & Alagado & 46 & 15 & 12 & 6 & 4039 & 630 \\
\hline & Intermediário & 60 & 46 & 14 & 16 & 7667 & 1617 \\
\hline & Umedecido & 41 & 36 & 14 & 13 & 2159 & 1126 \\
\hline \multirow{3}{*}{ PNB } & Alagado & 60 & 28 & 13 & 9 & 917 & 318 \\
\hline & Intermediário & 73 & 58 & 18 & 17 & 1859 & 628 \\
\hline & Umedecido & 60 & 50 & 16 & 11 & 743 & 568 \\
\hline
\end{tabular}

Não houve variação da composição florística em relação aos períodos de amostragem (chuva e seca) do banco de sementes, o mesmo ocorrendo entre as duas áreas (PNB e ESECAE) (Figura 3). 

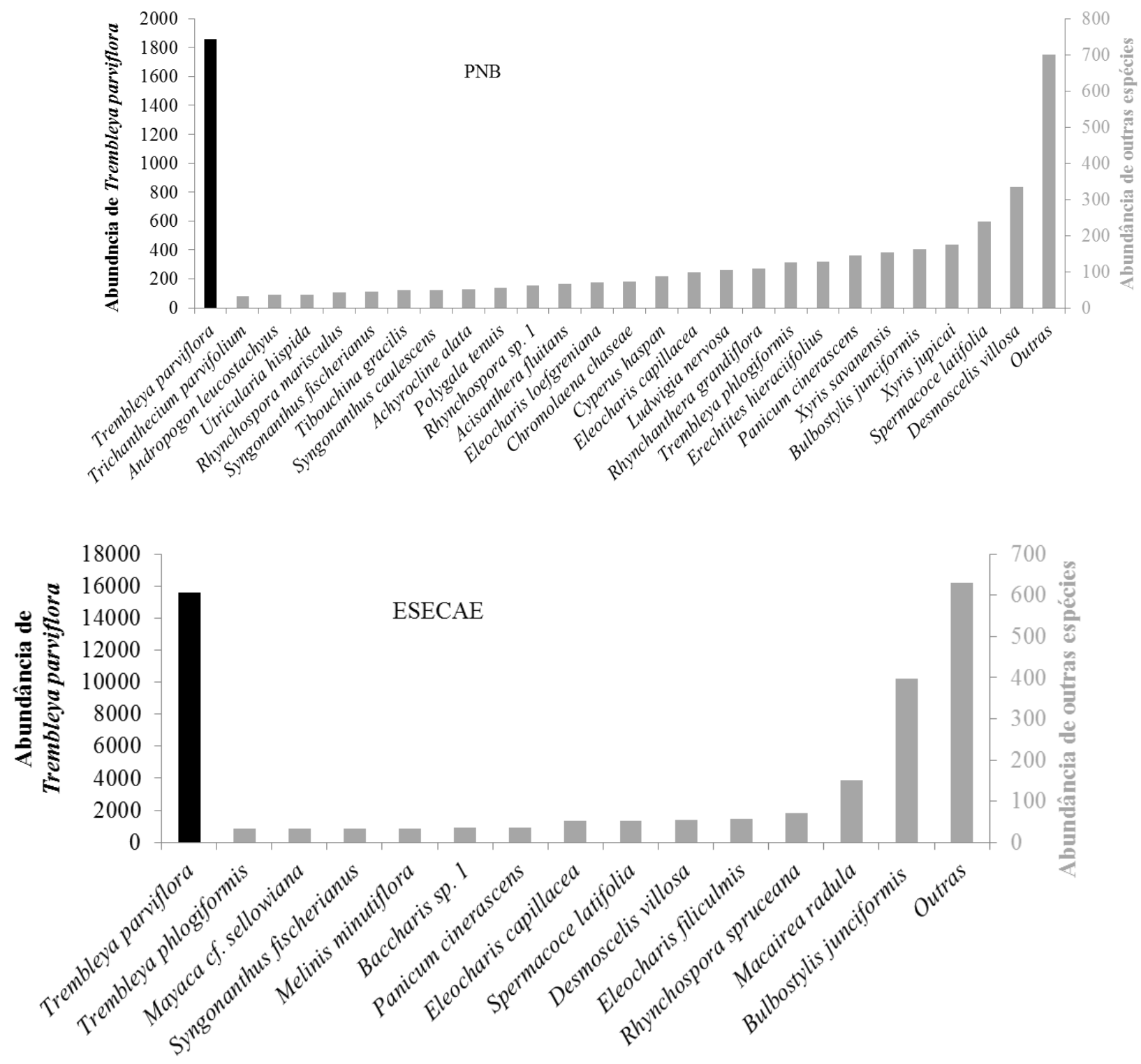

Figura 2. Abundância das espécies ocorrentes no banco de sementes germináveis no solo em Veredas do Parque Nacional de Brasília (PNB) e na Estação Ecológica de Águas Emendadas (ESECAE), Distrito Federal, Brasil. Trembleya parviflora está representada pelo eixo à esquerda, em preto, e as demais à direita, em cinza. 


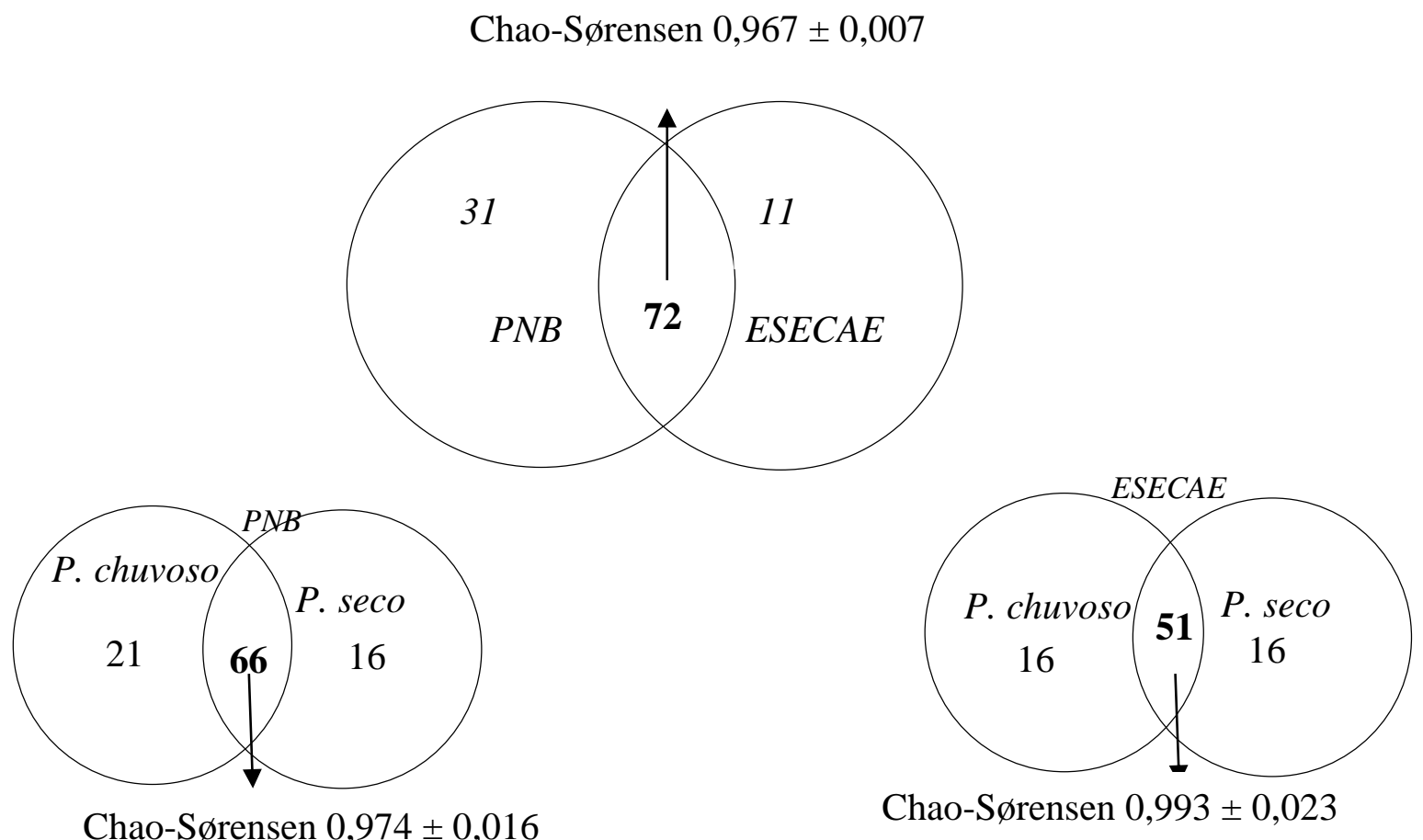

Figura 3. Diagrama de Venn demonstrando o número de espécies exclusivas e em comum do banco de sementes coletado após o período chuvoso e seco e o Índice de similaridade de Chao-Sørensen \pm intervalo de confiança, entre duas Veredas do Parque Nacional de Brasília (PNB) e na Estação Ecológica de Águas Emendadas (ESECAE), Distrito Federal, Brasil.

\section{Influência da flutuação hídrica no substrato do banco de sementes}

O Escalonamento Multidimensional Não-Métrico (NMDS) evidenciou a separação das áreas quando o banco de sementes foi submetido ao substrato alagado (PerMANOVA, $\mathrm{F}_{(1,12)}=$ 9,32; $\mathrm{p}=0,01$ ) e intermediário (PerMANOVA, $\mathrm{F}_{(1,12)}=11,57 ; \mathrm{p}=0,01$ ), o que não ocorreu na condição de substrato umedecido (PerMANOVA, $\mathrm{F}_{(1,12)}=2,60 ; \mathrm{p}=0,15$ ) (Figura 4). Considerando cada condição de umidade do substrato (alagado, intermediário e umedecido) o período de coleta (chuvoso e seco) não evidenciou diferença entre o banco de semente presente nas áreas. 

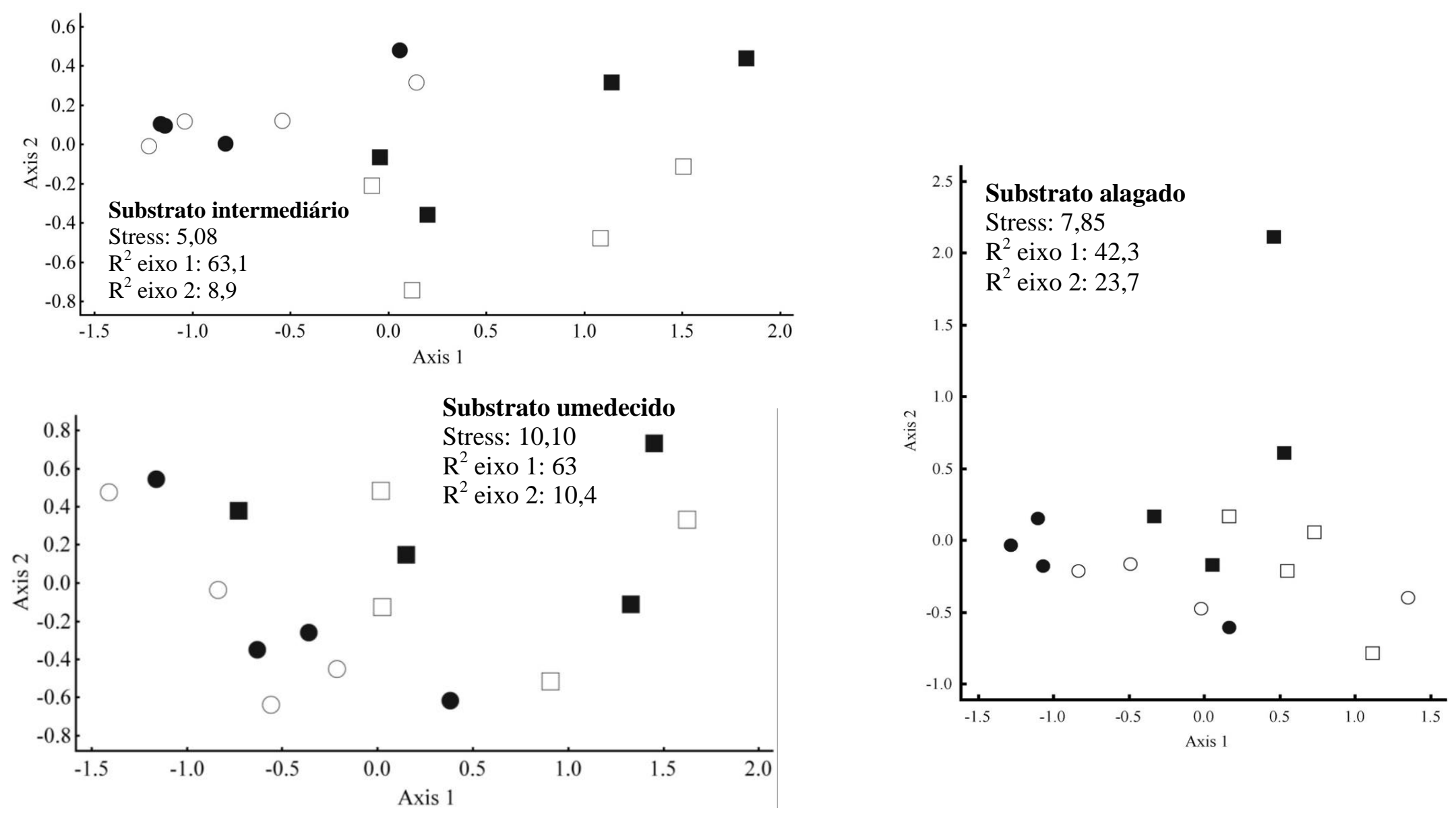

Substrato umedecido

Stress: 10,10

$\mathrm{R}^{2}$ eixo 1: 63

Figura 4. Ordenação NMDS para composição de espécies do banco de sementes germináveis de quatro pontos de coleta em Veredas do Parque Nacional de Brasília ( $\square$ e ๑) e da Estação Ecológica de Águas Emendadas ( $\circ$ e •) coletado após o período chuvoso (símbolo fechado) e seco (símbolo aberto) e submetido a três condições de umidade do substrato (alagado, intermediário e umedecido) no Distrito Federal, Brasil. 
A diversidade de espécies capazes de germinar nas condições testadas no banco de sementes da Vereda do PNB foi maior quando comparada a qualquer um dos tratamentos do banco de sementes da Vereda coletado na ESECAE (Figura 5), sendo que o tratamento com umidade intermediária do substrato apresentou maior diversidade de espécies.
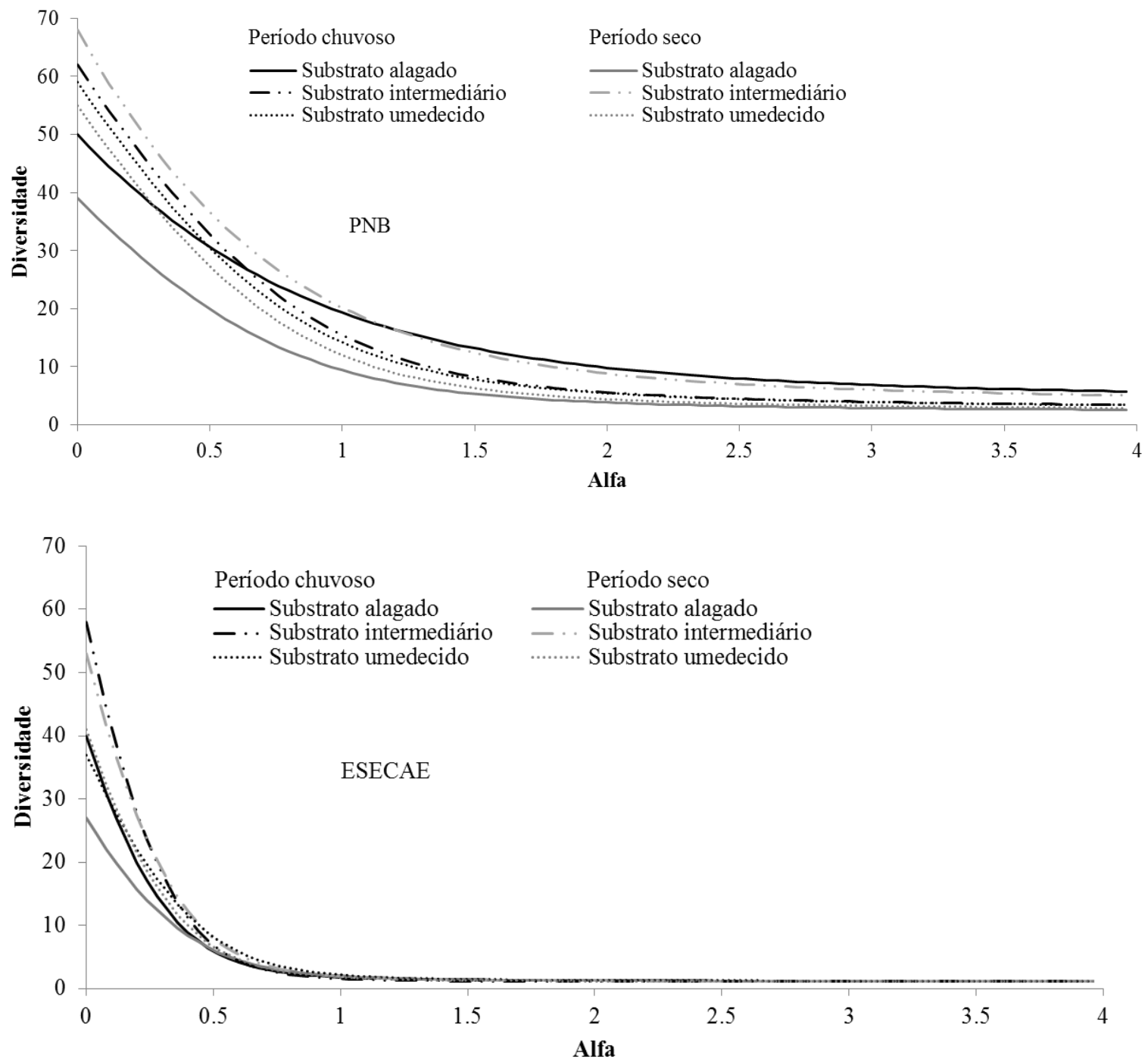

Figura 5. Perfis de Diversidade de espécies do banco de sementes germináveis no solo em Veredas do Parque Nacional de Brasília (PNB) e da Estação Ecológica de Águas Emendadas (ESECAE), coletado após o período chuvoso (linhas preta) e seco (linhas cinza) submetido a três condições de umidade do substrato (alagado, intermediário e umedecido) no Distrito Federal, Brasil.

A simulação de alagamento diminuiu a emergência de plântulas de espécies nos períodos seco e chuvoso nas duas áreas. A comunidade mais diversa (PNB) foi influenciada de forma mais acentuada pelo período de amostragem em relação à comunidade da ESECAE. A dominância do componente arbustivo-arbóreo na ESECAE, 
principalmente pela alta abundância de indivíduos de T. parviflora, reduz a diversidade de espécies na área (Figura 5).

A riqueza de espécies no banco de sementes da Vereda do PNB foi duas vezes maior que o da ESECAE para o mesmo esforço de coleta (Figura 6). No PNB, houve estabilização das curvas em todos os tratamentos, sendo o substrato com umidade intermediária na coleta realizada após o período seco a condição com maior necessidade de número de indivíduos para a estabilização. Na ESECAE, o esforço amostral para a estabilização da curva de riqueza demonstrou ser maior para o tratamento de média irrigação.

\section{Influência da flutuação hídrica no hábito}

Arbustos foram os hábitos que apresentaram o maior número de plântulas na ESECAE quando comparadas com o PNB $\left(\mathrm{X}_{\mathrm{gl}=4}^{2}=6458,3 ; \mathrm{p}<0,001\right)$. Na ESECAE, esse padrão manteve-se independente da umidade do substrato $\left(X_{\text {gl=4 }}^{2}=475,94 ; p<0,001\right)$. No PNB, o número de plântulas dos hábitos variou em relação à condição de umidade do substrato, mas com maioria de ervas graminóides e minoria de arbustos $\left(X_{\mathrm{gl}=4}^{2}=542,77\right.$; p<0,001). O substrato alagado favoreceu a emergência de plântulas de hábito herbáceograminóide nos dois períodos de amostragem. Entretanto, verificamos nos demais tratamentos maior emergência de plântulas de hábito arbustivo, devido à grande quantidade de plântulas de T. parviflora. As espécies arbóreas Cecropia pachystachya Trécul e Ilex affinis Gardner não emergiram sob condição de alagamento nos dois períodos e também em substrato umedecido após período chuvoso. 

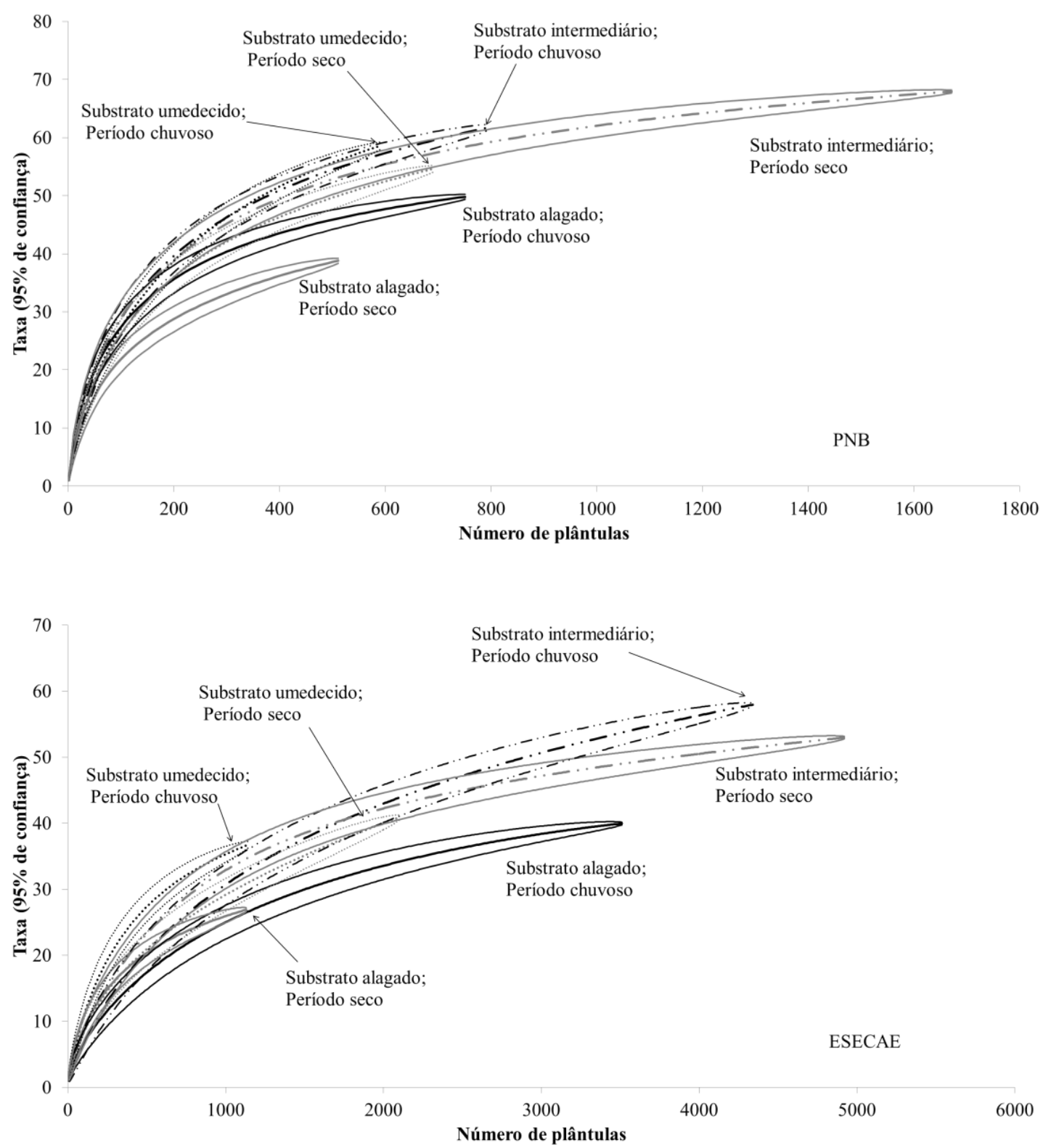

Figura 6. Curva de acumulação de espécies utilizando o método de rarefação para indivíduos do banco de sementes germináveis de Veredas do Parque Nacional de Brasília (PNB) e da Estação Ecológica de Águas Emendadas (ESECAE) coletado após o período chuvoso e seco submetido a três condições de umidade do substrato (alagado, intermediário e umedecido) no Distrito Federal, Brasil.

\section{Influência da adição de serapilheira}

A adição de serapilheira oriunda da queda de folhas de $T$. parviflora resultou na redução de $78 \%$ no geral das plântulas emergidas (Tabela 1), assim como afetou o número de indivíduos de T. parviflora, que reduziu de 13.630 para 3.801 plântulas, porém ainda assim a espécie manteve-se como a mais abundante no experimento. Entretanto, a riqueza 
de espécies variou de 89 a 104 na presença e ausência de serapilheira, respectivamente. Para a Vereda na ESECAE, houve redução de aproximadamente 925 plântulas por $\mathrm{m}^{2}$ quando foi adicionada serapilheira $\left(t_{28 ; 0,05}=37,11 ; \mathrm{p}<0,001\right)$, enquanto no PNB a diferença foi de 182 plântulas por $\mathrm{m}^{2}\left(t_{28} ; 0,05=7,83 ; \mathrm{p}<0,001\right)$.

\section{Discussão}

A área com maior adensamento de indivíduos de $T$. parviflora (ESECAE) apresentou menor riqueza e diversidade quando comparada à Vereda com início de colonização dessa espécie (PNB). Em campo, o maior número de espécies do hábito arbustivo e ainda a deposição de serapilheira pela caducifolia dessas plantas pode estar relacionado com a redução de riqueza e diversidade na ESECAE. A sazonalidade climática da região, evidenciada pelas estações chuvosa e seca, não afetaram a composição de espécies que germinaram no banco de sementes independente da Vereda estudada. Condições extremas de umidade do substrato, alagamento e redução hídrica, reduzem a riqueza e a diversidade da comunidade.

As famílias Poaceae, Cyperaceae e Asteraceae estão entre as mais ricas para a flora de Áreas Úmidas do Cerrado e foram amostradas em estudos florísticos representando grande importância na contribuição na riqueza de espécies (Araújo et al. 2002; Guimarães et al. 2002; Munhoz e Felfili 2007). Nos bancos de sementes analisados neste estudo, tanto no PNB e na ESECAE, essas famílias se mostraram abundantes. A presença de espécies dessas famílias e também de Xyridaceae, Eriocaulaceae e Polygalaceae mostraram-se comuns e são associadas às Veredas (Araújo et al. 2002; Guimarães et al. 2002; Munhoz e Felfili 2007; 2008ab). 
Sementes pequenas, raramente maiores do que $5 \mathrm{~mm}$, compõe o banco de sementes em sua maior parte (Foster 1986) e esse tamanho reduzido mostra-se como vantagem adaptativa favorecendo a dispersão e aumentando a probabilidade e a velocidade da incorporação no solo, diminuindo as chances de predação (Harper 1977; Garwood 1989). Isto foi verificado nas áreas úmidas nesse estudo, pois a maior parte das espécies encontradas nos bancos apresentou porte herbáceo e arbustivo-arbóreo com sementes pequenas.

A família Melastomataceae, a qual possui sementes diminutas, foi a mais abundante no estudo do banco de sementes em ambas as áreas. Isso ocorreu em relação a grande quantidade de plântulas de Trembleya parviflora (17431 plântulas), Desmoscelis villosa (390), Trembleya phlogiformis (158), Macairea radula (152) e Rhynchanthera grandiflora (119). Além dessas espécies foram observadas plântulas de Lavoisiera bergii (44), que juntamente com T. parviflora e Macairea radula vem formando comunidades com grandes populações nas áreas úmidas do Distrito Federal (Silva-Júnior e Felfili 1996; Meirelles et al. 2004; Munhoz e Ribeiro 2008).

A representatividade e a abundância de plântulas de Melastomataceae em bancos de sementes têm sido relatadas em estudos em diferentes comunidades (Araújo et al. 2002; Pereira-Diniz e Ranal 2006). Além disso, estudos de banco de sementes têm encontrado a dominância de uma ou poucas espécies na riqueza das áreas (Garwood 1989; de Andrade e Miranda 2014), o que pode ser explicado pela presença de fotoblastismo positivo na maioria das sementes das espécies arbustivas da família (Baskin et al. 1999; Zaidan e Carreira 2008). Levando em consideração que quando uma área sofre distúrbios por eventos naturais ou antrópicos, a estrutura da vegetação secundária é determinada primariamente pelas sementes encontradas no solo (Garwood 1989), a dominância de plântulas arbustivas como Trembleya parviflora nos bancos estudados pode estar 
relacionada com os distúrbios de redução de lençol freático por efeitos antrópicos nas áreas adjacentes às Veredas.

Além disso, a presença de grandes populações dessa espécie em áreas úmidas está promovendo o aumento do acúmulo de serapilheira no solo oriunda da caducifolia, que ocorre com maior intensidade na estação seca. Os resultados mostraram a redução da abundância e da riqueza de plântulas com a deposição de serapilheira. Quando cada área foi analisada - sem incluir plântulas de T. parviflora -, verificou-se maior abundância e riqueza no PNB, se comparado com a ESECAE; pois em Águas Emendadas, há grande acúmulo de serapilheira oriunda de T. parviflora.

O gradiente de umidade presente nas áreas úmidas também pode afetar negativamente a germinabilidade e o crescimento de certas plantas devido ao estresse hidrológico causado nos momentos de encharcamento e seca, os quais aumentam nas zonas mais extremas das áreas (Blom e Voesenek 1996). Os substratos com alagamento ou apenas umedecidos mostraram reduzida riqueza e abundância de plântulas em comparação com o tratamento intermediário. O estresse por excedente hídrico e por escassez de água bem como por formação de barreira física promovida pela presença de serapilheira influenciaram negativamente a riqueza e a abundância de plântulas nos bancos de sementes oriundos das áreas úmidas estudadas. Longos períodos de submersão podem reduzir a riqueza de espécies terrestres em bancos de sementes (Casanova e Brock 2000; Capon e Brock 2006). Por outro lado, as espécies aquáticas como Acisanthera fluitans Cogn., Eleocharis sps., Mayaca cf. sellowiana Kunth e Sagittaria lancifolia L. tiveram reduzida ou nenhuma emergência nas condições de substrato intermediário e umedecido.

A diversidade de sementes no solo foi semelhante no período chuvoso e no seco nas Veredas estudadas, que pode ser resultado da presença de banco de sementes persistente, conforme observado por Salazar et al. (2011), para ambiente de Cerrado. As espécies 
podem investir em sementes que germinam rapidamente em resposta às condições favoráveis ou em sementes que adiam a germinação, protegendo-se, assim, do risco de mortalidade ao espalhar a germinação ao longo do tempo (Baskin e Baskin 2001) e do espaço.

Verifica-se que o banco de sementes reflete a vegetação em certos locais em relação à escala espacial em estudos de curta duração (Leck e Simpson 1995). Entretanto, ao longo dos anos ocorre a alteração de espécies dominantes em uma determinada Área Úmida ou nessas áreas de tipos similares (Orson et al. 1992; Leck e Simpson 1995). A densidade, a composição de espécies e a reserva genética da comunidade são controladas diretamente pelas entradas e saídas do banco de sementes (Simpson et. al. 1989). Nas Veredas com grande quantidade de indivíduos em idade reprodutiva de T. parviflora, a entrada de sementes da espécie no banco aumenta a cada ciclo reprodutivo, resultando no aumento da densidade nos locais de ocorrência da espécie. Portanto, novos estudos incluindo experimentos com remoção de indivíduos - necessitam ser realizados para o acompanhamento da espécie e, assim, ajudar a responder algumas questões sobre a relação de T. parviflora com as comunidades de áreas úmidas onde se encontram.

\section{Conclusão}

A região encontrada com grande número de indivíduos de Trembleya parviflora apresenta menor riqueza, implicando desta forma que a presença dessa espécie afeta negativamente a diversidade das Veredas. Por outro lado, a época de coleta, chuvosa ou seca, não afeta a abundância de plântulas e a diversidade dos bancos de sementes estudados. Valores extremos de umidade do substrato apresentam menores valores de 
emergência de plântulas. Se por um lado a serapilheira de T. parviflora reduz a abundância de plântulas, por outro, não afeta a composição de espécies.

\section{Referências bibliográficas}

APG III. 2009. An update of the Angiosperm Phylogeny Group classification for the orders and families of flowering plants: APG III. Botanical Journal of the Linnean Society 161: 105-121.

Almeida, J.R.; Baruqui, F.M.; Baruqui, A.M. \& Motta, P.E.F. 1983. Principais solos de várzeas do Estado de Minas Gerais e suas potencialidades agrícolas. Informe Agropecuário 9: 70-78.

Anderson, M.J. 2001. A new method for non-parametric multivariate analysis of variance. Austral Ecology 26 (1): 32-46.

Araújo, G.M.; Barbosa, A.A.A.; Arantes, A.A. \& Amaral, A.F. 2002. Composição florística de Veredas no município de Uberlândia, MG. Revista Brasileira de Botânica 25: 475-493.

Baskin, C.C., Baskin, J.M. \& Chester, E.W. 1999. Seed dormancy and germination in Rhexia mariana var. interior (Melastomataceae) and eco-evolutionary implications. Canadian Journal of Botany 77: 488- 493.

Baskin, C.C. \& Baskin, J.M. 2001. Seeds - Ecology, Biogeography, and Evolution of Dormancy and Germination. Academic Press, San Diego.

Blom, C.W.P.M. \& Voesenek, L.A.C.J. 1996. Flooding: the survival strategies of plants. Trends in Ecology and Evolution 11: 290-295.

Capon, S.J. 2003. Plant community responses to wetting and drying in a large arid floodplain. River Research and Applications 19(5-6): 509-520.

Capon, S.J. \& Brock, M. 2006. Flooding, soil seed bank dynamics and vegetation resilience of a hydrologically variable desert floodplain. Freshwater Biology 51: 206-223.

Casanova, M.T. \& Brock, M.A. 2000. How do depth, duration and frequency of flooding influence the establishment of wetland plant communities? Plant Ecology 147: 237250. 
Chao, A.; Chazdon, R.L., Colwell; R.K. \& Shen, T.J. 2005. A new statistical approach for assessing similarity of species composition $w$ ith incidence and abundance data. Ecology Letters 8: 148-159.

Chao, A.; Chazdon, R.L.; Colwell; R.K. \& Shen, T.J. 2006. Abundance-based similarity indices and their estimation when there are unseen species in samples. Biometrics 62: $361-371$

Cherry, J.A. \& Gough, L. 2006. Temporary floating island formation maintains wetland plant species richness: The role of the seed bank. Aquatic Botany 85: 29-36.

Cianciaruso, M.V. \& Batalha, M.A. 2009. Short-term community dynamics in seasonal and hyperseasonal cerrados. Brazilian Journal of Biology 69(2): 231-240.

Colwell, R.K. 2013. EstimateS: Statistical Estimation of species richness and shared species from samples. Version 9.0.0 User's Guide and application published at: http://purl.oclc.org/estimates (Acesso em: 19 Fev. 2014).

de Andrade, L.A.Z. \& Miranda, H.S. 2014. The dynamics of the soil seed bank after a fire event in a woody savanna in central Brazil. Plant Ecology 215(10): 1199-1209.

Eiten, G. 2001. Vegetação natural do Distrito Federal. Brasília: Sebrae.

Facelli, J.M. \& Pickett, S.T.A. 1991. Plant litter: its dynamics and effects on plant community structure. Botanical Review 57: 1-32.

Foster, S.A. 1986. On adaptative value of large seeds for tropical moist forest trees: a review and synthesis. The Botanical Review 52: 260-269.

Garwood, N.C. 1989. Tropical soil seed banks: a review. Pp. 149-209. In: M.A. Leck, V.T. Parker \& R.L. Simpson (Eds.). Ecology of soil seed banks. Academic Press, San Diego.

Godron, M.,; Daget, P.; Emberger, L.; Long, G.L.E.; Floch, E.; Poissonet, J.; Sauvage, C. \& Wacquant, J.P. 1969. Vade-mécum pour le relevé méthodique de la végétation et du milieu. Éditions du Centre National de la Recherche Scientifique: Paris.

Graham, D.J. \& Hutchings, M.J. 1988. Estimation of the seed bank of a chalk grassland established on former arable land. Journal of applied ecology 25: 241-252.

Grime, J.P. 1979. Plant Strategies and Vegetation Processes. Chichester: Wiley.

Guimarães, A.J.M., Araújo, G.M. \& Corrêa, G.F. 2002. Estrutura fitossociológica em área natural e antropizada de uma Vereda em Uberlândia, MG. Acta Botanica Brasilica 16(3): 317-329.

Hammer, O.; Harper, D.A.T. \& Ryan, P.D. 2001. PAST: Paleontological Statistics Software Package for Education and Data Analysis. Palaeontologia Electronica 
4(1): 9. <http://palaeo-electronica.org/2001_1/ past/issue1_01.htm> (Acesso em: 09 Jul. 2014).

Harper, J.L. 1977. Population biology of plants. Londres: Academic Press.

Hughes, F. \& Vitousek, P.M. 1993. Barriers to shrub establishment following fire in the seazonal submontane zone of Hawaii. Oecologia (93): 557-563.

IBGE. 2004. Reserva Ecológica do IBGE: ambiente e plantas vasculares. Rio de Janeiro: IBGE-Divisão de Geociências. Estudos e Pesquisas. Informação Geográfica n. 3 .

Leck, M.A. \& Simpson, R.L. 1995. Ten-year seed bank and vegetation dynamics of a tidal freshwater marsh. American Journal of Botany 82(12): 1547-1557.

Lista de Espécies da Flora do Brasil. Jardim Botânico do Rio de Janeiro. Disponível em: <http://floradobrasil.jbrj.gov.br/> (Acesso em: 01 Jun. 2014).

Maccherini, S. \& Dominicis, V.D. 2003. Germinable soil seed-bank of former grassland converted to coniferous plantation. Ecological Research 18: 739-751.

Manly, B. 1997. Randomization, Bootstrap and Monte Carlo Methods in Biology. London: Chapman and Hall.

McCune, B. \& Grace, J.B. 2002. Analysis of ecological communities. MjM Software, Gleneden Beach.

McCune, B. \& Mefford, M.J. 2011. PC-ORD. Multivariate analysis of ecological data, Gleneden Beach, MjM Software Design.

Meirelles, M.L.; Guimarães, A.J. M.; Oliveira, R.C. de; Araújo, G.M.; \& Ribeiro, J.F. 2004. Impactos sobre o estrato herbáceo de áreas úmidas do Cerrado. Pp.41-68. In: Aguiar, L.M.S.; Camargo, A.J.A. (Ed.). Cerrado: ecologia e caracterização. Planaltina, DF: Embrapa Cerrados.

Meirelles, M.L.; Oliveira, L.C.; Vivaldi, J.L.; Santos, A.R. \& Correia, J.R. 2002. Espécies do estrato herbáceo e profundidade do lençol freático em áreas úmidas do cerrado. Planaltina, DF: Embrapa Cerrados.

Mendonça, R.C.; Felfili, J.M.; Walter, B.M.T.; Silva Júnior, M.C.; Rezende, A.V.; Filgueiras, T.S. \& Nogueira, P.E. 2008. Flora Vascular do Cerrado. Pp. 29-47. In: Sano, S.M.; Almeida, S.P. \& Ribeiro, J.F. (Eds.). Cerrado, Ecologia e flora. Embrapa-cpac, Brasília.

Munhoz, C.B.R. \& Felfili, J.M. 2007. Florística do estrato herbáceo-subarbustivo de um campo limpo úmido em Brasília, Brasil. Biota Neotropica 7(3): 205-215. 
Munhoz, C.B.R. \& Felfili, J.M. 2008a. Fitossociologia do estrato herbáceo-subarbustivo em campo limpo úmido no Brasil Central. Acta Botanica Brasilica 22(4): 905-913.

Munhoz, C.B.R. \& Felfili, J.M. 2008b. Florística do estrato herbáceo-subarbustivo de um campo limpo úmido em Brasília, Brasil. Biota Neotropica 7(3): 205-215.

Munhoz, C.B.R. \& Ribeiro, J.F. 2008. Veredas. Pp. 156-162. In: F.O. Fonseca (Org). Água emendadas/Distrito Federal. Secretaria de Desenvolvimento Urbano e Meio Ambiente. Brasília: Seduma.

Orson, R.A.; Simpson, R.L. \& Good, R.E. 1992. The paleoecological development of a late Holocene, tidal freshwater marsh of the Upper Delaware Estuary. Estuaries 15: 130-146.

Parker, V.T. \& Leck, M.A. 1985. Relationships of seed banks to plant distribution patterns in a freshwater tidal wetland. American Journal of Botany 72: 161-174.

Pereira-Diniz, S.G. \& Ranal, M.A. 2006 Germinable soil seed bank of a gallery forest in Brazilian Cerrado. Plant Ecology 183: 337-348.

Prado, A.L., Heckman, C.W. \& Martins, F.R. 1994. The seasonal succession of biotic communities in wetlands of the tropical wet-and-dry climatic zone: II. The Aquatic Macrophyte Vegetation in the Pantanal of Mato Grosso, Brazil. Internationale Revue gesamten Hydrobiologie 79(4): 569-589.

Raunkiaer, C. 1934. The Life Forms of Plants and Statistical Plant Geography. Oxford University Press, Oxford, UK.

Rebellato, L. \& Nunes da Cunha, C. 2005. Efeito do "fluxo sazonal mínimo da inundação" sobre a composição e estrutura de um campo inundável no Pantanal de Poconé, MT, Brasil. Acta Botanica Brasilica 19: 789-799.

Roberts, H.A. 1981. Seed banks in soils. Advances in applied biology 6: 1-55.

Salazar, A.; Goldstein, G.; Franco, A.C. \& Miralles-Wilhelm, Fernando. 2011. Timing of seed dispersal and dormancy, rather than persistent soil seed-banks, control seedling recruitment of woody plants in Neotropical savannas. Seed Science Research 21: 103-116.

Silva-Júnior, M.C. \& Felfili, J.M. 1996. A vegetação da Estação Ecológica de Águas Emendadas. Brasília: Instituto de Ecologia e Meio Ambiente do Distrito Federal.

Simpson, R.L., Allessio Leck, M. \& Parker, V.T. 1989. Seed banks: general concepts and methodological issues. Pp. 3-8. In: Ecology of Soil Seed Banks. M.A. Leck, V.T. Parker \& R.L. Simpson (Eds). Academic Press, San Diego, California. 
Sousa, P.W. 1984. The role of disturbance in natural communities. Annual Review of Ecology and Systematics 15: 353-391

Tóthmérész, B. 1995. Comparison of different methods for diversity ordering. Journal of Vegetation Science 6(2): 283-290.

van der Valk, A.G. 1981. Succession in wetlands: a Gleasonian approach. Ecology 62(3): 689-696.

van der Valk, A.G. \& Pederson, R.L. 1989. Seed bank and management and restoration of natural vegetation. Pp. 329- 346. In: Leck, M.A.; Parker, V.T. \& Simpson, R.L. Ecology of soil seed banks. San Diego: Academic.

Vivian-Smith, G. 1997. Microtopographic heterogeneity and floristic diversity in experimental wetland communities. Journal of Ecology 85(1): 71-82.

Xiong, S. \& Nilsson, C. 1997. Dynamics of leaf litter accumulation and its effects on riparian vegetation: a review. The Botanical Review 63: 240-264.

Zaidan, L.B.P. \& Carreira, R.C. 2008. Seed germination in Cerrado species. Brazilian journal of plant physiology 20(3): 167-181. 


\section{Capítulo 3 - Estrutura populacional de Trembleya parviflora (Melastomataceae), um arbusto que está dominando as Veredas no Brasil Central}

\section{Resumo}

Características populacionais permitem compreender a capacidade de regeneração dos indivíduos, bem como a ocorrência de perturbações em locais específicos e essas características resultam de fatores evolutivos, ecológicos e bioclimáticos. O objetivo deste estudo foi avaliar a estrutura de duas populações de Trembleya parviflora em Vereda, uma no Parque Nacional de Brasília (PNB) e outra na Estação Ecológica de Águas Emendadas (ESECAE) no Distrito Federal, procurando relacionar as características de crescimento de indivíduos, mortalidade, recrutamento e incremento à densidade da população na área no intervalo de um ano e meio. A estrutura populacional de $T$. parviflora foi avaliada em quatro pontos de amostragem, distantes de 200 a 300m entre si, em cada Vereda. Foram mensurados altura e diâmetro de indivíduos nos estratos de inferior, médio e superior. Houve recrutamento de todos os estratos nas duas Veredas. A área avaliada na ESECAE (14.295 ind.ha $\left.{ }^{-1}\right)$ apresentou maior densidade que a área do PNB (725 ind.ha $\left.{ }^{-1}\right)$ em todos os estratos e nos inventários inicial e final. A taxa de recrutamento foi elevada no PNB para todos os estratos, mas com alta mortalidade no estrato superior. Houve maior frequência de indivíduos nas classes entre um e três metros de altura para o estrato superior, principalmente na ESECAE.

Palavras-chave: áreas úmidas, bioma Cerrado, estrutura de população, invasão populacional, Vereda. 


\section{Introdução}

As características estruturais da população permitem compreender a capacidade de regeneração dos indivíduos, assim como a ocorrência de perturbações em locais específicos, e essas características resultam de fatores evolutivos, ecológicos e bioclimáticos (Hutchings 1997). Tais fatores são responsáveis pela flutuação de taxas de natalidade e mortalidade na população (Watkinson 1997; Marques e Joly 2000; Schiavini et al. 2001). Os estágios ontogênicos, o crescimento, a mortalidade e o recrutamento de indivíduos nas populações são correlacionados com fatores ambientais que afetam a distribuição, o desenvolvimento e a estrutura dessas populações (Hutchings 1997; Aquino et al. 1999; Arieira e Nunes da Cunha 2006) com influência na dinâmica da comunidade (Lieberman et al. 1985; Felfili 1995).

O aumento na densidade de algumas espécies nativas nos ambientes naturais pode ser considerado invasão ou avanço para um estágio sucessional monodominante ou superdominante (PySek 1995; Richardson et al. 2000). Espécies nativas têm sido consideradas invasoras quando há um aumento excessivo nas suas abundâncias e no seu alcance espacial, gerando mudanças constantes no ambiente, normalmente em resposta a mudanças causadas pelo homem em seus habitats naturais (Alpert et al. 2000).

A influência da população de uma única espécie pode ser extrema em certos ambientes, quando apresenta parâmetros como abundância, área basal, biomassa, cobertura do dossel ou medidas de dominâcia superiores a 50\%, ou seja, são espécies monodominantes (Connell e Lowman 1989; Hart et al. 1989; Hart 1990). As espécies monodominantes normalmente possuem frutificação maciça (Nascimento e Proctor 1996; Henkel 2003), sementes de fácil dispersão e taxas de crescimento rápido (Connell e Lowman 1989; Hart 1990; Richards 1996). As três primeiras características também foram 
relatadas para espécies invasoras, além de alta eficiência fotossintética e no uso dos nutrientes, tolerância ao desfolhamento e herbivoria, alta capacidade de rebrotamento e regeneração, alta capacidade de reprodução, dispersão pelo vento, ciclo reprodutivo rápido, e intensa capacidade de germinação (Rejmánek e Richardson 1996; Williamson e Fitter 1996).

A presença dessas características conduz a formação de sub-bosque sombreado (Hart 1995; Nascimento e Proctor 1997a; Torti et al. 2001), com alta produção de serapilheira (Davis e Richards 1934; Torti et al. 2001) e com taxas de decomposição reduzidas (Martijena e Bullock 1994; Torti et al. 2001). Portanto, diversos mecanismos atuam em conjunto para formar e manter áreas com espécies monodominantes (Torti et al. 2001), os quais impedem a expansão de outras espécies (Richards 1996).

Especificamente, formações com espécies monodominantes são encontradas em diferentes regiões do mundo: na África, com a espécie Gilbertiodendron dewevrei (De Wild.) J. Léonard (Hart et al. 1989; Hart 1995; Torti et al. 2001) e Microberlinia bisulcata A. Chev. (Fabaceae) (Green e Newbery 2001); na Nova Guiné e na Austrália, com Nothofagus aequilateralis (Baum.-Bod.) Steenis, N. discoidea (Baum.-Bod.) Steenis, $N$. balansae (Baill.) Steenis ou N. codonandra (Baill.) Steenis (Fagaceae) (Read et al. 2000); no México, com Celaenodendron mexicanum Standl. (Euphorbiaceae) (Martijena e Bullock 1994); nas Guianas, com Dicymbe corymbosa Spruce ex Benth. (Fabaceae); e no Brasil, com Peltogyne gracilipes Ducke (Fabaceae) (Nascimento e Proctor 1997ab; Nascimento e Proctor 2001).

Nos trópicos, em particular, a baixa diversidade de espécies arbóreas e a monodominância podem estar associadas a condições de ambientes sazonalmente inundados (Hart 1990; Richards 1996). Formações reconhecidas como monodominantes sob regime de inundação foram estudadas com as espécies Mora gonggrijpii (Kleinhoonte) 
Sandwith, Mora excelsa Benth. (ter Steegem 1994) e Dicymber corymbosa na Guiana (Henkel 2003). No Brasil, em áreas inundáveis, foram estudadas comunidades dominadas por Byrsonima orbignyana (Canjiqueiral) (Silva et al. 2000), Tabebuia aurea (Paratudal) (Ribeiro e Brown 2006; Scremin-Dias et al. 2011), Vochysia divergens (Cambarazal) (Nunes da Cunha e Junk 2004; Arieira e Nunes da Cunha 2006), Brosimum rubescens (Felfili et al. 1998; Marimon et al. 2001) e Curatella americana (Lixeiral) (Silva et al. 2000; Pott et al. 2011). Além dessas, Pott et al. (2011) citam para o Pantanal outros tipos de vegetações monodominantes em áreas sob influência fluvial e/ou lacustre com as espécies Attalea phalerata (acurizal), A. speciosa (babaçual) e Mauritia flexuosa (buritizal).

Quando as formações monodominantes permanecem por poucas gerações elas são consideradas não persistentes, sendo caracterizadas como uma fase sucessional (Hart 1995; Torti et al. 2001). Além disso, alguns autores relatam que a presença de espécies arbustivas e arbóreas em fisionomias campestres com excedente hídrico sugere substituição seral (Rizzini 1979; Meguro et al. 1996), consistindo em fases iniciais da dinâmica de estabelecimento de florestas paludosas ou de galeria em ecossistemas abertos (Meguro et al. 1996).

No bioma Cerrado, populações de Trembleya parviflora (Silva-Júnior e Felfili 1996; Meirelles et al. 2004), Macairea radula, Lavoisiera bergii e Lycopodiella cernua (Munhoz e Ribeiro 2008) estão colonizando densamente Veredas. Abioticamente, a sazonalidade nos períodos de saturação hídrica e ressecamento do solo podem ter efeito acentuado na distribuição das espécies vegetais em Veredas do bioma Cerrado (Araújo et al. 2002, Munhoz et al. 2008).

A presença de adaptações morfofisiológicas ao excesso hídrico no solo possibilitam a certas espécies vantagem competitiva em solos saturados, sobrepujando espécies menos 
adaptadas (Parolin et al. 2010). A tolerância de uma espécie à inundação é condicionada pela sobrevivência da semente e pela manutenção do crescimento das plantas em condições anóxicas (Kozlowski 1984; Marques e Joly 2000). A presença de tecidos radiciais e caulinares mais frouxos, pode melhorar a difusão de oxigênio da parte aérea para o sistema de raízes, possibilitando uma respiração aeróbia mais equilibrada em relação à rota anaeróbia em espécies tolerantes ao alagamento (Kozlowski 1984). Outros fatores de tolerância referem-se à formação de sistemas radiciais ou caulinares aerenquimatosos e lenticelas hipertrofiadas (Somavilla e Graciano-Ribeiro 2011; 2012), bem como diminuição do crescimento da parte aérea e inibição da iniciação e expansão de folhas (Kozlowski 1984) devido à senescência e a abscisão foliar (Tsukahara e Kozlowski 1985; 1986).

As sementes de algumas espécies, como Himatanthus sucuuba (Apocynaceae) (Ferreira et al. 2007), Salix martiana (Salicaceae) e Pseudobombax munguba (Malvaceae) (Wittmann et al. 2007) são capazes de germinar e formar plântulas que toleram a inundação. Esta estratégia favorece o estabelecimento de plântulas quando o período terrestre começa e formam-se bancos de mudas nas margens de cursos hídricos na Amazônia (Ferreira et al. 2009). Outras espécies formam mudas que crescem rapidamente em estratégia de fuga de submersão (Parolin 2001) e quando ocorre o alagamento as folhas permanecem acima da água, fotosinteticamente ativas (Ferreira et al. 2007).

Em ambientes de áreas úmidas campestres, as alterações nos regimes hidrológicos de longo prazo podem facilitar a entrada de espécies lenhosas com redução de riqueza e da abundância de espécies do estrato herbáceo (Meirelles et al. 2004). Monitoramentos em longo prazo da dinâmica da população são cruciais para o manejo e a conservação dos ambientes naturais (Felfili 1995). Para tanto, são necessários mais estudos de campo que 
verifiquem a estabilidade e a detecção de oscilações populacionais, competição (Duncun 1991), bem como para classificar eficientemente a forma de colonização da espécie.

Alguns estudos relatam que a espécie Trembleya parviflora apresenta caráter invasor, já que apresenta maior sucesso na colonização em comparação com outras espécies (Meirelles et al. 2004; Munhoz e Ribeiro 2008). Entretanto, também se acredita que as Veredas, onde a espécie é encontrada, passam atualmente por estádio sucessional para a formação futura de mata de galeria alagada (Ribeiro e Walter 1998) e a classificação de $T$. parviflora como pioneira por alguns estudos auxilia na questão da sucessão (Oliveira-Filho e Fluminhan-Filho 1999).

O objetivo deste estudo foi avaliar a estrutura de duas populações de Trembleya parviflora no Distrito Federal em diferentes Veredas, procurando relacionar as características de crescimento de plantas, mortalidade, recrutamento, incremento à densidade da população na área no intervalo de um ano e meio. Essas variáveis e características edáficas foram coletadas visando a associação com a estrutura populacional da espécie estudada.

\section{Material e Métodos}

\section{Áreas de estudo}

A amostragem de populações foi realizada em parcelas permanentes de Veredas de duas Unidades de Conservação, uma no Parque Nacional de Brasília (PNB - 1546'37,56"S e 4758'29,49"W) e outra na Estação Ecológica de Águas Emendadas (ESECAE $15^{\circ} 33^{\prime} 31,18^{\prime \prime S}$ e $\left.47^{\circ} 35^{\prime} 45,36^{\prime \prime} \mathrm{W}\right)$

Os solos nas Veredas são hidromórficos gley húmicos. O clima da região é do tipo Aw, segundo a classificação de Köppen, caracterizado pela marcante sazonalidade, onde 
cerca de $90 \%$ das precipitações ocorrem de outubro a abril, com média anual de $1453 \mathrm{~mm}$ (IBGE 2004).

Amostragem da população

Os indivíduos de T. parviflora foram amostrados em quatro pontos nas Veredas, definidos de acordo com os gradientes de umidade presentes na Vereda, declividade e densidade de T. parviflora, distantes 200 a 300m entre si. Em cada ponto foram alocados sistematicamente três transectos de $25 \times 5 \mathrm{~m}$ em relação ao gradiente de declividade. Cada transecto foi dividido em cinco parcelas de $5 \times 5 \mathrm{~m}$ e cada uma dessas continha uma subparcela de $2 \times 2$ e uma de 1x1m (Figura 1, adaptado de Felfili et al. 2005), sendo considerados os seguintes estratos de crescimento:

a) Inferior - foram amostrados todos os indivíduos de $T$. parviflora com altura $\leq$ $30 \mathrm{~cm} \mathrm{e} \geq 5 \mathrm{~cm}$ nas subparcelas de $1 \times 1 \mathrm{~m}$, no extremo diagonal à parcela de $2 \times 2 \mathrm{~m}$ (Felfili et al. 2005).

b) Médio - foram amostrados todos os indivíduos de $T$. parviflora com altura < $1,0 \mathrm{~m}$ e $>30 \mathrm{~cm}$ nas subparcelas de $2 \times 2 \mathrm{~m}$.

c) Superior - todos os indivíduos arbustivo-arbóreos de T. parviflora com altura $\geq$ $1,0 \mathrm{~m}$ foram avaliados nas parcelas de $5 \times 5 \mathrm{~m}$. 


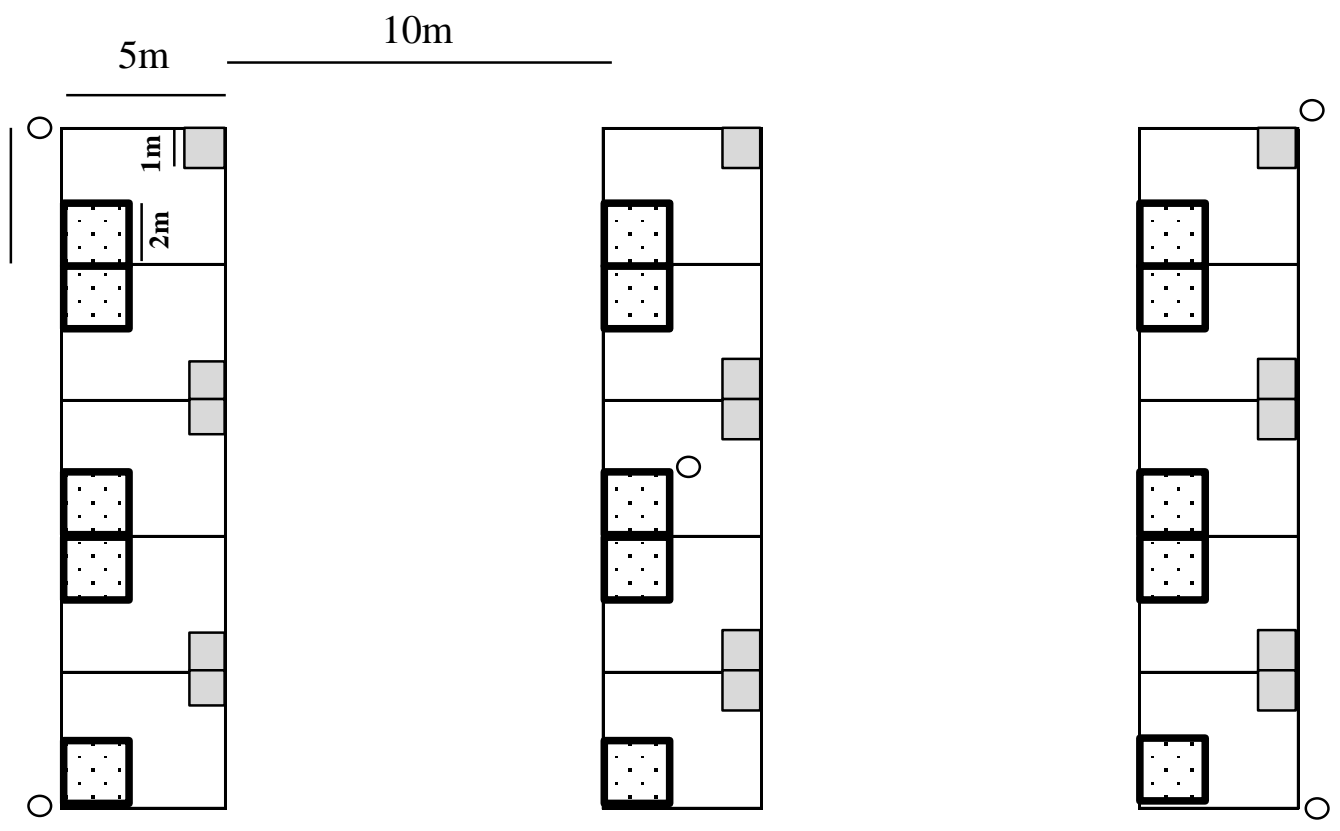

Figura 1. Transectos de amostragem de indivíduos de Trembleya parviflora no Parque Nacional de Brasília e na Estação Experimental de Águas Emendadas, Distrito Federal. ○ Pontos de coleta de solo para análises físico-químicas.

Indivíduos de T. parviflora em seus respectivos estratos e parcelas foram contados, medidos em altura e diâmetro do caule à altura do solo. $\mathrm{O}$ diâmetro foi medido com paquímetro, exceto para indivíduos do estrato inferior que não tiveram o diâmetro medido. Cada indivíduo foi marcado com uma placa de alumínio contendo um número de identificação. As medições nas duas Veredas ocorreram no primeiro semestre de 2012 (entre março e abril) e as reavaliações foram realizadas no segundo semestre de 2013 (em agosto). Nas remedições registrou-se o número de sobreviventes, indivíduos que atingiram os critérios de inclusão (recrutas) e mortos. Os indivíduos que caíram totalmente secos sobre o solo foram considerados mortos.

Para cada Vereda, a densidade de indivíduos foi estimada em hectares para cada estrato pela área das parcelas mensuradas. Para avaliar a diferença entre a frequência de indivíduos por estrato entre as áreas realizou-se o Qui-quadrado (Zar 2009). A taxa de recrutamento foi calculada pelo acréscimo de indivíduos que atingiram os critérios de inclusão em cada estrato no último levantamento (Sheil et al. 2000). A taxa de mortalidade 
foi calculada pelo número de indivíduos mortos que possuíam registros do primeiro levantamento, em relação ao número total de indivíduos que permaneceram na população no último levantamento.

Para estabelecer a estrutura de tamanho das populações de $T$. parviflora nos períodos de amostragem os dados de diâmetro e altura foram distribuídos em intervalos de classe, calculados pela fórmula $\mathrm{A} / \mathrm{K}(\mathrm{A}=$ amplitude dos valores de altura ou diâmetro; $\mathrm{K}=$ o número de intervalos de classes). A determinação do K partiu do cálculo do algoritmo de Sturges $(K=1+3,3 * \log N ; N=$ o número de indivíduos) (Gerardi e Silva 1981). Para o cálculo da variação em cada intervalo e do número de classes utilizou-se os dados da ESECAE de 2012. Entretanto, na distribuição de classes foram incorporados dados fora da amplitude de 2012, pois foram inseridos os dados de 2013. A distribuição da frequência resultante foi representada em histograma para verificar a variação temporal e espacial.

Diferenças entre a altura média ou área basal dos indivíduos de $T$. parviflora presentes entre as áreas foram encontradas por meio de teste $t$ para amostras independentes com homogeneidade de variância, para tanto, foi utilizada a altura dos indivíduos presentes no último levantamento em cada área. A diferença temporal dessas variáveis em cada Vereda foi estimada por meio de teste $t$ para amostras dependentes utilizando-se apenas indivíduos que sobreviveram entre a primeira e a última amostragem.

\section{Medição do lençol freático}

A variação da profundidade do lençol freático foi mensurada mensalmente durante um ano em dois a quatro poços por ponto de amostragem da população. As perfurações do solo, para a instalação dos poços, foram feitas com trado holandês de $6 \mathrm{~cm}$ de diâmetro e em seguida forradas com tubos de PVC de $5 \mathrm{~cm}$ de diâmetro e $2 \mathrm{~m}$ de comprimento previamente perfurados, para que a pressão da água do lençol freático não ejetasse os tubos 
dos poços e para que a água penetrasse facilmente no interior do cano. A profundidade do lençol freático foi representada pela distância entre a superfície do solo e a lâmina de água aferida com trena.

A diferença entre os valores máximos, mínimos e de média anual entre os pontos de coleta superficial e de maior profundidade do lençol entre as Veredas do PNB e da ESECAE foi calculada por meio do teste $t$ de Student para amostras independentes com homodasticidade. Homogeneidade e distribuição normal dos dados foram verificadas pelo teste F (Fisher) e teste Shapiro-Wilk, respectivamente no Programa Past 3.01 (Hammer et al. 2001).

Análise de solo

Em cada ponto de estudo da população foram coletadas cinco amostras que constituíram uma única amostra homogênea de $500 \mathrm{~g}$ de solo superficial $(0-20 \mathrm{~cm})$ para análises químicas e texturais, realizadas segundo o protocolo da Embrapa (1997). As variáveis de solo obtidas foram teores de $\mathrm{Ca}+\mathrm{Mg}, \mathrm{Ca}, \mathrm{Mg}, \mathrm{Al}, \mathrm{H}+\mathrm{Al}, \mathrm{K}, \mathrm{P}, \mathrm{S}, \mathrm{Na}, \mathrm{Zn}, \mathrm{B}$, $\mathrm{Cu}, \mathrm{Fe}$ e $\mathrm{Mn}$; capacidade de troca catiônica (CTC), saturação de bases; saturação de Al; saturação de Magnésio, matéria orgânica; carbono; $\mathrm{pH}$ e teores de argila, silte e areia.

Para correlacionar a estrutura populacional com as variáveis edáficas (físicoquímicas do solo e flutuação do lençol freático) foi realizada uma técnica de ordenação indireta à Análise de Componentes Principais (Principal Component Analysis - PCA). Desta forma pode-se definir sobre os pesos das variáveis na separação dos pontos de amostragem, visto que se trata de uma auto-análise com base em uma matriz de variância e covariância dos componentes onde o primeiro eixo explica a maior variação da distribuição dos dados no espaço de ordenação (Kent e Coker 1992). Os autos-valores dos eixos 
representam a contribuição relativa de cada componente na explicação da variância total dos dados (Kent e Coker 1992).

\section{Resultados}

\section{Estrutura e dinâmica da população}

Houve recrutamento em todos os estratos (inferior, médio e superior), nas duas Veredas. A área avaliada na ESECAE apresentou maior densidade que a área do PNB em todos os estratos e nos inventários inicial e final (Tabela 1). A proporção de indivíduos por estrato mostrou-se diferente nas duas Veredas $\left(x^{2}{ }_{3,2 ; 0,05}=273,35 ; \mathrm{p}<0,01\right)$. A taxa de recrutamento foi elevada no PNB para todos os estratos, mas com alta mortalidade no estrato superior.

Tabela 1. Densidade inicial e final, recrutamento e mortalidade de indivíduos de Trembleya parviflora amostrados nos estratos de inferior, médio e superior em 2012 e 2013 no Parque Nacional de Brasília e na Estação Ecológica de Águas Emendadas, Distrito Federal, Brasil.

\begin{tabular}{|c|c|c|c|c|}
\hline Estrato & $\begin{array}{c}\text { Densidade Inicial } \\
\left.\text { (ind.ha }^{-1}\right)\end{array}$ & $\begin{array}{l}\text { Densidade Final } \\
\text { (ind.ha }^{-1} \text { ) }\end{array}$ & $\begin{array}{c}\text { Recrutamento } \\
(\%)\end{array}$ & $\begin{array}{c}\text { Mortalidade } \\
(\%)\end{array}$ \\
\hline \multicolumn{5}{|c|}{ ESECAE } \\
\hline Inferior & 6.833 & 3.667 & 6,16 & 38,03 \\
\hline Médio & 2.542 & 2.917 & 15,89 & 7,80 \\
\hline Superior & 4.920 & 4.907 & 8,52 & 8,68 \\
\hline Total & 14.295 & 11.490 & - & - \\
\hline \multicolumn{5}{|c|}{ PNB } \\
\hline Inferior & 333 & 1.167 & 72,67 & 37,00 \\
\hline Médio & 292 & 1.292 & 62,92 & 0,00 \\
\hline Superior & 100 & 80 & 80,92 & 83,56 \\
\hline Total & 725 & 2.538 & - & - \\
\hline
\end{tabular}

Não se observou aumento significativo para o incremento de altura (Figura 2) entre os levantamentos no estrato inferior na $\operatorname{ESECAE~}\left(\mathrm{t}_{11 ; 0,05}=-1,89 ; \mathrm{p}=0,08\right)$ e para o PNB não se avaliou porque houve a sobrevivência de apenas um indivíduo entre o levantamento inicial e o final. Para o estrato médio observou-se aumento significativo na altura tanto na 
ESECAE $\left(\mathrm{t}_{42 ; 0,05}=-4,38 ; \mathrm{p}<0,01\right)$ quanto no PNB $\left(\mathrm{t}_{5} ; 0,05=-10,78 ; \mathrm{p}<0,01\right)$. Houve incremento significativo para indivíduos do estrato superior amostrados na ESECAE $\left(\mathrm{t}_{642}\right.$; $0,05=-21,28 ; \mathrm{p}<0,01)$ e para o PNB não se avaliou porque apenas um indivíduo sobreviveu. Em relação ao diâmetro, somente PNB apresentou incremento significativo para indivíduos do estrato médio $\left(\mathrm{t}_{5 ; 0,05}=-5,21 ; \mathrm{p}<0,01 ; \mathrm{ESECAE}=\mathrm{t}_{25 ; 0,05}=-1,56 ; \mathrm{p}=0,12\right)($ Figura 3$)$.

A estrutura da população evidenciou, para o estrato inferior, redução na frequência de indivíduos na ESECAE e aumento no PNB após um ano e meio de avaliação (Figura 4). 

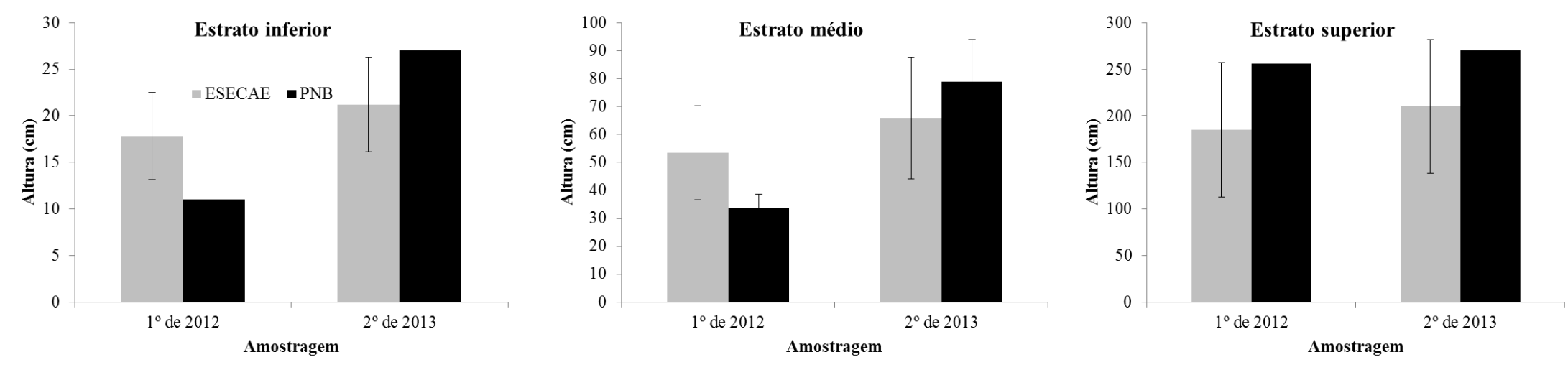

Figura 2. Altura média $(\mathrm{cm})$ de indivíduos de Trembleya parviflora amostrados nos estratos inferior, médio e superior em 2012 e 2013 em Veredas na Estação Ecológica de Águas Emendadas e no Parque Nacional de Brasília, Distrito Federal, Brasil. (Média \pm desvio padrão).
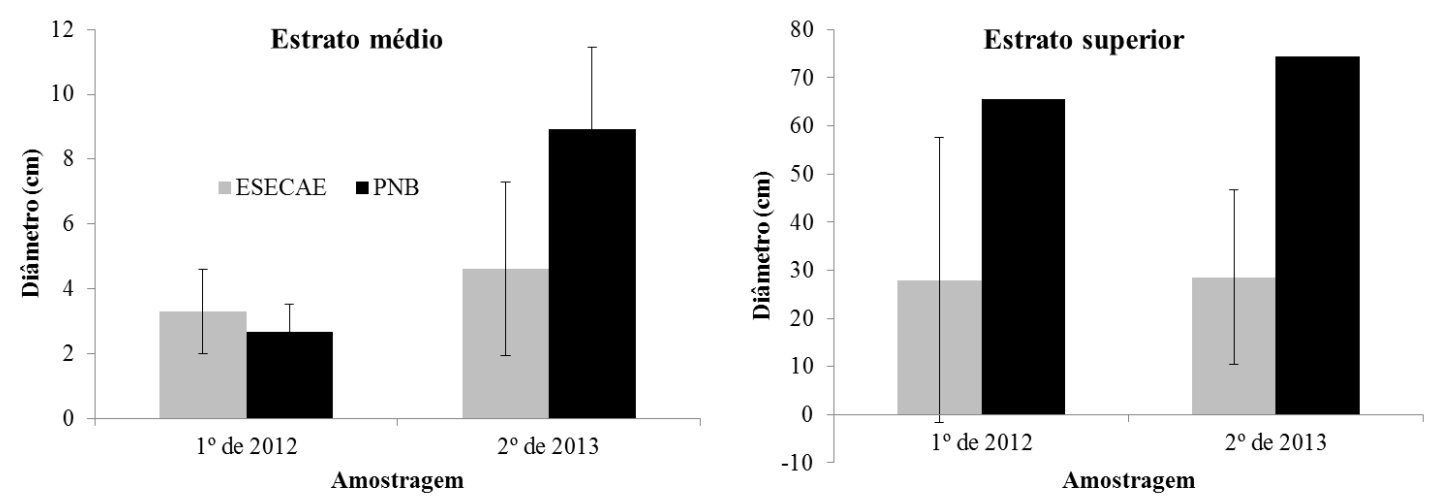

Figura 3. Diâmetro médio (cm) de indivíduos de Trembleya parviflora amostrados nos estratos médio e superior em 2012 e 2013 em Veredas na Estação Ecológica de Águas Emendadas e no Parque Nacional de Brasília, Distrito Federal, Brasil. (Média \pm desvio padrão). 

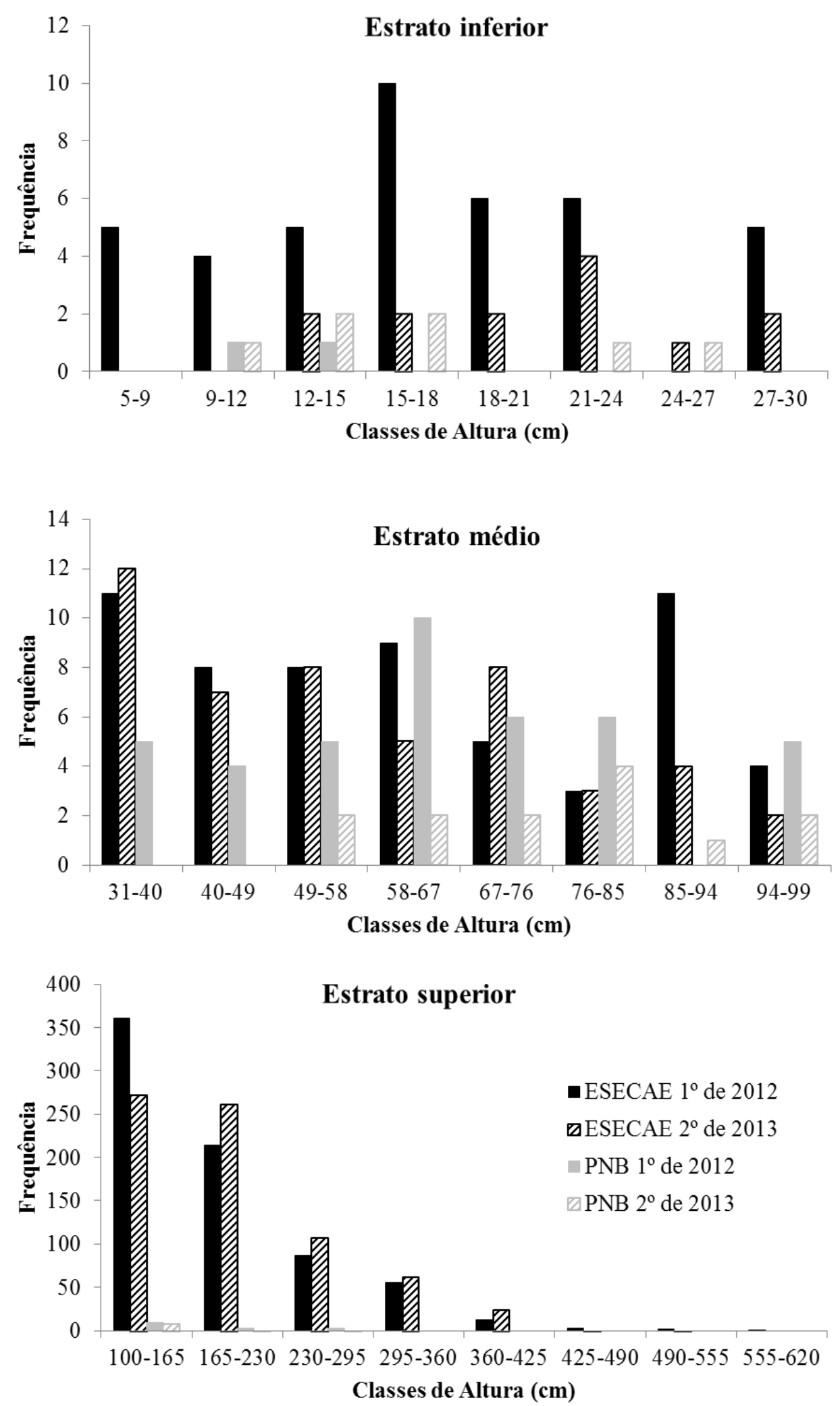

Figura 4. Frequência de classes de altura de indivíduos de Trembleya parviflora amostrados nos estratos inferior, médio e superior em 2012 e 2013 em Veredas na Estação Ecológica de Águas Emendadas e no Parque Nacional de Brasília, Distrito Federal, Brasil. 
Houve maior frequência de indivíduos nas classes entre um e três metros de altura para o estrato superior, sendo esse estrato marcantemente mais frequente na ESECAE se comparado com o PNB. As classes de diâmetros mais frequentes para o estrato médio e superior ocorreram principalmente nos primeiros intervalos (Figura 5).
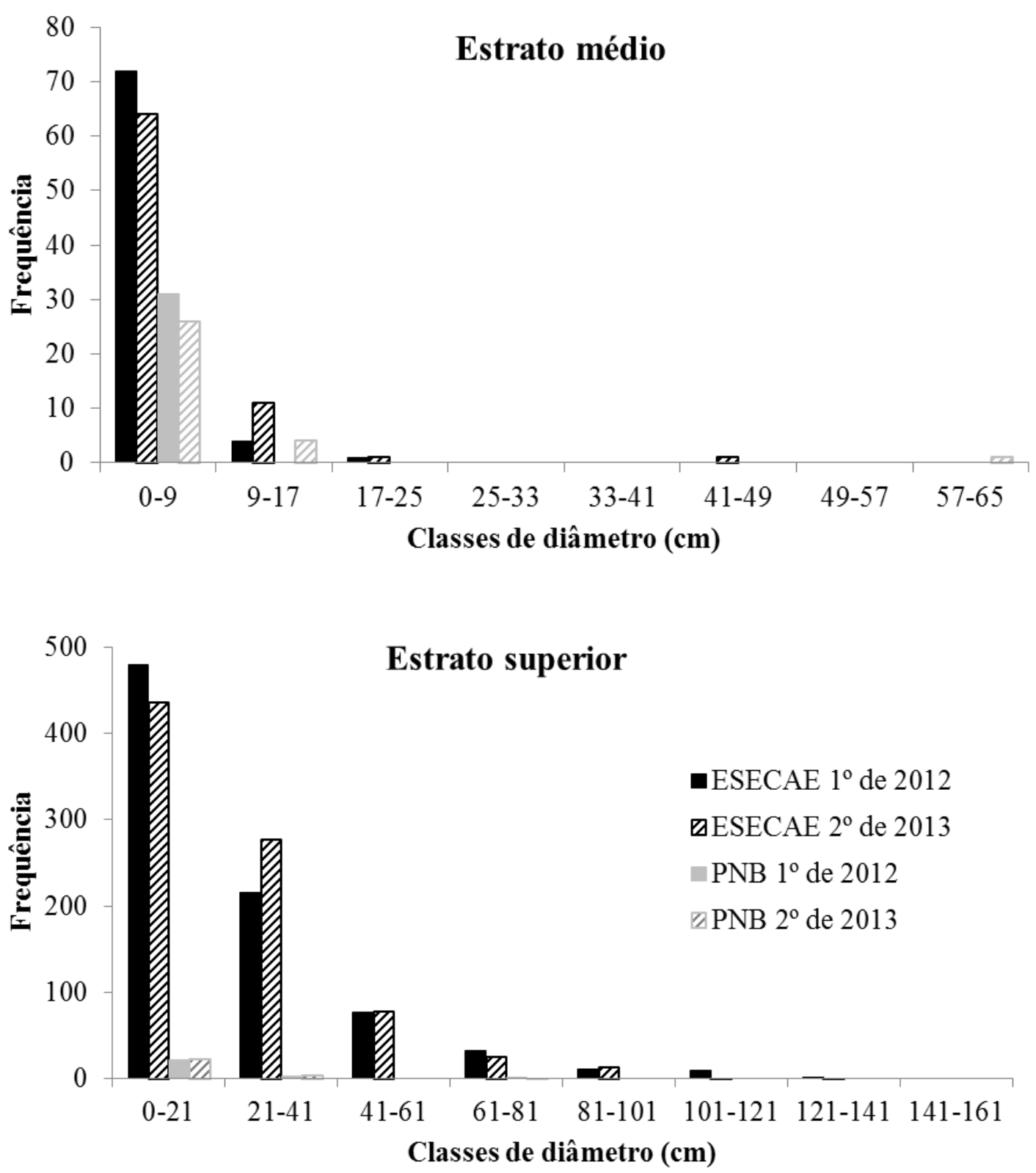

Figura 5. Frequência de classes de diâmetro de indivíduos de Trembleya parviflora amostrados nos estratos médio e superior em 2012 e 2013 em Veredas na Estação Ecológica de Águas Emendadas e no Parque Nacional de Brasília, Distrito Federal, Brasil. 


\section{Flutuação da profundidade do lençol freático}

As Veredas apresentaram flutuação do lençol freático ao longo do período avaliado, com áreas permanentemente secas ou alagadas e pontos de alagamento sazonais, evidenciando assim o mosaico de ambientes que as Veredas possuem (Figura 6). Os pontos de coleta que apresentaram lençol freático mais profundo tiveram diferenças nos valores máximos $\left(t_{0,05} ; 10=\right.$ $5,73 ; \mathrm{p}<0,01)$, mínimos $\left(t_{0,05 ; 10}=2,83 ; \mathrm{p}=0,02\right)$ e de média anual $\left(t_{0,05 ; 10}=4,92 ; \mathrm{p}<0,01\right)$ entre as Veredas do PNB e da ESECAE. Entretanto, tais medições não apresentaram diferenças para pontos com lençol freático superficial $\left(t_{0,05 ; 10}=-0,60 ; \mathrm{p}=0,55 ; t_{0,05 ; 10}=-1,46 ; \mathrm{p}=0,17 ; t_{0,05 ; 10}=-\right.$ 0,71; $\mathrm{p}=0,49$; respectivamente) (Figura 6). Os poços nos pontos com solo mais seco no PNB, apesar de não terem afloramento do lençol acima do solo, foram mais sazonais que pontos com reduzida umidade na ESECAE, garantindo substrato mais úmido durante o período de um ano se comparado com a ESECAE. Durante a estação seca, o lençol freático tornou-se mais profundo nos locais com reduzida umidade do solo.

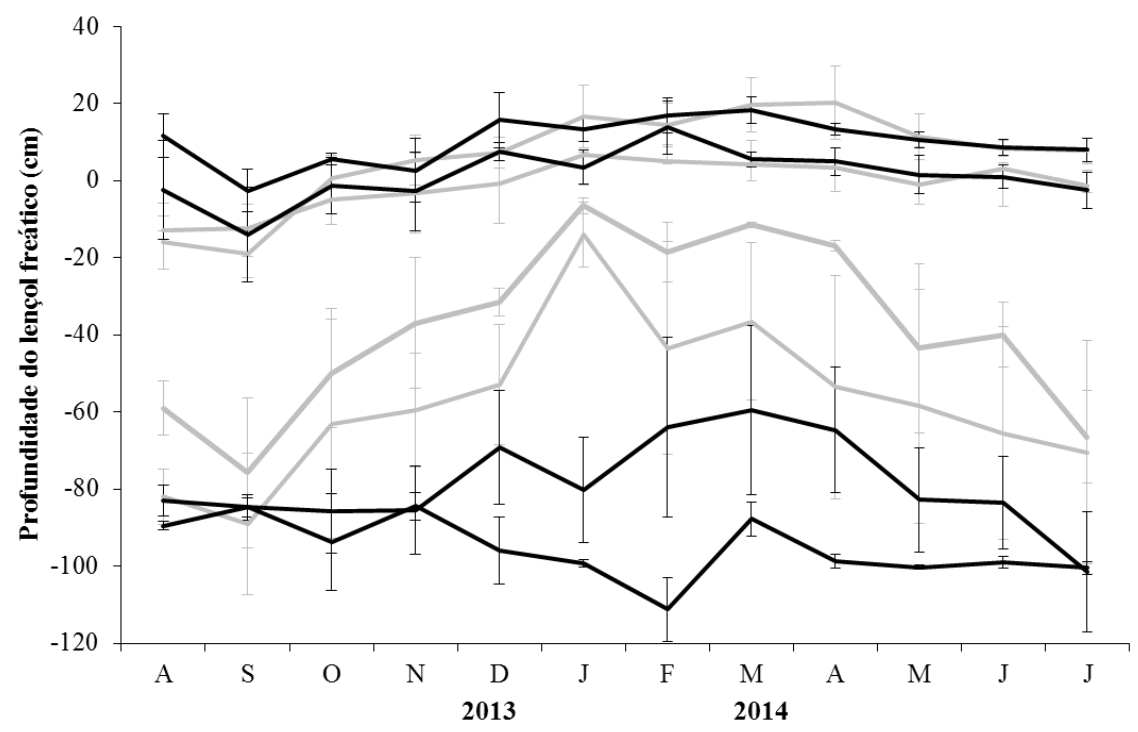

Figura 6. Distância entre a lâmina de água do lençol freático e a superfície do solo em poços instalados em cada um dos quatro pontos de amostragem no Parque Nacional de Brasília (PNB, em cinza) e na Estação Ecológica de Águas Emendadas (ESECAE, em preto), Distrito Federal, Brasil. Valores negativos representam lençol freático abaixo da superfície do solo. 


\section{Análise do solo}

As flutuações média, máxima e mínima, assim como ferro, apresentaram maior peso na variância para a separação dos pontos de amostragem explicando 59,17\% no primeiro componente e 29,22\% no segundo, totalizando 88,39\% da variância (Tabela 2 e Figura 7). Entretanto, não houve separação evidente entre as duas áreas do PNB e da ESECAE. Desta forma, não foi possível correlacionar à densidade de $T$. parviflora às variáveis edáficas analisadas (Tabela 2).

Tabela 2. Variáveis químicas e físicas de amostras do solo coletadas em quatro pontos de amostragem, nas Veredas do Parque Nacional de Brasília (PNB) e na Estação Ecológica de Águas Emendadas (ESECAE), Brasília.

\begin{tabular}{|c|c|c|c|c|c|c|c|c|}
\hline \multirow[b]{2}{*}{$\mathrm{Ca}+\mathrm{Mg}$ cmolc. $\mathrm{dm}^{-3}$} & \multicolumn{4}{|c|}{ PNB } & \multicolumn{4}{|c|}{ ESECAE } \\
\hline & 0,3 & 0,3 & 0,6 & 0,3 & 0,3 & 0,5 & 0,5 & 0,5 \\
\hline Ca cmolc.. $\mathrm{dm}^{-3}$ & 0,2 & 0,2 & 0,4 & 0,2 & 0,2 & 0,3 & 0,3 & 0,3 \\
\hline Mg cmolc. $\mathrm{dm}^{-3}$ & 0,1 & 0,1 & 0,2 & 0,1 & 0,1 & 0,2 & 0,2 & 0,2 \\
\hline $\mathrm{Al} \mathrm{cmolc} \cdot \mathrm{dm}^{-3}$ & 0,7 & 0,6 & 0,8 & 0,7 & 1,6 & 0,7 & 1,5 & 1,7 \\
\hline $\mathrm{H}+\mathrm{Al} \mathrm{cmolc} \cdot \mathrm{dm}^{-3}$ & 10,6 & 10,7 & 12,1 & 9,3 & 12,2 & 12,1 & 15,8 & 12,4 \\
\hline $\mathrm{K}$ cmolc. $\mathrm{dm}^{-3}$ & 0,08 & 0,11 & 0,13 & 0,9 & 0,07 & 0,06 & 0,06 & 1,12 \\
\hline P mg.dm ${ }^{-3}$ & 1,5 & 1,5 & 1,5 & 0,8 & 5,3 & 4 & 3,7 & 0,8 \\
\hline $\mathrm{S} \mathrm{mg} \cdot \mathrm{dm}^{-3}$ & 3,4 & 3,4 & 2,8 & 2 & 11 & 11,8 & 15 & 3,4 \\
\hline $\mathrm{Na} \mathrm{mg} \cdot \mathrm{dm}^{-3}$ & 15 & 19 & 18 & 9 & 11 & 9 & 10 & 10 \\
\hline Zn mg.dm ${ }^{-3}$ & 1,2 & 2 & 0,4 & 0,5 & 3,4 & 1,7 & 0,3 & 0,8 \\
\hline B mg.dm ${ }^{-3}$ & 0,14 & 0,23 & 0,19 & 0,23 & 0,14 & 0,23 & 0,19 & 0,19 \\
\hline $\mathrm{Cu}$ mg.dm ${ }^{-3}$ & 0,5 & 0,1 & 0,9 & 0,8 & 0,2 & 0,2 & 0,2 & 0,6 \\
\hline $\mathrm{Fe} \mathrm{mg} \cdot \mathrm{dm}^{-3}$ & 101,1 & 199,2 & 32,8 & 169,5 & 260 & 215,1 & 70,9 & 201,2 \\
\hline Mn mg.dm ${ }^{-3}$ & 1,4 & 2,8 & 3,6 & 1,9 & 2,5 & 1,9 & 2,4 & 11,6 \\
\hline CTC & 11,04 & 11,19 & 12,91 & 9,73 & 14,62 & 12,7 & 16,4 & 13,06 \\
\hline SatBas \% & 4,03 & 4,4 & 6,26 & 4,41 & 2,86 & 4,72 & 3,68 & 5,08 \\
\hline SatAl \% & 64,81 & 59,41 & 52,29 & 64,22 & 81,22 & 55,56 & 72,82 & 73,28 \\
\hline Mat.Org mg.dm ${ }^{-3}$ & 78 & 100 & 72 & 59 & 120 & 150 & 104 & 78 \\
\hline Carbono & 45,24 & 58 & 41,76 & 34,22 & 69,61 & 87,01 & 60,32 & 45,24 \\
\hline $\mathrm{pHCaCl} \mathrm{Cl}_{2}$ & 4,3 & 4,3 & 4,2 & 4,2 & 3,8 & 3,9 & 4,2 & 4 \\
\hline Argila $g / k g$ & 470 & 470 & 530 & 660 & $*$ & $*$ & $*$ & 700 \\
\hline Silte $\mathrm{g} / \mathrm{kg}$ & 110 & 110 & 120 & 110 & $*$ & $*$ & $*$ & 100 \\
\hline Areia g/kg & 420 & 420 & 350 & 230 & $*$ & $*$ & $*$ & 200 \\
\hline
\end{tabular}

* Dados não mensurados. 


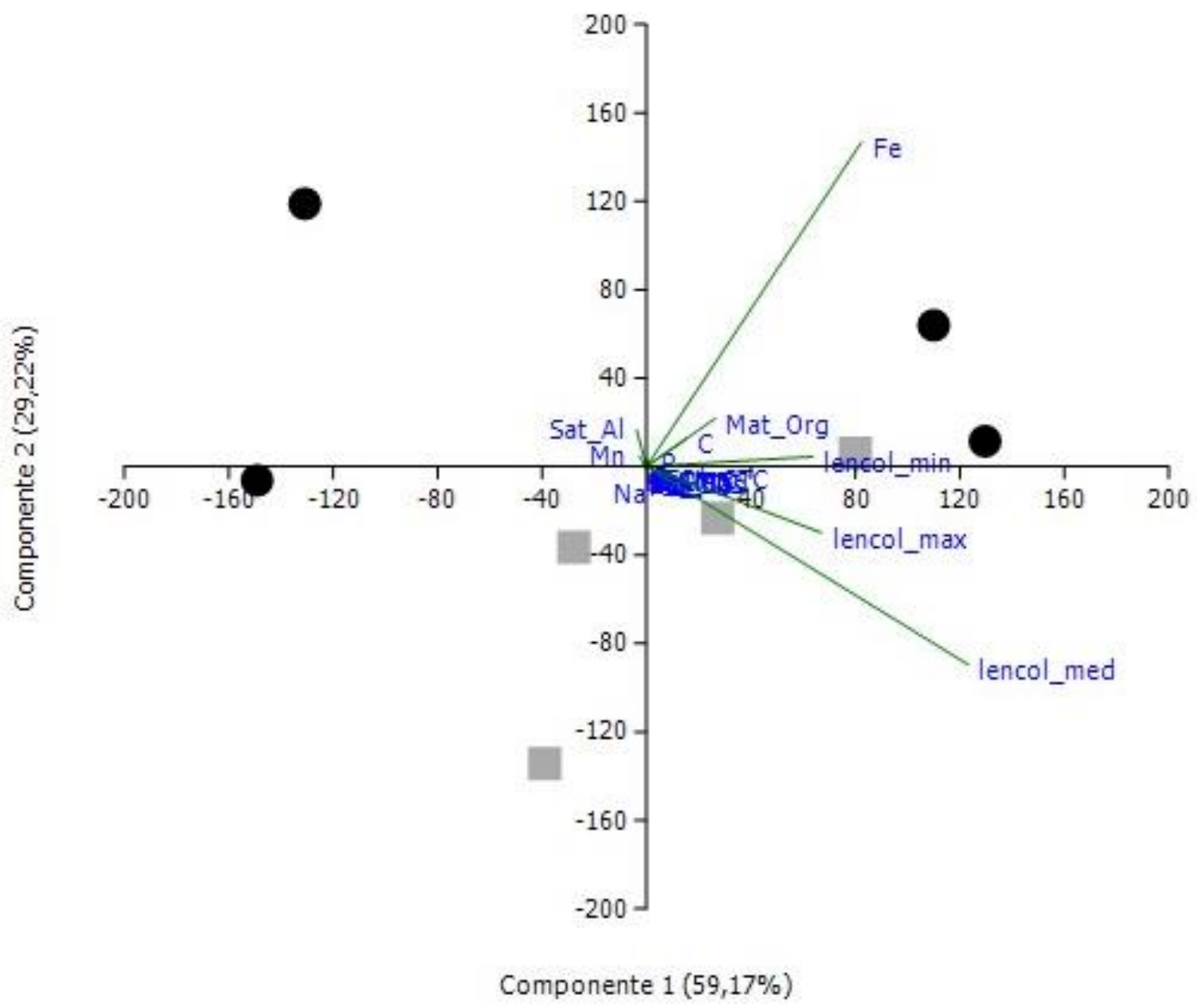

Figura 7. Combinação do primeiro e do segundo componente principal da análise de PCA ilustrando a influência das variáveis edáficas na densidade de Trembleya parviflora do Parque Nacional de Brasília (PNB, em cinza) e da Estação Ecológica de Águas Emendadas (ESECAE, em preto), Distrito Federal, Brasil.

\section{Discussão}

A estrutura populacional da vegetação provém da ação de forças bióticas e abióticas sobre os indivíduos atuais e ancestrais, que afetam o arranjo espacial e as estruturas etária e genética (Hutchings 1997). A presença de maiores taxas de recrutamento em relação às taxas de mortalidade evidencia populações em expansão sendo favorecidas no processo de competição por recursos locais (Arantes e Schiavini 2011), como pode ser observado para indivíduos de T. parviflora no estrato médio em ambas as áreas estudadas. Desta forma, existe 
a possibilidade de substituição natural dos indivíduos mortos pelo recrutamento dos indivíduos das classes diamétricas inferiores. Ademais, há a inserção de novas plântulas, pois $T$. parviflora apresenta grande investimento em reprodução por semente (Albuquerque et al. 2013), que se inicia quando indivíduos estão no estrato médio.

Estima-se que populações vegetais tendem a aumentar exponencialmente o número de indivíduos e atinja tamanho máximo em ambientes favoráveis, com recursos disponíveis (Watkinson 1997). Infere-se que isso pode ocorrer na população do PNB, visto que se observou baixa densidade de indivíduos de $T$. parviflora e elevadas taxas de recrutamento. Entretanto, populações com grande adensamento de indivíduos de mesma espécie em determinada área intensifica os processos de competição intraespecífica por recursos, limitando a quantidade de plantas que sobrevivem no local, levando à estabilidade populacional (Watkinson 1997; Marques e Joly 2000). Esse estágio estaria ocorrendo na ESECAE, como pode ser observado pela baixa taxa de recrutamento e estabilidade da população estudada com grande número de indivíduos no estrato superior.

A alta mortalidade de indivíduos de T. parviflora no estrato inferior pode ser resultante de ações bióticas e abióticas. Uma vez que as plântulas são mais suscetíveis à ação de patógenos, herbívoros, competição intra e interespecífica (Swaine et al. 1987; Howe 1990) e à variação hídrica do local (Ferreira et al. 2009). Especificamente a ação do alagamento sobre a distribuição de espécies aponta para a importância da inundação como fator estressor para comunidades vegetais ou como promotor de diversidade de habitats e espécies (Arieira e Nunes da Cunha 2006). Em área úmida com presença marcante de T. parviflora ocorre redução da riqueza (Santos e Munhoz 2012), que pode ser associada às alterações nos regimes hidrológicos de longo prazo que, por sua vez, facilitam a entrada de espécies lenhosas (Meirelles et al. 2004). 
O favorecimento de população monodominante está relacionado com a alta frequência de distúrbios, que possibilitariam o recrutamento da própria espécie (Connell e Lowman 1989; Hart et al. 1989). A redução do lençol freático pode ser considerada distúrbio por efeitos indiretos de atividades antrópicas em áreas agrícolas vizinhas na ESECAE que poderiam explicar o adensamento de T. parviflora (Silva-Júnior e Felfili 1996; Meirelles et al. 2004; Munhoz e Ribeiro 2008). Estudos de longa duração possibilitarão auxiliar no entendimento sobre a presença e permanência das populações de T. parviflora nas Veredas, permitindo embasar o manejo e a conservação da biodiversidade nessas áreas úmidas.

Como verificado no capítulo 1 e 2 desta tese, T. parviflora apresenta alta capacidade de germinação e alta emergência de plântulas nos bancos de sementes estudados. A grande produção de sementes, a alta plasticidade e limite de tolerância evidenciados pela ampla distribuição de T. parviflora nas diferentes fitofisionomias do bioma Cerrado determinam o risco de aumento populacional descontrolado da espécie (Albuquerque et al. 2013). A expansão de uma espécie necessita ser acompanhada para que planos de manejo sejam aplicados, caso esta expansão afete a conservação da comunidade, impedindo que outras espécies se regenerem (Arantes e Schiavini 2011).

\section{Conclusão}

Foram amostrados todos os estratos estudados, entretanto, a densidade de indivíduos amostrados no Parque Nacional foi menor quando comparada com Águas Emendadas. Se a redução do lençol freático continuar, futuramente a colonização de plantas de Trembleya parviflora pode aumentar no Parque Nacional, como resultado da dispersão de sementes dos indivíduos presentes na população. 


\section{Referências bibliográficas}

Albuquerque, L.B., Aquino, F.G., Costa, L.C., Miranda, Z.J., \& Sousa, S.R. 2013. Espécies de Melastomataceae Juss. com potencial para restauração ecológica de Mata Ripária no Cerrado. Polibotánica 35: 1-19.

Alpert, P.; Bone, E. \& Holzapfel, C. 2000. Invasiveness, invasibility and the role of environmental stress in the spread of non-native plants. Perspectives in plant ecology, evolution and systematics 3: 52-66.

Aquino, F.G., Oliveira, M.C., Schiavini, I. \& Ribeiro, J.F. 1999. Dinâmica de populações de Anadenanthera macrocarpa e Acacia glomerosa em mata seca semidecídua na Estação Ecológica do Panga (Uberlândia-MG). Boletim de Herbário Ezechias Paulo Heringer 4: $90-102$.

Araújo, G.M.; Barbosa, A.A.A.; Arantes, A.A. \& Amaral, A.F. 2002. Composição florística de Veredas no município de Uberlândia, MG. Revista Brasileira de Botânica 25: 475-493.

Arantes, C.S. \& Schiavini, I. 2011. Estrutura e dinâmica da população de Amaioua guianensis Aubl. (Rubiaceae) em fragmento urbano de floresta estacional semidecidual Uberlândia, Minas Gerais. Bioscience Journal 27(2): 312-321.

Arieira, J. \& Nunes da Cunha, C. 2006. Fitossociologia de uma floresta inundável monodominante de Vochysia divergens Pohl (Vochysiaceae), no Pantanal Norte, MT, Brasil. Acta botanica brasilica 20(3): 569-580.

Connell, J.H. \& Lowman, M.D. 1989. Low-diversity tropical rainforests: Some possible mechanisms for their existence. American Naturalist 134: 88-119.

Davis, T.A.W. \& Richards, P.W. 1934. The vegetation of Moraballi Creek, British Guiana: an ecological study of a limited area of tropical rain forest. Part II. Journal of Ecology 22: 106-155.

Duncun, R.D. 1991. Competition and the coexistence of species in a mixed podocarp stand. The Journal of Ecology 79: 1073-1084.

Embrapa. Centro Nacional de Pesquisa de Solos. 1997. Manual de Métodos de Análise de Solo. $2^{\text {a }}$ ed. Rio de janeiro: Embrapa Solos. 212p. (EMBRAPA - CNPS. Documentos).

Felfili, J.M. 1995. Growth, recruitment and mortality in the Gama gallery forest in central Brazil over a six-year period (1985-1991). Journal of Tropical Ecology 11: 67-83. 
Felfili, J.M.; Carvalho, F.A. \& Haidar, R.F. 2005. Manual para o monitoramento de parcelas permanentes nos biomas cerrado e pantanal. Brasília: Universidade de Brasília, Departamento de Engenharia Florestal, 55p.

Felfili, J.M., Silva-Júnior, M.C. \& Nogueira, P.E. 1998. Levantamento da vegetação arbórea na região de Nova Xavantina, MT. Boletim do Herbário Ezechias Paulo Heringer 3: 63-81.

Ferreira, C.S., Piedade, M.T.F., Junk, W.J. \& Parolin, P. 2007. Floodplain and upland populations of Amazonian Himatanthus sucuuba: effects of flooding on germination, seedling growth and mortality. Environmental and Experimental Botany 60: 477483.

Ferreira, C.S., Piedade, M.T.F., Tine, M.A.S, Rossatto, D.R., Parolin, P. \& Buckeridge, M.S. 2009. The role of carbohydrates in seed germination and seedling establishment of Himatanthus sucuuba, an Amazonian tree with populations adapted to flooded and nonflooded conditions. Annals of Botany 104: 1111-1119.

Gerardi, L.H.O. \& Silva, B.C.N. 1981. Quantificação em Geografia. Editora Difel, São Paulo.

Green, J.J. \& Newbery, D.M. 2001. Light and seed size affect establishment of grove-forming ectomycorrhizal rain forest tree species. New Phytologist 151: 271- 289.

Hammer, O.; Harper, D.A.T. \& Ryan, P.D. 2001. PAST: Paleontological Statistics Software Package for Education and Data Analysis. Palaeontologia Electronica 4(1): 9. <http://palaeo-electronica.org/2001_1/ past/issue1_01.htm> (Acesso em: 09 Jul. 2014).

Hart, T.B. 1995. Seed, seedling and sub-canopy survival in monodominant and mixed forests of the Ituri Forest, Africa. Journal of Tropical Ecology 11(03): 443-459.

Hart, T.B., Hart, J.A. \& Murphy, P.G. 1989. Monodominant and species-rich forests of the humid tropics: causes for their co-occurrence. The American Naturalist 133: 613-633.

Hart, T.B. 1990. Monospecific dominance in tropical rain forests. Trends in Ecology and Evolution 5: 6-11.

Henkel, T.W. 2003. Monodominance in the ectomycorrhizal Dicymbe corymbosa (Caesalpiniaceae) from Guyana. Journal of Tropical Ecology 19: 417-437.

Howe, H.F. 1990. Survival and growth of juvenile Virola surinamensis in Panama: effects of herbivory and canopy closure. Journal of Tropical Ecology 6: 259-280. 
Hutchings, M.J. 1997. The structure of plant populations. Pp.325-358. In: Plant ecology. M.J. Crawley (Ed.). Blackwell Science, Oxford.

IBGE. 2004. Reserva Ecológica do IBGE: ambiente e plantas vasculares. Rio de Janeiro: IBGE-Divisão de Geociências. Estudos e Pesquisas. Informação Geográfica n. 3.

Kent, M. \& Coker, P. 1992. Vegetation description and analysis: a pratical Approach. Belhaven Press, London.

Kozlowski, T.T. 1984. Responses of woody plants to flooding. Pp 129-163. In: Flooding and Plant Growth. Ed. T.T. Kozlowski. Academic Press, Orlando.

Lieberman, D., Lieberman, M., Hartshorn, G.S. \& Peralta, R. 1985. Growth rates and age-size relationships of tropical wet forest trees in Costa Rica. Journal of Tropical Ecology 1: 97-109.

Marimon, B.S., Felfili, J.M. \& Haridasan, M. 2001a. Studies in monodominant forests in eastern Mato Grosso, Brazil: I. A forest of Brosimum rubescens Taub. Edinburgh Journal of Botany 58(1): 123-137.

Marques, M.C.M. \& C.A. Joly. 2000. Estrutura e dinâmica de uma população de Calophyllum brasiliense Camb. em floresta higrófila do sudeste do Brasil. Revista Brasileira de Botânica 23: 107-112.

Martijena, N.E. \& Bullock, S.H. 1994. Monospecific dominance of a tropical deciduous forest in México. Journal of Biogeography 21: 63-74.

Meguro, M.; Pirani, J. R.; Mello-Silva, R. \& Giulietti, A. M. 1996. Caracterização florística e estrutural de matas ripárias e capões de altitude da Serra do Cipó, Minas Gerais. Boletim de Botânica da Universidade de São Paulo 15: 13-29.

Meirelles, M.L.; Guimarães, A.J.M.; Oliveira, R.C. de; Araújo, G.M. \& Ribeiro, J.F. 2004. Impactos sobre o estrato herbáceo de Áreas Úmidas do Cerrado. Pp. 41-68. In: Aguiar, L.M.S. \& Camargo, A.J.A. (Eds.). Cerrado: ecologia e caracterização. Planaltina, DF: Embrapa Cerrados.

Munhoz, C.B.R. \& Ribeiro, J.F. 2008. Veredas. Pp. 156-162. In: F.O. Fonseca (Org). Água emendadas/Distrito Federal. Secretaria de Desenvolvimento Urbano e Meio Ambiente. Brasília: Seduma. 
Munhoz, C.B.R., Felfili, J.M. \& Rodrigues, C. 2008. Species-environment relationship in the herb-subshrub layer of a moist Savanna site, Federal District, Brazil. Brazilian Journal of Biology 68(1): 25-35.

Nascimento, M.T. \& Proctor, J. 1996. Seed attack by beetles and leaf-cutter ants on Peltogyne gracilipes Ducke (Caesalpiniaceae) on Maracá Island, Brazilian Amazonia. Journal of Tropical Ecology 12: 723-727.

Nascimento, M.T. \& Proctor, J. 1997a. Population dynamics of five tree species in a monodominant Peltogyne forest and two other forest types on Maracá Island, Roraima, Brazil. Forest Ecology and Management 94: 115-128.

Nascimento, M.T. \& Proctor, J. 1997b. Soil and plant changes across a monodominant rain forest boundary on Maracá Island, Roraima, Brazil. Global Ecology and Biogeography Letters 6: 387-395.

Nascimento, M.T. \& Proctor, J. 2001. Leaf herbivory on three tree species in a monodominant and two other Terra Firme forests on Maracá Island, Brazil. Acta Amazonica 31(1): $27-$ 38.

Nunes da Cunha, C. \& Junk, W.J. 2004. Year-to-year changes in water level drive the invasion of Vochysia divergens in Pantanal grasslands. Applied Vegetation Science 7: 103-110.

Oliveira-Filho \& Fluminhan-Filho. 1999. Ecologia da vegetação do Parque Florestal Quedas do Rio Bonito. Cerne 5: 051-064

Parolin, P. 2001. Morphological and physiological adjustments to waterlogging and drought in seedlings of Amazonian floodplain trees. Oecologia 128: 326-335.

Parolin, P.; Lucas, C.; Piedade, M.T.F. \& Wittmann, F. 2010. Drought responses of floodtolerant trees in Amazonian floodplains. Annals of Botany 105(1): 129-139.

PySek, P. 1995. On the terminology used in plant invasion studies. Plant invasions: general aspects and special problems: $71-81$.

Pott, A. \& Oliveira, A.K.M.; Damasceno-Junior, G.A. \& Silva, J.S.V. 2011. Plant diversity of the Pantanal wetland. Brazilian Journal of Biology 71(1): 265-273.

Read, J.; Jaffré, T.; Godrie, E.; Hope, G.S. \& Veillon, J.M. 2000. Structural and floristic characteristics of some monodominant and adjacent mixed rainforests in New Caledonia. Journal of Biogeography 27: 233-250. 
Rejmánek, M. \& Richardson, D.M. 1996. What attributes make some plant species more invasive? Ecology 77: 1655-1661.

Ribeiro, J.F. \& Walter, B.M.T. 1998. Fitofisionomias do bioma Cerrado. Pp. 87-166. In: Sano, S.M. \& Almeida S.P. de (Eds.). Cerrado: ambiente e flora. Brasília, Embrapa Cerrados.

Ribeiro, S.P. \& Brown, V.K. 2006. Prevalence of monodominant vigorous tree populations in the tropics: herbivory pressure on Tabebuia species in very different habitats. Journal of Ecology 94(5): 932-941.

Richards, P.W. 1996. The Tropical Rain Forest. Cambridge University Press, Cambridge, $575 \mathrm{p}$.

Richardson, D.M.; Pysek, P.; Rejmanek, M.; Barbour, M.G.; Panetta, D. \& West, C.J. 2000. Naturalization and invasion of alien plants: concepts and definitions. Diversity and Distributions 6: 93-107.

Rizzini, C.T. 1979. Tratado de fitogeografia do Brasil: aspectos sociológicos e florísticos. v.2. EDUSP, São Paulo.

Santos, F.F.M. \& Munhoz, C.B.R. 2012. Diversidade de espécies herbáceo-arbustivas e zonação florística em uma Vereda no Distrito Federal. Heringeriana 6: 21-27.

Scremin-Dias, E.; Lorenz-Lemke, A.P. \& Oliveira, A.K.M. 2011. The floristic heterogeneity of the Pantanal and the occurrence of species with different adaptive strategies to water stress. Brazilian Journal of Biology 71: 275-282.

Schiavini, I.; Resende, J.C.F. \& Aquino, F.G. 2001. Dinâmica de populações de espécies arbóreas em Mata de Galeria e Mata Mesófila na margem do Ribeirão Panga, MG. Pp. 267-296. In: Ribeiro, J.F.; Fonseca, C.E.L.; Souza-Silva, J.C. (Ed.). Cerrado: caracterização e recuperação de Matas de Galeria. Planaltina: Embrapa.

Sheil, D.; Jennings, S. \& Savill, P. 2000. Long-term permanent plot observations of vegetation dynamics in Budongo, a Ugandan rain forest. Journal of Tropical Ecology 16(6): 865882.

Silva-Júnior, M.C. \& Felfili, J.M. 1996. A vegetação da Estação Ecológica de Águas Emendadas. Instituto de Ecologia e Meio Ambiente do Distrito Federal. Brasília, DF. $43 \mathrm{p}$. 
Silva, M.P.; Mauro, R.; Mourão, G. \& Coutinho, M. 2000. Distribuição e quantificação de classes de vegetação do Pantanal através de levantamento aéreo. Revista Brasileira de Botânica 23: 143-152.

Somavilla, N.S. \& Graciano-Ribeiro, D. 2011. Análise comparativa da anatomia foliar de Melastomataceae em ambiente de Vereda e cerrado Sensu Stricto. Acta Botanica Brasiliza 25(4): 764-775.

Somavilla, N.S. \& Graciano-Ribeiro. D. 2012. Ontogeny and characterization of aerenchymatous tissues of Melastomataceae in the flooded and well-drained soils of a Neotropical savanna. Flora - Morphology, Distribution, Functional Ecology of Plants 207(3): 212-222.

Swaine, M.D.; Lieberman, D. \& Putz, F.E. 1987. The dynamics of tree population in tropical forest: a review. Journal of Tropical Ecology 3: 359-366.

ter Steegem, H. 1994. Flooding and drought tolerance in seeds and seedlings of two Mora species segregated along a soil hydrological gradient in the tropical rain forest of Guyana. Oecologia 100: 356-367.

Torti, S.D.; Coley, P.D. \& Kursar, T.A. 2001. Causes and consequences of monodominance in tropical lowland forests. The American Naturalist 157(2): 141-153.

Tsukahara, H. \& Kozlowski, T.T. 1985. Importance of adventitious roots to growth of flooded Platanus occidentalis seedlings. Plant Soil 88: 123-132.

Tsukahara, H. \& Kozlowski, T.T. 1986. Effect of flooding and temperature regime on growth and stomatal resistence of Betula platyphyla var. japonica. Plant Soil 92: 103-112.

Watkinson, A.R. 1997. Plant population dynamics. Pp. 359-400. In: Crawley, M.J. (Ed.). Plant ecology. Londres: Blackwell Scientific Publications.

Williamson, M.H. \& Fitter A. 1996. The characters of successful invaders. Biological Conservation 78: $163-170$.

Wittmann, A.D.O.; Piedade, M.T.; Parolin, P., \& Wittmann, F. 2007. Germination in four lowvárzea tree species of Central Amazonia. Aquatic Botany 86(3): 197-203.

Zar, J.H. 1999. Biostatistical analisys. New Jersey, USA. 


\section{Conclusão Geral}

A densidade de indivíduos de Trembleya parviflora amostrados na Estação Ecológica de Águas Emendadas (ESECAE) foi maior quando comparada com o Parque Nacional de Brasília (PNB) e a elevada abundância dessa espécie está associada negativamente à diversidade das Veredas. A colonização de plantas de T. parviflora pode aumentar no PNB de acordo com as taxas de recrutamento e mortalidade da população. Ademais, os indivíduos no estrato superior, amostrados em ambas as Veredas, apresentam-se em estágio reprodutivo, com liberação de sementes no início do período chuvoso. Contribuindo para a colonização de novos indivíduos, pois os dados de germinação mostraram que a espécie apresenta germinabilidade relativamente rápida, iniciando entre o $4^{\circ}$ e o $10^{\circ}$ dia, e acima de $20 \% \operatorname{logo}$ após a dispersão e que mantém a longevidade por período superior a um ano, podendo formar assim banco de sementes persistente. Desta forma, as perturbações geradas por excesso ou déficit hídrico não prejudicam a espécie devido à facilidade de germinação, emergência de plântulas e desenvolvimento dos indivíduos em diferentes condições ambientais. Trembleya parviflora, mesmo em área com baixa densidade de indivíduos, mostrou-se como a principal espécie presente no banco de sementes nas Veredas e foi capaz de tolerar as condições de diferentes disponibilidades hídricas, ainda na presença de serapilheira que forma uma barreira física. Os resultados obtidos nesse e em futuros estudos, como acompanhamento de populações e da comunidade em longo prazo, poderão caracterizar de forma precisa a dinâmica de T. parviflora em Áreas Úmidas na ESECAE, no PNB e em locais com diferentes abundâncias da espécie auxiliando na conservação, no manejo e na proteção das Áreas de Preservação Permanentes. 
Apêndice 1. Composição florística e abundância de espécies no banco de sementes coletado após o período chuvoso e seco, sob os tratamentos de umidade de substrato (alagado-SA, intermediário-SI e umedecido-SU) e influência de serapilheira de Veredas do Parque Nacional de Brasília (PNB) e da Estação Ecológica de Águas Emendadas (ESECAE), Distrito Federal, Brasil. Ab=arbusto; ar=árvore; eg=erva graminóides; en=erva não graminóides; e sb= subarbusto. Dados entre parênteses referem-se às plântulas oriundas do tratamento com deposição de serapilheira. 


\begin{tabular}{|c|c|c|c|c|c|c|c|c|}
\hline & \multicolumn{3}{|c|}{ ESECAE } & \multicolumn{3}{|c|}{ PNB } & \multirow[b]{2}{*}{ Total } & \\
\hline & SA & SI & SU & SA & SI & SU & & \\
\hline \multicolumn{9}{|l|}{ ALISMATACEAE } \\
\hline Alismataceae sp.1 & $-(2)$ & $-(-)$ & $-(-)$ & $-(1)$ & $-(-)$ & $-(-)$ & $-(3)$ & en \\
\hline Sagittaria lancifolia $\mathrm{L}$. & $-(2)$ & $-(-)$ & $-(-)$ & $-(-)$ & $-(-)$ & $-(-)$ & $-(2)$ & en \\
\hline \multicolumn{9}{|l|}{ APOCYNACEAE } \\
\hline Apocynaceae sp.1 & $-(-)$ & $-(-)$ & $-(-)$ & $-(-)$ & $-(-)$ & $-(1)$ & $-(1)$ & em \\
\hline \multicolumn{9}{|l|}{ AQUIFOLIACEAE } \\
\hline Ilex affinis Gardner & $-(-)$ & $4(7)$ & $9(9)$ & $-(-)$ & $-(-)$ & $-(3)$ & $13(19)$ & ar \\
\hline \multicolumn{9}{|l|}{ ASTERACEAE } \\
\hline Achyrocline alata (Kunth) DC. & $-(-)$ & $-(5)$ & $1(2)$ & $-(7)$ & $6(15)$ & $1(23)$ & $8(52)$ & $\mathrm{sb}$ \\
\hline Achyrocline satureioides (Lam.) DC. & $-(-)$ & $-(-)$ & $-(-)$ & $-(-)$ & $-(1)$ & $-(1)$ & $-(2)$ & $\mathrm{sb}$ \\
\hline Asteraceae sp. 1 & $-(-)$ & $-(-)$ & $-(-)$ & $-(-)$ & $-(-)$ & $1(-)$ & $1(-)$ & $\mathrm{ab}$ \\
\hline Asteraceae sp. 2 & $-(-)$ & $-(4)$ & $-(4)$ & $-(-)$ & $1(3)$ & $-(1)$ & $1(12)$ & $\mathrm{ab}$ \\
\hline Baccharis sp. 1 & $-(3)$ & $4(11)$ & $6(11)$ & $1(-)$ & $2(14)$ & $1(10)$ & $14(49)$ & $\mathrm{ab}$ \\
\hline $\begin{array}{l}\text { Chromolaena chaseae (B.L.Rob.) R.M.King } \\
\text { \& H.Rob. }\end{array}$ & $-(-)$ & $2(-)$ & $-(3)$ & $-(2)$ & $15(30)$ & $4(21)$ & $21(56)$ & $\mathrm{sb}$ \\
\hline Erechtites hieraciifolius (L.) Raf. ex DC. & $5(2)$ & $1(3)$ & $-(-)$ & $6(8)$ & $21(36)$ & $23(33)$ & $56(82)$ & en \\
\hline Mikania sp. 1 & $-(-)$ & $-(-)$ & $1(-)$ & $-(-)$ & $-(-)$ & $-(-)$ & $1(-)$ & $\mathrm{sb}$ \\
\hline Trixis sp. 1 & $-(-)$ & $-(-)$ & $-(-)$ & $-(1)$ & $-(-)$ & $-(-)$ & $-(1)$ & en \\
\hline Vernonia aurea Mart. ex DC. & $-(-)$ & $1(-)$ & $-(-)$ & $-(-)$ & $-(-)$ & $-(-)$ & $1(-)$ & $\mathrm{sb}$ \\
\hline Vernonia sp. 1 & $-(-)$ & $-(-)$ & $-(-)$ & $-(-)$ & $-(-)$ & $-(2)$ & $-(2)$ & $\mathrm{sb}$ \\
\hline Willoughbya officinalis (Mart.) Kuntze & $-(-)$ & $-(-)$ & $-(1)$ & $-(-)$ & $-(6)$ & $-(4)$ & $-(11)$ & en \\
\hline \multicolumn{9}{|l|}{ CONVOLVULACEAE } \\
\hline Convolvulaceae sp. 1 & $-(-)$ & $-(-)$ & $-(-)$ & $-(-)$ & $-(-)$ & $-(1)$ & $-(1)$ & $\mathrm{sb}$ \\
\hline
\end{tabular}




\begin{tabular}{|c|c|c|c|c|c|c|c|c|}
\hline \multicolumn{9}{|l|}{ Cont. } \\
\hline & \multicolumn{3}{|c|}{ ESECAE } & \multicolumn{3}{|c|}{ PNB } & \multirow[b]{2}{*}{ Total } & \\
\hline & SA & SI & SU & $\mathbf{S A}$ & SI & SU & & \\
\hline \multicolumn{9}{|l|}{ CYPERACEAE } \\
\hline $\begin{array}{l}\text { Ascolepis brasiliensis (Kunth) Benth. ex C.B. } \\
\text { Clarke }\end{array}$ & $-(2)$ & $1(3)$ & $-(4)$ & $-(1)$ & $-(-)$ & $-(-)$ & $1(10)$ & eg \\
\hline Bulbostylis junciformis (Kunth) C.B. Clarke & $27(192)$ & $34(124)$ & $11(10)$ & $8(65)$ & $17(55)$ & $7(10)$ & $104(456)$ & eg \\
\hline Cyperus haspan $\mathrm{L}$. & 2(9) & $-(6)$ & $-(3)$ & $3(21)$ & $15(40)$ & $1(8)$ & $21(87)$ & eg \\
\hline Eleocharis capillacea Kunth & $6(43)$ & $-(2)$ & $-(-)$ & $5(79)$ & $1(10)$ & $2(-)$ & $14(134)$ & eg \\
\hline Eleocharis filiculmis Kunth & $-(23)$ & $6(23)$ & $1(3)$ & $4(18)$ & $-(10)$ & $-(-)$ & $11(77)$ & eg \\
\hline Eleocharis loefgreniana Boeckeler & $1(3)$ & $-(3)$ & $-(-)$ & $6(62)$ & $-(2)$ & $-(1)$ & $7(71)$ & eg \\
\hline Rhynchospora brasiliensis Boeckeler & $-(-)$ & $1(12)$ & $-(-)$ & $-(-)$ & $-(-)$ & $-(-)$ & $1(12)$ & eg \\
\hline Rhynchospora confinis (Nees) C.B. Clarke & $-(1)$ & $-(2)$ & $-(-)$ & $1(5)$ & $2(-)$ & $2(-)$ & $5(8)$ & eg \\
\hline $\begin{array}{l}\text { Rhynchospora consanguinea (Kunth) } \\
\text { Boeckeler }\end{array}$ & $-(5)$ & 2(3) & $-(1)$ & $-(1)$ & $1(2)$ & $1(-)$ & $4(12)$ & eg \\
\hline $\begin{array}{l}\text { Rhynchospora globosa (Kunth) Roem. \& } \\
\text { Schult. }\end{array}$ & $-(3)$ & 2(4) & $-(-)$ & 1(3) & $9(5)$ & $6(2)$ & $18(17)$ & eg \\
\hline Rhynchospora hirsuta (Vahl) Vahl & $-(1)$ & $-(-)$ & $-(-)$ & $-(1)$ & $3(-)$ & $-(-)$ & $3(2)$ & eg \\
\hline Rhynchospora marisculus Lindl. ex Nees & $-(2)$ & 2(7) & $2(1)$ & $-(-)$ & $-(-)$ & $-(-)$ & $4(10)$ & eg \\
\hline Rhynchospora sp. 1 & $2(5)$ & $2(4)$ & $-(-)$ & $7(23)$ & $1(6)$ & $6(-)$ & $18(38)$ & eg \\
\hline Rhynchospora sp. 2 & $-(9)$ & $-(20)$ & $-(-)$ & $3(29)$ & $2(23)$ & 2(3) & $7(84)$ & eg \\
\hline Rhynchospora spruceana C.B. Clarke & $5(-)$ & $2(5)$ & $3(2)$ & $-(-)$ & $2(-)$ & $-(-)$ & $12(7)$ & eg \\
\hline Scleria setacea Poir. & $12(37)$ & $-(19)$ & $1(2)$ & $-(11)$ & $-(2)$ & $-(1)$ & $13(72)$ & en \\
\hline Scleria leptostachya Kunth & $-(2)$ & $2(-)$ & $-(-)$ & $-(2)$ & $-(3)$ & $-(-)$ & $2(7)$ & en \\
\hline \multicolumn{9}{|l|}{ DENNSTAEDTIACEAE } \\
\hline Pteridium arachnoideum (Kaulf.) Maxon & $-(-)$ & $4(7)$ & 18(3) & $-(-)$ & $2(-)$ & $-(-)$ & $24(10)$ & en \\
\hline \multicolumn{9}{|l|}{ DROSERACEAE } \\
\hline Drosera montana A. St.-Hil. & $-(-)$ & $-(-)$ & $-(-)$ & $-(-)$ & $-(15)$ & $-(-)$ & $-(15)$ & en \\
\hline
\end{tabular}




\begin{tabular}{|c|c|c|c|c|c|c|c|c|}
\hline Cont. & \multicolumn{3}{|c|}{ ESECAE } & \multicolumn{3}{|c|}{ PNB } & \multirow{2}{*}{\multicolumn{2}{|c|}{ Total Geral }} \\
\hline & $\mathbf{S A}$ & SI & SU & SA & SI & SU & & \\
\hline \multicolumn{9}{|l|}{ ERIOCAULACEAE } \\
\hline Eriocaulon sellowianum Kunth & $-(-)$ & $-(5)$ & $-(-)$ & $-(7)$ & $-(1)$ & $-(-)$ & $-(13)$ & eg \\
\hline Paepalanthus flaccidus (Bong.) Kunth & $-(1)$ & $-(5)$ & $-(-)$ & $-(1)$ & $-(-)$ & $-(-)$ & $-(7)$ & en \\
\hline Paepalanthus trichophyllus Körn. & $-(1)$ & $1(16)$ & $12(-)$ & $-(11)$ & $3(33)$ & $-(2)$ & $16(63)$ & en \\
\hline Syngonanthus caulescens (Poir.) Ruhland & $-(6)$ & $1(21)$ & $1(4)$ & $-(35)$ & $1(8)$ & $-(-)$ & $3(74)$ & en \\
\hline Syngonanthus fischerianus (Bong.) Ruhland & $-(-)$ & $-(5)$ & $-(-)$ & $-(-)$ & $-(8)$ & $-(-)$ & $-(13)$ & eg \\
\hline Syngonanthus sp. 1 & $-(-)$ & $-(5)$ & $-(-)$ & $-(7)$ & $-(1)$ & $-(-)$ & $-(13)$ & eg \\
\hline \multicolumn{9}{|l|}{ EUPHORBIACEAE } \\
\hline Chamaesyce thymifolia (L.) Millsp. & $-(-)$ & $-(-)$ & $-(-)$ & $-(-)$ & 1(4) & $2(-)$ & $3(4)$ & en \\
\hline \multicolumn{9}{|l|}{ GENTIANACEAE } \\
\hline Irlbachia sp. 1 & $-(-)$ & $6(14)$ & $-(-)$ & $-(-)$ & $-(8)$ & $-(-)$ & $6(22)$ & $\mathrm{sb}$ \\
\hline Schultesia sp. 1 & $-(-)$ & $-(-)$ & $-(-)$ & $-(-)$ & $-(1)$ & $-(-)$ & $-(1)$ & en \\
\hline \multicolumn{9}{|l|}{ GESNERIACEAE } \\
\hline Sinningia elatior (Kunth) Chautems & $-(-)$ & $-(-)$ & $-(-)$ & $-(1)$ & $-(1)$ & $-(-)$ & $-(2)$ & $\mathrm{sb}$ \\
\hline \multicolumn{9}{|l|}{ FABACEAE } \\
\hline Mimosa sp. 1 & $-(-)$ & $-(-)$ & $-(-)$ & $-(-)$ & $1(-)$ & $-(-)$ & $1(-)$ & $\mathrm{ab}$ \\
\hline \multicolumn{9}{|l|}{ INDETERMINADA } \\
\hline Indeteterminada 1 & $-(-)$ & $-(-)$ & $-(-)$ & $-(-)$ & $1(-)$ & $-(-)$ & $1(-)$ & $\mathrm{sb}$ \\
\hline \multicolumn{9}{|l|}{ IRIDACEAE } \\
\hline Sisyrinchium restioides Spreng. & $-(-)$ & $-(-)$ & $-(1)$ & $-(2)$ & $-(5)$ & $3(3)$ & $3(11)$ & en \\
\hline Sisyrinchium vaginatum Spreng. & $1(2)$ & $4(6)$ & $4(1)$ & $1(2)$ & $1(10)$ & $-(2)$ & $11(23)$ & en \\
\hline \multicolumn{9}{|l|}{ LAMIACEAE } \\
\hline Hyptis linarioides Pohl ex Benth. & $-(-)$ & $-(-)$ & $1(-)$ & $-(-)$ & 2(12) & $2(8)$ & $5(20)$ & $\mathrm{sb}$ \\
\hline
\end{tabular}




\begin{tabular}{|c|c|c|c|c|c|c|c|c|}
\hline \multirow[t]{2}{*}{ Cont. } & \multicolumn{3}{|c|}{ ESECAE } & \multicolumn{3}{|c|}{ PNB } & \multirow[b]{2}{*}{ Total Geral } & \\
\hline & SA & SI & SU & $\mathbf{S A}$ & SI & SU & & \\
\hline \multicolumn{9}{|l|}{ LENTIBULARIACEAE } \\
\hline Utricularia hispida Lam. & $-(-)$ & $-(-)$ & $-(-)$ & $-(14)$ & $1(21)$ & $-(-)$ & $1(35)$ & en \\
\hline \multicolumn{9}{|l|}{ MAYACACEAE } \\
\hline Mayaca cf. sellowiana Kunth & $1(12)$ & $5(10)$ & $4(1)$ & $-(-)$ & $-(1)$ & $-(3)$ & $10(27)$ & en \\
\hline \multicolumn{9}{|l|}{ MELASTOMATACEAE } \\
\hline Acisanthera fluitans Cogn. & $-(-)$ & $-(-)$ & $-(-)$ & $2(20)$ & $3(36)$ & $1(5)$ & $6(61)$ & en \\
\hline Desmoscelis villosa (Aubl.) Naudin & 2(7) & $3(26)$ & $4(13)$ & $2(19)$ & $35(196)$ & $37(46)$ & $83(307)$ & $\mathrm{sb}$ \\
\hline Lavoisiera bergii Cogn. & $1(6)$ & $2(16)$ & $1(2)$ & $-(7)$ & $1(5)$ & $2(1)$ & $7(37)$ & $\mathrm{ab}$ \\
\hline Macairea radula (Bonpl.) DC. & $-(1)$ & $21(92)$ & $22(14)$ & $-(-)$ & $-(2)$ & $-(-)$ & $43(109)$ & $a b$ \\
\hline Miconia albicans (Sw.) Steud. & $-(-)$ & $4(5)$ & $4(3)$ & $-(-)$ & $2(4)$ & 1(3) & $11(15)$ & $\mathrm{ab}$ \\
\hline Miconia chamissois Naudin & $-(3)$ & $3(11)$ & $7(-)$ & $-(5)$ & $1(17)$ & $3(3)$ & $14(39)$ & $a b$ \\
\hline Microlicia euphorbioides Mart. & $-(-)$ & $-(-)$ & $-(-)$ & $-(-)$ & $3(25)$ & 1(1) & $4(26)$ & $\mathrm{sb}$ \\
\hline Microlicia sp. 1 & $-(-)$ & $-(-)$ & $-(-)$ & $-(-)$ & $-(4)$ & $1(-)$ & $1(4)$ & $\mathrm{sb}$ \\
\hline Rhynchanthera grandiflora (Aubl.) DC. & $-(7)$ & 1(1) & $1(1)$ & $1(8)$ & $15(56)$ & $11(17)$ & $29(90)$ & $\mathrm{ab}$ \\
\hline Tibouchina gracilis (Bonpl.) Cogn. & $-(-)$ & $-(-)$ & $-(-)$ & $-(-)$ & $3(36)$ & $4(5)$ & $7(41)$ & $\mathrm{sb}$ \\
\hline Tibouchina stenocarpa (DC.) Cogn. & $-(-)$ & 2(6) & $-(-)$ & $-(-)$ & $-(8)$ & $1(2)$ & $3(16)$ & $\mathrm{ab}$ \\
\hline Tococa formicaria Mart. & $-(1)$ & $-(6)$ & $-(4)$ & $-(5)$ & $-(-)$ & $-(1)$ & $-(17)$ & $\mathrm{ab}$ \\
\hline Trembleya parviflora (D. Don) Cogn. & $562(3576)$ & $1447(7044)$ & $956(1988)$ & $239(228)$ & $297(528)$ & $300(266)$ & 3801(13630) & $\mathrm{ab}$ \\
\hline Trembleya phlogiformis DC. & $1(1)$ & $6(18)$ & $3(4)$ & $4(5)$ & $12(81)$ & $12(11)$ & $38(120)$ & $\mathrm{ab}$ \\
\hline \multicolumn{9}{|l|}{ OCHNACEAE } \\
\hline Sauvagesia linearifolia A. St.-Hil. & $-(-)$ & $1(-)$ & $-(1)$ & $-(-)$ & $-(-)$ & $-(-)$ & 1(1) & $\mathrm{sb}$ \\
\hline \multicolumn{9}{|l|}{ ONAGRACEAE } \\
\hline Ludwigia nervosa (Poir.) H. Hara & $-(6)$ & 1(1) & $7(-)$ & $4(25)$ & $12(45)$ & $3(16)$ & $27(93)$ & $\mathrm{ab}$ \\
\hline Ludwigia tomentosa (Cambess.) H. Hara & $-(-)$ & $1(-)$ & $-(-)$ & $-(-)$ & $-(-)$ & $-(-)$ & $1(-)$ & $\mathrm{ab}$ \\
\hline
\end{tabular}

Cont. 
ESECAE

PNB

\begin{tabular}{|c|c|c|c|c|c|c|c|c|}
\hline & SA & SI & SU & SA & SI & SU & Total Geral & \\
\hline \multicolumn{9}{|l|}{ PASSIFLORACEAE } \\
\hline Turnera oblongifolia Cambess. & $-(-)$ & $-(-)$ & $-(-)$ & $-(-)$ & $1(2)$ & $1(1)$ & $2(3)$ & $\mathrm{sb}$ \\
\hline \multicolumn{9}{|l|}{ POACEAE } \\
\hline Andropogon bicornis L. & $-(-)$ & $-(-)$ & $-(-)$ & $-(1)$ & $-(-)$ & $-(-)$ & $-(1)$ & eg \\
\hline Andropogon leucostachyus Kunth & $-(-)$ & $1(2)$ & $2(-)$ & $2(11)$ & $3(10)$ & $5(5)$ & $13(28)$ & eg \\
\hline Andropogon virgatus Desv. ex Ham. & $-(-)$ & $-(-)$ & $-(-)$ & $-(2)$ & $-(1)$ & $-(-)$ & $-(3)$ & eg \\
\hline Axonopus aureus P. Beauv. & $-(-)$ & $-(-)$ & $-(-)$ & $-(-)$ & $-(1)$ & $2(5)$ & $2(6)$ & eg \\
\hline $\begin{array}{l}\text { Axonopus pellitus (Nees ex Trin.) Hitchc. \& } \\
\text { Chase }\end{array}$ & $-(-)$ & $-(1)$ & $-(-)$ & $-(-)$ & $3(5)$ & $4(10)$ & $7(16)$ & eg \\
\hline Axonopus sp. 1 & $-(-)$ & $-(-)$ & $-(-)$ & $-(-)$ & $1(8)$ & $3(3)$ & $4(11)$ & eg \\
\hline Ctenium sp. 1 & $-(-)$ & $-(-)$ & $-(-)$ & $-(-)$ & $1(-)$ & $-(-)$ & $1(-)$ & eg \\
\hline Echinolaena inflexa (Poir.) Chase & $-(-)$ & $-(-)$ & $-(1)$ & $-(1)$ & $1(-)$ & $-(4)$ & $1(6)$ & eg \\
\hline $\begin{array}{l}\text { Ichnanthus procurrens (Nees ex Trin.) } \\
\text { Swallen }\end{array}$ & $-(-)$ & $-(-)$ & $-(-)$ & $-(2)$ & $8(5)$ & $7(8)$ & $15(15)$ & eg \\
\hline Melinis minutiflora P. Beauv. & $-(-)$ & $4(9)$ & $9(12)$ & $-(-)$ & $1(-)$ & $5(2)$ & $19(23)$ & eg \\
\hline Melinis repens (Willd.) Zizka & $-(-)$ & $1(-)$ & $-(-)$ & $-(-)$ & $-(-)$ & $-(-)$ & $1(-)$ & eg \\
\hline Panicum cinerascens Döll & $-(5)$ & $3(7)$ & $8(13)$ & $1(12)$ & $26(49)$ & $22(35)$ & $60(121)$ & eg \\
\hline Panicum sp. 1 & $-(9)$ & $3(8)$ & $2(5)$ & $-(-)$ & $1(1)$ & $-(1)$ & $6(24)$ & eg \\
\hline Paspalum hyalinum Nees ex Trin. & $-(-)$ & $-(-)$ & $-(-)$ & $-(-)$ & $-(5)$ & $1(-)$ & $1(5)$ & eg \\
\hline Paspalum maculosum Trin. & $-(-)$ & $-(-)$ & $-(-)$ & $-(3)$ & $-(-)$ & $-(2)$ & $-(5)$ & eg \\
\hline Paspalum pilosum Lam. & $-(-)$ & $-(1)$ & $-(-)$ & $-(2)$ & $-(-)$ & $-(2)$ & $-(5)$ & eg \\
\hline Pennisetum setosum (Sw.) Rich. & $-(-)$ & $-(-)$ & $1(-)$ & $-(-)$ & $-(-)$ & $-(-)$ & $1(-)$ & eg \\
\hline Poaceae sp. 1 & $-(-)$ & $-(3)$ & $-(-)$ & $-(-)$ & $1(1)$ & $-(-)$ & $1(4)$ & eg \\
\hline Poaceae sp. 2 & $-(-)$ & $-(-)$ & $-(-)$ & $-(2)$ & $-(-)$ & $-(1)$ & $-(3)$ & eg \\
\hline Poaceae sp. 3 & $-(1)$ & $-(-)$ & $-(-)$ & $-(-)$ & $-(-)$ & $-(1)$ & $-(2)$ & eg \\
\hline Poaceae sp. 4 & $-(1)$ & $-(-)$ & $-(-)$ & $-(2)$ & $-(-)$ & $-(-)$ & $-(3)$ & eg \\
\hline
\end{tabular}

Cont. 


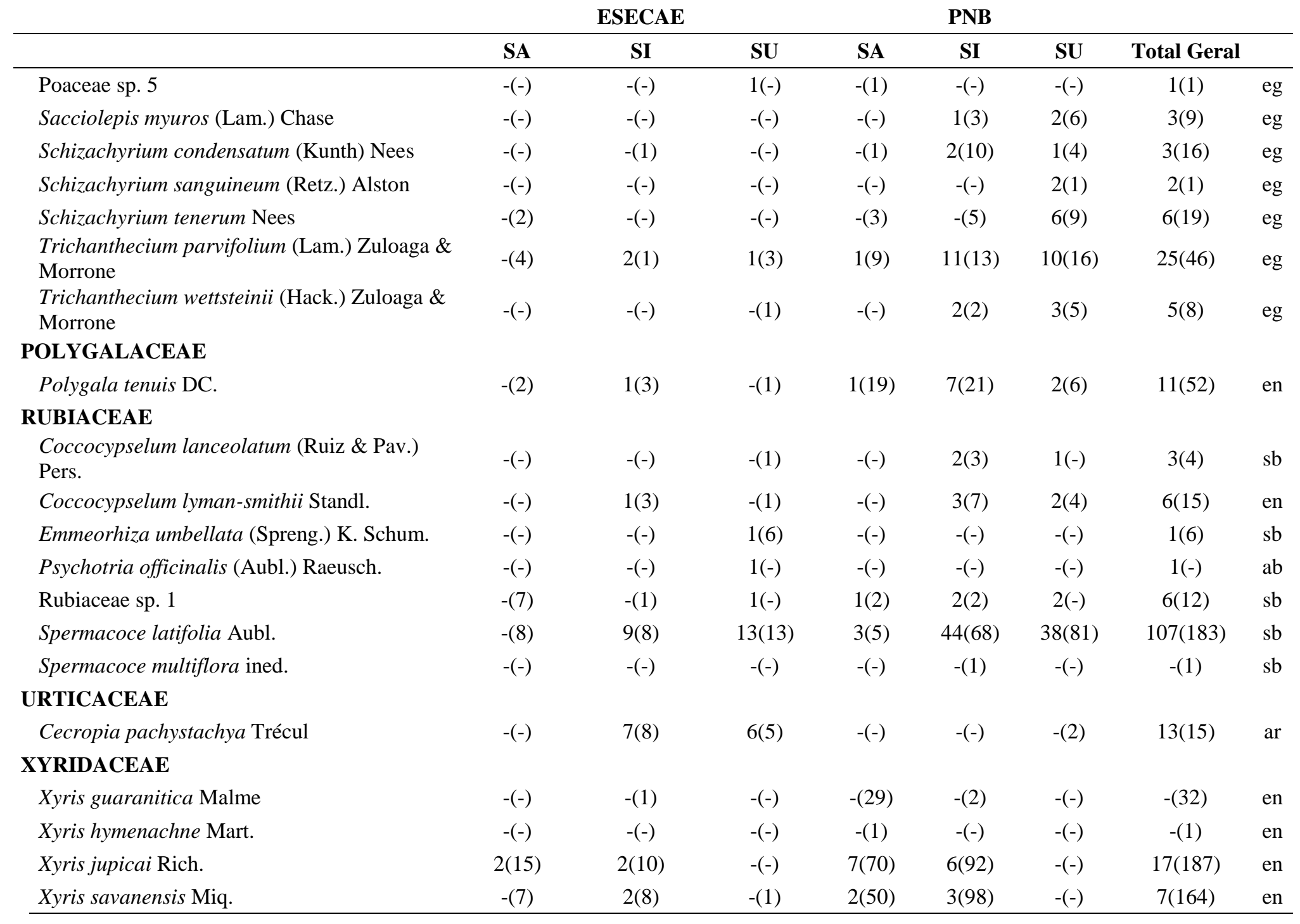




\begin{tabular}{lcccccccc}
\hline Cont. & \multicolumn{3}{c}{ ESECAE } & \multicolumn{3}{c}{ PNB } \\
& SA & SI & SU & SA & SI & SU & Total Geral \\
\hline Xyris schizachne Mart. & $-(1)$ & $-(-)$ & $-(2)$ & $1(5)$ & $-(-)$ & $-(1)$ & $1(9)$ & en \\
Xyris tenella Kunth & $-(1)$ & $-(-)$ & $-(7)$ & $1(2)$ & $-(-)$ & $-(-)$ & $1(10)$ & en \\
\hline
\end{tabular}

